\title{
The use of risk tables for cardiovascular prevention in general practice : evaluation of decision support for doctors and patients
}

Citation for published version (APA):

van Steenkiste, B. (2008). The use of risk tables for cardiovascular prevention in general practice : evaluation of decision support for doctors and patients. [Doctoral Thesis, Maastricht University]. Datawyse / Universitaire Pers Maastricht. https://doi.org/10.26481/dis.20080619bs

Document status and date:

Published: 01/01/2008

DOI:

10.26481/dis.20080619bs

Document Version:

Publisher's PDF, also known as Version of record

Please check the document version of this publication:

- A submitted manuscript is the version of the article upon submission and before peer-review. There can be important differences between the submitted version and the official published version of record.

People interested in the research are advised to contact the author for the final version of the publication, or visit the DOI to the publisher's website.

- The final author version and the galley proof are versions of the publication after peer review.

- The final published version features the final layout of the paper including the volume, issue and page numbers.

Link to publication

\footnotetext{
General rights rights.

- You may freely distribute the URL identifying the publication in the public portal. please follow below link for the End User Agreement:

www.umlib.nl/taverne-license

Take down policy

If you believe that this document breaches copyright please contact us at:

repository@maastrichtuniversity.nl

providing details and we will investigate your claim.
}

Copyright and moral rights for the publications made accessible in the public portal are retained by the authors and/or other copyright owners and it is a condition of accessing publications that users recognise and abide by the legal requirements associated with these

- Users may download and print one copy of any publication from the public portal for the purpose of private study or research.

- You may not further distribute the material or use it for any profit-making activity or commercial gain

If the publication is distributed under the terms of Article 25fa of the Dutch Copyright Act, indicated by the "Taverne" license above, 
The use of risk tables for cardiovascular prevention in general practice

evaluation of decision support for doctors and patients 
The studies presented in this dissertation were conducted under the auspices of the school for Public Health and Primary Care (Caphri) at Maastricht University, The Netherlands. The school for Public Health and Primary Care (Caphri) is part of the Netherlands School of Primary Care Research (CaRe), which has been acknowledged since 1995 by The Royal Netherlands Academy of Art en Sciences (KNAW).

(c) B. van Steenkiste, Maastricht 2008

ISBN: 978-90-5278-719-0

Layout: Tiny Wouters

Cover: Len Munnik

Production: Datawyse | Universitaire Pers Maastricht 


\title{
The use of risk tables for cardiovascular prevention in general practice
}

evaluation of decision support for doctors and patients

\author{
Proefschrift
}

ter verkrijging van de graad van doctor aan de Universiteit Maastricht, op gezag van de Rector Magnificus, Prof. mr. G.P.M.F. Mols, volgens het besluit van het College van Decanen, in het openbaar te verdedigen op donderdag 19 juni 2008 om 14.00 uur

door

Ben van Steenkiste

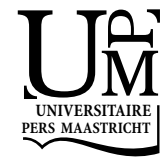




\section{Promotor:}

Prof. dr. R.P.T.M. Grol

\section{Copromotor:}

Dr. T. van der Weijden

Beoordelingscommissie:

Prof. dr. J.F.M. Metsemakers, voorzitter

Prof. dr. A.P.M. Gorgels

Prof. dr. J.C.J.M. de Haes (AMC Universiteit van Amsterdam)

Prof. dr. N.K. de Vries

Dr. M. Wensing (UMC St Radboud Nijmegen)

The study described in this thesis was supported by a grant of the Netherlands Heart Foundation (NHF-602.312.3).Financial support by the Netherlands Heart Foundation for the publication of this thesis is gratefully acknowledged. 
Geluk zit in het ontmoeten 



\section{Contents}

Chapter 1 Introduction 9

Chapter 2 Barriers to implementing cardiovascular risk tables 21 in routine general practice

Chapter 3 Patients' ideas, fears and expectations of their coronary risk: 35 barriers for primary prevention

Chapter 4 Primary prevention of cardiovascular diseases in general practice: mismatch between evidence based guidelines and the individual patient

Chapter 5 Improving cardiovascular risk management: a randomized controlled trial on the effect of a decision support tool for patients and physicians

Chapter 6 Patients' responsiveness of a decision support tool for primary prevention of cardiovascular diseases in primary care

Chapter 7 Systematic review of implementation strategies for risk tables in the prevention of cardiovascular diseases

Chapter 8 General discussion

Summary

Samenvatting

Dankwoord

Curriculum vitae 



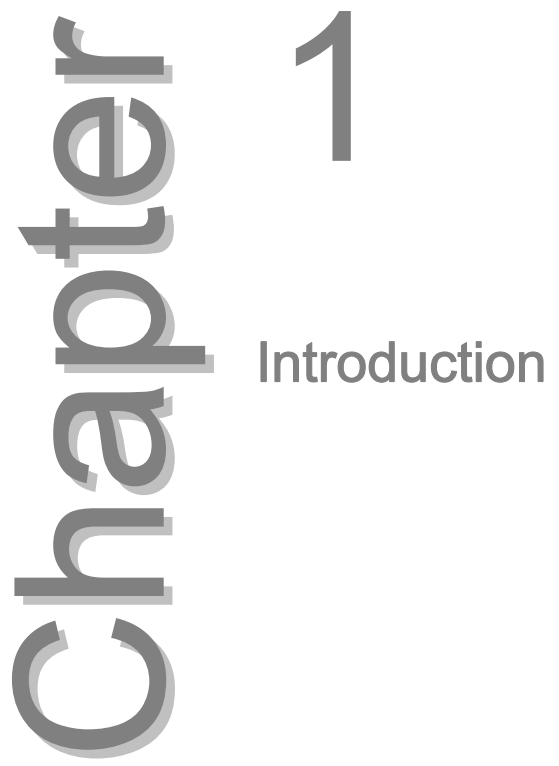


$10 \mid$ Chapter 1 


\section{Introduction}

The incidence of cardiovascular diseases (CVD) in Western industrialised countries remains high, and the associated burden of illness is increasing. In 2003, about 47,800 persons in the Netherlands died of CVD; CVD were the leading cause of death in that year, accounting for $34 \%$ of the total mortality rate $^{1}$. Primary prevention, an important strategy to delay the onset of CVD, is embedded in national and international guidelines for the assessment and modification of the relevant risk factors ${ }^{2-5}$.

International guidelines for cardiovascular risk management often incorporate risk tables to support the management of patients without established cardiovascular diseases (primary prevention). These risk tables aim to improve the quality of care by rationalising decisions on identification and management of patients at high risk. They are based on findings in randomised controlled trials on the effect of treatment to lower cholesterol or blood pressure, which showed that it is only above a certain minimum level of the 10-year CVD risk that relevant clinical effects are found. The cardiovascular risks in these tables are mostly derived from cohorts such as the Framingham study ${ }^{67}$. Examples of these tables are the Sheffield table, the New Zealand table, and the joint European and British societies risk chart ${ }^{3,4,8,9}$. Although these tables vary in the way they present risks, in the cut-off points for high risk, and in the data used to calculate absolute risk, the underlying concepts are largely similar. The tables are used for individualised risk calculation, the so-called high-risk approach, in which various demographic and risk factor data can be integrated to determine a personal risk profile. This approach is entirely different from those used in the past, when single risk factors were the starting point for risk management ${ }^{10,11}$. Although equations for risk calculation in coronary heart disease have existed since the 1960s, they only started to attract significant clinical interest in the 1990s. The impact of these risk-scoring systems increased amidst the enthusiasm surrounding new drugs like HMG-Co-A reductase inhibitors or statins. These drugs were first licensed in the UK in 1989 to reduce cholesterol levels, which were regarded as an important CHD risk factor ${ }^{12}$.

More than 20 years ago, the Dutch College of General Practitioners (DCGP) started to publish guidelines on the prevention of cardiovascular diseases in primary care, such as those on cholesterol, hypertension, diabetes and peripheral arterial diseases. Each offered its own key recommendations for the selection of patients, diagnosis and treatment ${ }^{13}$. The evolution of knowledge about optimal prevention of cardiovascular diseases resulted in 1999 in a revised guideline on cholesterol, which incorporated a risk table for the primary 
prevention of cardiovascular diseases. ${ }^{*}$ This was the first guideline in the Netherlands to include such a risk table, introducing a new approach to the prevention of CVD 5 . The Dutch risk table showed the (10-year) absolute risk of an acute fatal and non-fatal myocardial infarction for individuals without CVD, and offered options for decisions on multiple risk management, such as drug treatment, life-style change or reassurance (Box 1.1). The table facilitates a highly individualised risk calculation based on the risk factors age, sex, diabetes, cholesterol and hypertension, to determine a personal risk profile. The availability of numerical information on personal risk profiles offers opportunities for effective risk communication, which in turn might stimulate patient participation in decision-making and patient compliance.

As yet, not much is known about the use of risk tables in daily practice. While their use has been associated with significant reduction in systolic blood pressure ${ }^{11}$, barriers relating to their format and scaling have also been reported $^{10,15}$. It often takes a lot of energy and time before knowledge resulting from research translates into effective and efficient care provided by doctors, nurses and other care workers. Stop-smoking advice and the prescription of aspirin, beta-blockers, antihypertensives, cholesterol-lowering drugs and anticoagulants have all proved to be valuable for specific high-risk groups of patients. Despite the proven effectiveness of these key recommendations from various guidelines, they are often not applied in daily practice ${ }^{16}$. Guidelines and risk tables have to be seen as new technologies, and effective implementation methods are needed to ensure that they find their way into daily practice ${ }^{17}$. Simple dissemination and easy access to the guidelines and risk tables do not guarantee successful implementation of such new scientific knowledge. Even intensive implementation strategies focusing on changing professional behaviour and adjusting practice organisation have so far often resulted in limited improvement in clinical performance ${ }^{18,19}$.

\footnotetext{
* The revised guideline on cholesterol, published in 1999, holds a central position in this thesis. It describes the recommendations and targets for professional performance. Meanwhile, an update to the 1999 guideline has recently been published, describing the concept of Cardiovascular Risk Management (CVRM) and establishing a complete integration of the previous single risk factor guidelines on hypertension and cholesterol $^{14}$. The 1999 cholesterol guideline could be regarded as a forerunner of the 2006 CVRM guideline, as the single risk factor perspective was already shifting towards the multiple risk factor perspective in 1999.
} 
Box 1.1 Key recommendations for primary prevention from the DCGP Guideline on Cholesterol

\section{General}

- Screening the practice population is not useful.

- Assess the cardiovascular risk of men (18-70 yrs.) and women (18-75 yrs.) visiting the practice.

Diagnosing hypercholesterolemia

- Whether a cholesterol test is indicated can be derived from the risk table.

- Only if there is a chance of an orange or a red square or if familial hypercholesterolaemia is suspected, is testing useful.

- If fasting blood glucose level is unknown, check it when the patient needs to be tested for cholesterol.

- Test for total cholesterol/HDL-cholesterol ratio, two tests within 2-3 weeks, non-fasting.

- If the first total cholesterol/HDL ratio $<5.0 \mathrm{mmol} / \mathrm{l}$ then a second test is not necessary.

Treatment of hypercholesterolaemia

- Cholesterol-lowering therapy is indicated for patients in red or orange squares (if there is also a family history of CHD) (see risk table).

- The indication for statins is based on two conditions: the level of the absolute risk has to be at least $25 \%$, and the treatment has to be cost-effective for the relevant subgroup.

Risk table: absolute risk (\%) of developing Acute Myocardial Infarction (AMI) in 10 years

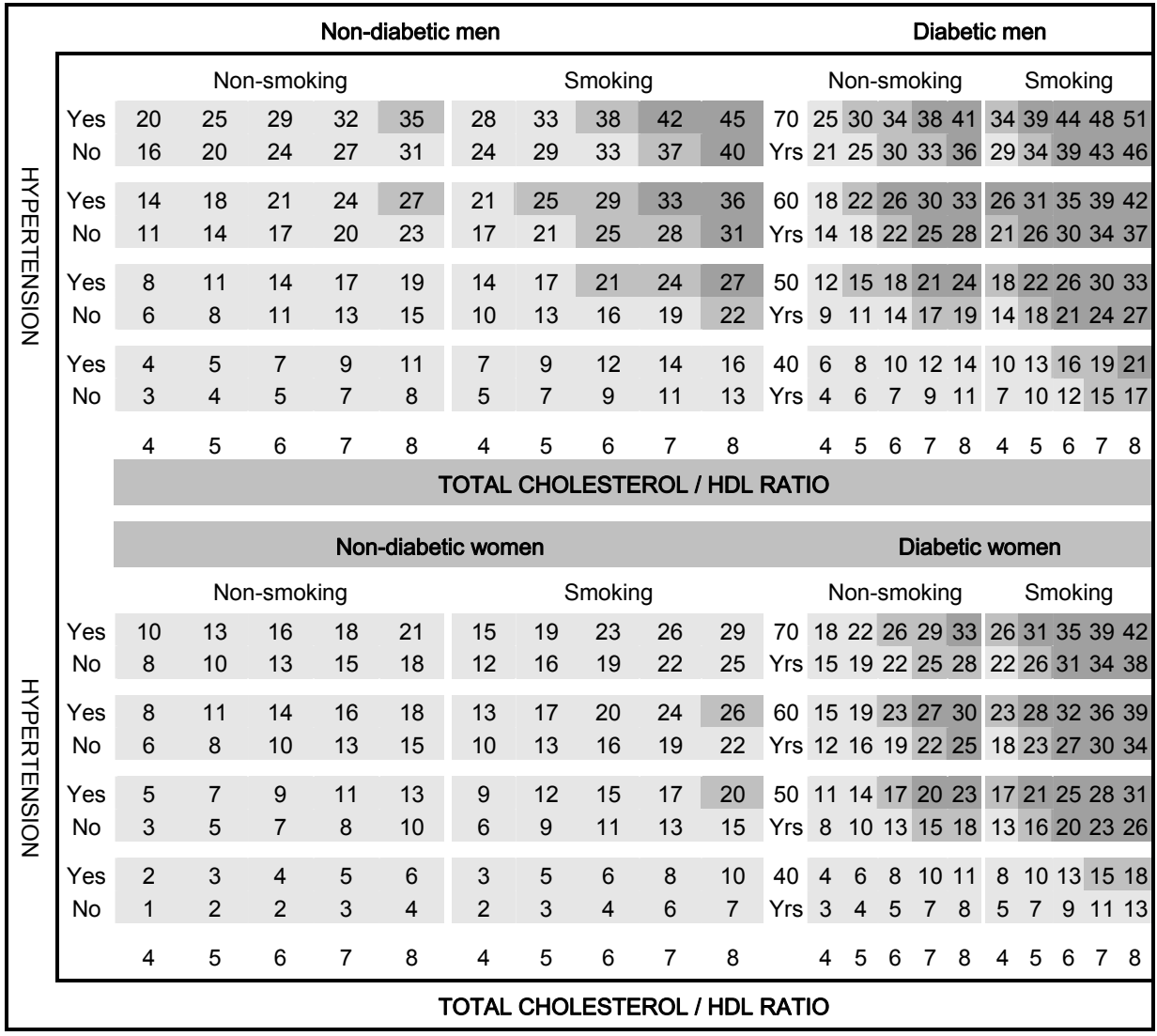




\section{Barriers for cardiovascular prevention in primary care}

Optimal use of cardiovascular guidelines and risk tables requires a thorough insight into the barriers to change that play a role during consultations about the prevention of cardiovascular diseases. General practitioners (GPs) might experience many barriers that make them deviate from the guidelines, resulting in overuse of health care such as repeated unnecessary diagnostic testing and over-treatment, where reassurance and explanation should perhaps have been the preferred management. At the same time, GPs also often underuse tests and drugs $^{20}$. In addition, it seems difficult to motivate high-risk patients to engage in preventive strategies such as lifestyle change or long-term drug compliance.

GP- and patient-related barriers may hamper the implementation of the recommended high-risk approach to the prevention of CVD. For instance, many health professionals find it difficult to integrate multiple risk factors into an accurate assessment of cardiovascular risk by applying the risk table ${ }^{10,15,19}$.

Effective cardiovascular risk management also requires GPs to have a clear view of patients' risk perceptions, and their preferences and expectations regarding risk management. A mismatch between patients' actual cardiovascular risk and their risk perceptions might lead to conflicts between GPs' intended management and patients' expectations. Explaining risk to patients in order to reach a common understanding of the risk level might be quite a challenge to both physicians and patients ${ }^{21}$. Misconceptions seem to be common among primary care patients ${ }^{22-25}$. A thorough understanding of patients' fears and risk perceptions, and efforts to bring them into line with the actual risk, seem prerequisites for effective management ${ }^{26}$.

\section{A new implementation strategy for cardiovascular prevention}

Involving patients in decision-making on the management of high risk may improve their satisfaction, well-being, and even lifestyle and health outcomes ${ }^{24}$, and probably also the GPs' adherence to the recommended high-risk approach. The challenge is therefore to find effective ways to implement the guideline, the risk tables and new knowledge relating to CVD prevention. To achieve this, a new implementation strategy needs to be developed.

Our research group had already gained considerable experience with the implementation of primary CVD prevention, and the cholesterol guideline in particular. Three of their studies are relevant here. In 1997, van der Weijden evaluated an implementation strategy for the first national guideline on 
cholesterol, published in 1991. This study focused on improving GPs' knowledge of the guideline and trying to motivate them for this task. The strategy was composed of an educational group meeting, supportive educational materials, recording consultations on cholesterol, feedback on performance and face-to-face instruction at the surgery. This approach was found to have no effect on the GPs' performance ${ }^{19}$, a finding which was deemed to have been caused by organisational and attitudinal barriers to effective CVD prevention in primary care.

A subsequent study explored the impact of outreach visits by trained practice nurses who supported GPs in organising CVD prevention. The programme was designed for individual practices and interventions were guided by the needs and capabilities of the practice teams. It proved to be an effective instrument for improved recording of risk factors and led to a moderate improvement in the GPs' performance in terms of preventive activities ${ }^{27,28}$. The educational outreach model was further developed to address a large number of issues relating to task delegation, availability of instruments and patient leaflets, record-keeping, follow-up routines and risk factor management. It resulted in significant improvement in all aspects of organising preventive care, as well as significant improvement in five of the 12 indicators of CVD risk factor management $^{29-31}$. However, nationwide implementation of this new successful management approach to primary CVD prevention failed, with the extra workload and lack of support and reimbursement for the GPs being the most important barriers ${ }^{32}$.

In summary, the implementation of the guidelines on CVD prevention has so far mainly focused on the barriers at GP level (knowledge and attitude) and on improving practice organisation. Changing professionals' knowledge and attitudes is not enough to bring about change in performance. Improving the organisational conditions does affect performance favourably, but is not sufficient to implement the risk tables either. We then turned our attention to the importance of patient-related barriers in addition to those relating to professional and organisational aspects. One study revealed that up to $40 \%$ of the patients actively demand a cholesterol test, and a considerably proportion of them are upset when the request is rejected by the $\mathrm{GP}^{20}$. Patient demands, combined with the marketing activities of drug companies, such as the provision of desktop cholesterol test devices, induce overuse and make it difficult for GPs to negotiate with patients when a request for testing does not match the recommended indications for testing. To overcome this, it would be helpful if GPs could share the guideline recommendations with their patients. To this end, guidelines should offer an accessible presentation of treatment outcomes in terms of benefit (e.g. quality-adjusted life years gained), hazard (e.g. numbers needed to treat) and costs for a range of absolute risks, which would enable patients and their doctor to weigh the pros and cons of risk- 
reducing interventions in their particular circumstances ${ }^{33}$. Enhanced patient involvement might in turn improve the GPs' performance in terms of adherence to the key recommendations of the cholesterol guidelines ${ }^{34}$.

\section{Aim and outline of the study}

The objective of our project was to develop and evaluate an implementation strategy for the 1999 Dutch College of General Practitioners guideline on cholesterol, which advocated a new 'high risk' approach to primary prevention of CVD, based on risk tables, a new technology in general practice. Previous research had shown that the guideline needed an extensive implementation strategy tailored to professionals, patients and context-related barriers to ensure that it found its way into daily practice ${ }^{35}$. The area of CVD prevention and risk tables was first explored among both patients and professionals. Next we conducted a controlled study to evaluate the effect and feasibility of a programme to implement CVD prevention in primary care. Finally, we reviewed the current state of the art in implementing CVD risk tables, as described in the literature.

\section{The following research questions were addressed}

1. What are the barriers, from the GPs' and patients' perspectives, that impede effective implementation of the 1999 DCGP guideline on cholesterol and its incorporated risk tables?

2. How often are GPs confronted with mismatches between patients' actual cardiovascular risk and their perceived risk or anxiety, and what factors determine a high perceived risk or anxiety?

3. What is the effect of a decision support system for both physicians and patients, which aims at their common understanding of the risk and the options for risk management, on the physicians' performance in terms of adherence to the key recommendations of the cholesterol guideline and the patients' risk perception and lifestyle?

4. How do patients respond to active decision support?

5. What is known in the literature about effective implementation strategies for cardiovascular risk tables? 


\section{Outline of this thesis}

The study started with a qualitative inventory of the barriers to adherence to the DCGP guideline on cholesterol and its incorporated risk tables, as perceived by GPs (Chapter 2).

Chapter 3 examines the patients' ideas, fears and expectations, as potential barriers to effective implementation of the guideline, again using qualitative methods.

Chapter 4 further explores the patients' risk perception, anxiety and perceived cardiovascular risk in relation to the actual risk, using quantitative methods. It was deemed important to know whether there was a mismatch between the patients' perceived risk and actual risk, since this is regarded as an important barrier to the GPs' self-efficacy in terms of adherence to the guideline, and is thought to affect the patients' attitude towards adopting a healthy lifestyle.

Chapter 5 reports on a cluster-randomised controlled trial in primary care on the effect of the use of a decision support tool for the prevention of CVD on the GPs' performance in terms of the key recommendations of the national guideline, and on some outcomes at patient level, such as risk perception and lifestyle.

Since not much was known about the way patients appreciate such decision support, we examined patients' responses to the decision support tool. The results are reported in Chapter 6.

Chapter 7 systematically reviews the literature on health professionals' performance with respect to cardiovascular risk tables.

Finally, Chapter 8 discusses the findings of the project reported on in this thesis, offers recommendations for effective implementation strategies for the appropriate application of cardiovascular risk tables in the context of cardiovascular risk management, and discusses implications for future research. 


\section{References}

1. Koek H, Van Dis S, Peters R, Bots M. Hart- en vaatziekten in Nederland. 2005 ed. Den Haag: Nederlandse Hartstichting, 2005.

2. De Backer G, Ambrosioni E, Borch-Johnsen K, Brotons C, Cifkova R, Dallongeville J, Ebrahim S, Faergeman O, Graham I, Mancia G, Cats VM, Orth-Gomér K, Perk J, Pyörälä K, Rodicio JL, Sans S, Sansoy V, Sechtem U, Silber S, Thomsen T, Wood D; Third Joint Force of European and other Societies on Cardiovascular Disease and Prevention in Clinical Practice. European guidelines on cardiovascular disease and prevention in clinical practice. Atherosclerosis 2003;171:145-55.

3. Jackson R. Updated New Zealand cardiovascular disease risk-benefit prediction guide. BMJ 2000;320:709-10.

4. Anonymous. Joint British recommendations on prevention of coronary heart disease in clinical practice: summary. British Cardiac Society, British Hyperlipidaemia Association, British Hypertension Society, British Diabetic Association. BMJ 2000;320:705-8.

5. Thomas S, van der Weijden T, van Drenth BB, Haverkort AFM, Hooi JD, van der Laan JD. NHG-Standaard Cholesterol (eerste herziening). Huisarts Wet 1999;42:406-17.

6. Grundy SM, Pasternak R, Greenland P, Smith S, Jr., Fuster V. Assessment of cardiovascular risk by use of multiple-risk-factor assessment equations: a statement for healthcare professionals from the American Heart Association and the American College of Cardiology. Circulation 1999;100:1481-92.

7. Haq IU, Ramsay LE, Yeo WW, Jackson PR, Wallis EJ. Is the Framingham risk function valid for northern European populations? A comparison of methods for estimating absolute coronary risk in high risk men. Heart 1999;81:40-6.

8. Wallis EJ, Ramsay LE, UI Haq I, Ghahramani P, Jackson PR, Rowland-Yeo K, Yeo WW. Coronary and cardiovascular risk estimation for primary prevention: validation of a new Sheffield table in the 1995 Scottish health survey population. BMJ 2000;320:671-6.

9. Wood D, De Backer G, Faergeman O, Graham I, Mancia G, Pyorala K. Prevention of coronary heart disease in clinical practice: recommendations of the Second Joint Task Force of European and other Societies on Coronary Prevention. Atherosclerosis 1998;140:199-270.

10. Isles CG, Ritchie LD, Murchie P, Norrie J. Risk assessment in primary prevention of coronary heart disease: randomised comparison of three scoring methods. BMJ 2000;320:690-1.

11. Montgomery AA, Fahey T, Peters TJ, Maclntosh C, Sharp DJ. Evaluation of computer based clinical decision support system and risk chart for management of hypertension in primary care: randomised controlled trial. BMJ 2000;320:686-90.

12. Will CM. Arguing about the evidence: readers, writers and inscription devices in coronary heart disease risk assessment. Sociol Health IIIn 2005;27:780-801.

13. Geijer R. NHG-standaarden voor de huisarts. 2e ed. Maarssen: Elsevier/Bunge, 1999.

14. Burgers JS, Simoons ML, Hoes AW, Stehouwer CD, Stalman WA. Richtlijn 'cardiovasculair risicomanagement'. [Guideline 'Cardiovascular Risk Management']. Ned Tijdschr Geneeskd 2007;151:1068-74.

15. Peters TJ, Montgomery AA, Fahey T. How accurately do primary health care professionals use cardiovascular risk tables in the management of hypertension? $\mathrm{Br} \mathrm{J}$ Gen Pract 1999;49:987-8.

16. Woods KL, Ketley D, Lowy A, Agusti A, Hagn C, Kala R, Karatzas NB, Leizorowicz A, Reikvam A, Schilling J, Seabra-Gomes R, Vasiliauskas D, Wilhelmsen L. Beta-blockers and antithrombotic treatment for secondary prevention after acute myocardial infarction. Towards an understanding of factors influencing clinical practice. The European Secondary Prevention Study Group. Eur Heart J 1998;19:74-9.

17. Grol R. Implementation of changes in practice. In: Grol R, Wensing M, Eccles M, editors. Improving Patient Care. 1e ed. London: Elsevier Limited, 2005:6-14.

18. Rosser WW, Palmer WH. Dissemination of guidelines on cholesterol. Effect on patterns of practice of general practitioners and family physicians in Ontario. Can Fam Physician 1993;39:280-4. 
19. van der Weijden T, Grol RP, Knottnerus JA. Feasibility of a national cholesterol guideline in daily practice. A randomized controlled trial in 20 general practices. Int $\mathrm{J}$ Qual Health Care 1999;11(2):131-7.

20. Weijden van der G. Evaluation of cholesterol guidelines in general practice. Maastricht University, 1997.

21. Elwyn G, Edwards A, Gwyn R, Grol R. Towards a feasible model for shared decision making: focus group study with general practice registrars. BMJ 1999;319:753-6.

22. Goodman S. Probability at the bedside: the knowing of chances or the chances of knowing? Ann Intern Med 1999;130:604-6.

23. Hux J, Naylor C. Communicating the benefits of chronic preventive therapy: does the format of efficacy data determine patients' acceptance of treatment? Med Decis Making 1995;15:152-7.

24. O'Connor AM, Rostom A, Fiset V, Tetroe J, Entwistle V, Llewellyn-Thomas H, HolmesRovner M, Barry M, Jones J. Decision aids for patients facing health treatment or screening decisions: systematic review. BMJ 1999;319:731-4.

25. Steiner JF. Talking about treatment: the language of populations and the language of individuals [see comments]. Ann Intern Med 1999;130:618-22.

26. Naylor C, Chen E, Strauss B. Measured enthusiasm: does the method of reporting trial results alter perceptions of therapeutic effectiveness? Ann Intern Med 1992;117:916-21.

27. Drenth van B. Organizing cardiovascular preventive care in general practice. University of Nijmegen, 1998.

28. Hulscher M. Implementing prevention in general practice: a study on cardiovascular disease. Nijmegen University, 1998.

29. Lobo CM, Frijling BD, Hulscher ME, Bernsen RM, Braspenning JC, Grol RP, Prins A, van der Wouden JC. Improving quality of organizing cardiovascular preventive care in general practice by outreach visitors: a randomized controlled trial. Prev Med 2002;35:422-9.

30. Lobo CM, Frijling BD, Hulscher ME, Braspenning JC, Grol RP, Prins A, van der Wouden JC. Organizing cardiovascular preventive care in general practice: determinants of a successful intervention. Prev Med 2002;35(5):430-6.

31. Frijling BD, Lobo CM, Hulscher ME, Akkermans RP, van Drenth BB, Prins A, van der Wouden JC, Grol RP. Intensive support to improve clinical decision making in cardiovascular care: a randomised controlled trial in general practice. Qual Saf Health Care 2003;12:181-7.

32. Frijling B, Hulscher ME, van Leest LA, Braspenning JC, van den Hoogen $H$, Drenthen AJ, Grol RP. Multifaceted support to improve preventive cardiovascular care: a nationwide, controlled trial in general practice. Br J Gen Pract 2003;53:934-41.

33. Robson J. Information needed to decide about cardiovascular treatment in primary care. BMJ 1997;314:277-280.

34. McAlister FA, O'Connor AM, Wells G, Grover SA, Laupacis A. When should hypertension be treated? The different perspectives of Canadian family physicians and patients. CMAJ 2000;163:403-8.

35. Grol R, Grimshaw J. From best evidence to best practice: effective implementation of change in patients' care. Lancet 2003;362:1225-30. 



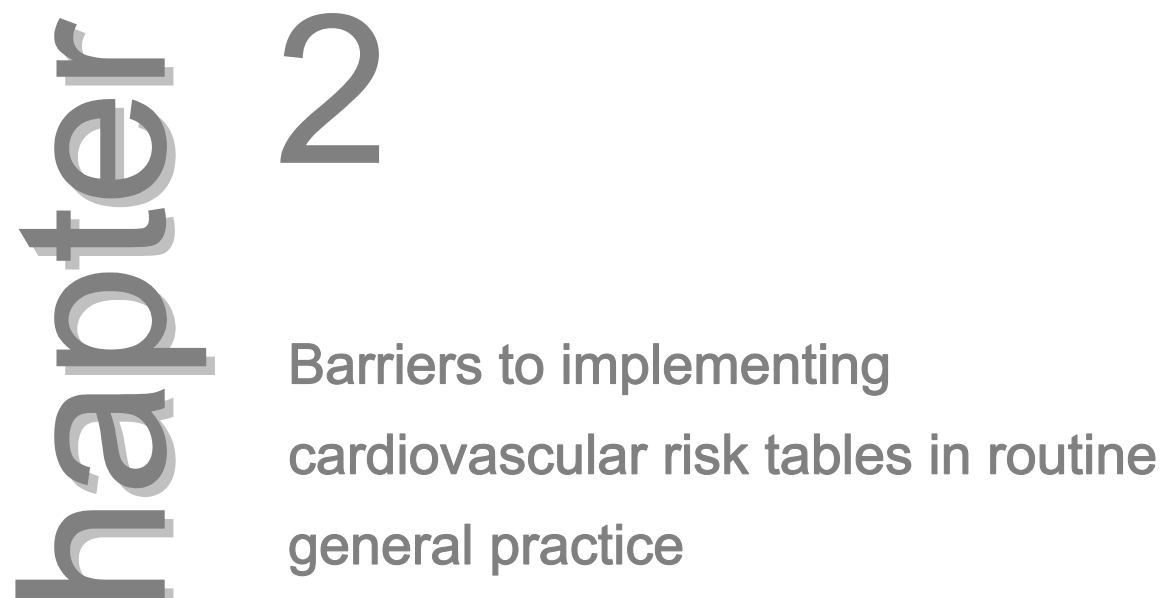

Ben van Steenkiste, Trudy van der Weijden, Jelle Stoffers, Richard Grol Scand J Prim Health Care 2004;22:32-7 


\section{Abstract}

\section{Background}

Risk tables for cardiovascular risk management improve the quality of care of patients at high risk. While their use has been associated with CVD risk reduction, barriers have also been reported.

\section{Objectives}

We aimed to examine the barriers that prevent general practitioners (GPs) from adopting the Dutch cholesterol guidelines with its incorporated risk tables in order to develop an effective implementation strategy..

\section{Methods}

Barriers that hampered the GPs to follow the guideline were examined by means of a qualitative study among a sample of fifteen GPs, Each of them audiotaped two consultations on primary prevention of CVD and was interviewed after analysing the tapes.

\section{Results}

Data saturation was reached after about 13 interviews. The 25 identified barriers were related to either the risk table, the GP or to environmental factors. Lack of knowledge and poor communication skills of the GP, along with pressure of work and demanding patients cause the GPs to deviate from the guideline. The GPs regarded barriers external to themselves as most important.

\section{Conclusions}

Using the risk table as a key element of the high-risk approach in primary prevention encounters many barriers. Merely incorporating risk tables in guidelines is not sufficient for the implementation of such guidelines. Time-efficient implementation strategies dealing in particular with the communication and presentation of cardiovascular risk are needed. 


\section{Introduction}

New guidelines for cardiovascular risk management often incorporate risk tables to support the management of patients without established cardiovascular diseases (primary prevention). These tables aim to improve the quality of care by rationalising decisions on identification and management of patients at high risk. The cardiovascular risks in these tables are mostly derived from Framingham data ${ }^{1,2}$. Examples are: the Sheffield table, the New Zealand table, and the joint European and British societies chart ${ }^{3-6}$. Although these tables vary in the way they present risks, in the cut-off points for high risk, and in the data used to calculate absolute risk, the underlying concepts are largely similar. The tables are used for highly individualised risk calculation, the so-called high-risk approach; various demographic and risk factor data can be integrated to determine a personal risk profile (Box 2.1). This approach is entirely different from those used in the past, when single risk factors were the starting point ${ }^{7,8}$. Another innovative element is that risk tables can support risk communication, which in turn could stimulate patient participation and patient compliance.

As yet, not much is known about the use of risk tables. While their use has been associated with significant reduction in systolic blood pressure ${ }^{7}$, barriers relating to their format, and scaling have also been reported ${ }^{8,9}$. We aimed to examine the barriers that prevent general practitioners (GPs) from adopting the cholesterol guideline with its incorporated risk tables since a systematic inventory is crucial for the development of effective implementation strategies.

\section{Methods}

A qualitative study was conducted in the southern part of the Netherlands. The first 20 consecutive GPs who responded to the recruitment letter were eligible to take part in the study. The GPs were asked to audiotape two consultations in which the cardiovascular risk table was used. The transcripts were used to guide the semi-structured in-depth interviews with the GPs after one to two weeks. Awareness of, the problems they had encountered in implementing, and motivations for deviation of the guideline were standard items for the interview. One of the authors (BvS) executed and audiotaped the interviews that lasted between 30 and 45 minutes. Two researchers (BvS and TvdW) independently examined the transcripts (consultations and interviews). A constant comparative approach was adopted, in which data were collected and analysed concurrently, allowing both expected and emergent themes and ideas to be incorporated and explored in subsequent interviews. All barriers to implementation of the guideline, even if mentioned by only one GP, were recorded. Differences in coding were solved through consensus. 
Box 2.1 Key recommendations for primary prevention from the Dutch College of General Practitioners' Guideline on Cholesterol

General

- Screening the practice population is not useful.

- Assess the cardiovascular risk of men (18-70 yrs.) and women (18-75 yrs.) visiting the practice.

Diagnosing hypercholesterolemia

- Whether a cholesterol test is indicated can be derived from the risk table.

- Only if there is a chance of an orange or a red square or if familial hypercholesterolaemia is suspected, is testing useful.

- If fasting blood glucose level is unknown, check it when the patient needs to be tested for cholesterol.

- Test for total cholesterol/HDL-cholesterol ratio, two tests within 2-3 weeks, non-fasting.

- If the first total cholesterol/HDL ratio $<5.0 \mathrm{mmol} / \mathrm{l}$ then a second test is not necessary.

Treatment of hypercholesterolaemia

- Cholesterol-lowering therapy is indicated for patients in red or orange squares (if there is also a family history of $\mathrm{CHD}$ ) (see risk table).

- The indication for statins is based on two conditions: the level of the absolute risk has to be at least $25 \%$, and the treatment has to be cost-effective for the relevant subgroup.

Risk table: absolute risk (\%) of developing Acute Myocardial Infarction (AMI) in 10 years

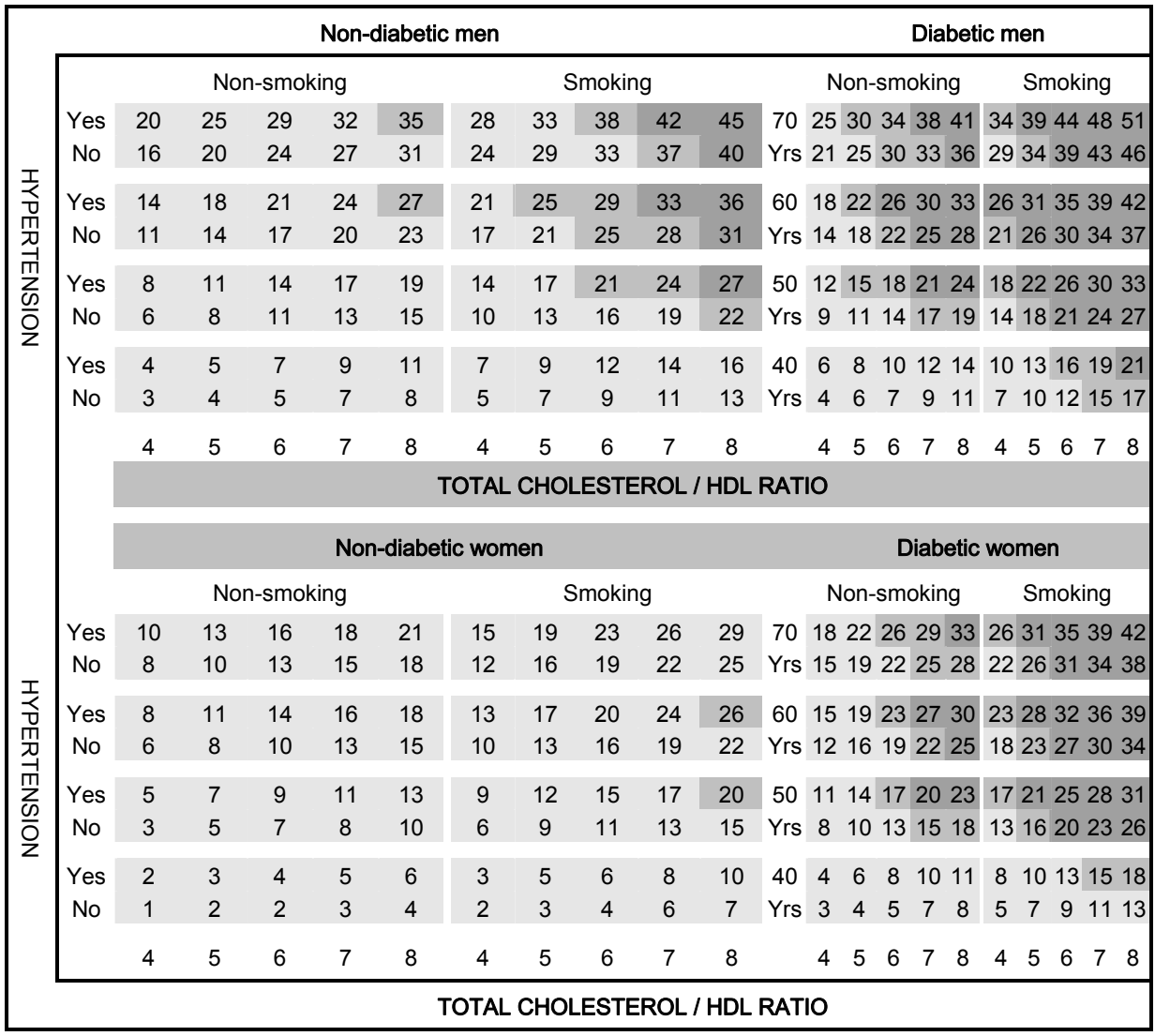


The ethics committee of the University Hospital of Maastricht approved the study and written informed consent was obtained from the patients participating in the study.

\section{Results}

\section{Population}

Of the first 20 GPs who responded to the recruiting letter, 15 were actually interviewed, because data saturation emerged after 13 interviews and was definitely reached after 15 interviews. The GPs showed sufficient variation in demographic and practice characteristics. GPs interviewed were aged 37-57 years; two were female. They worked either in group practices or had a singlehanded practice in towns, cities or rural areas. The GPs managed to record 22 consultations within the arranged time (four weeks). Many non-specific barriers were mentioned that reflect the tension between guidelines and daily practice. GPs seem to act as a conduit within the consultation and regard clinical evidence as a square peg to fit in the round hole of the patient's life ${ }^{10}$. Twenty-five barriers were identified as being specific for cardiovascular risk management. They were divided into three main categories, and several subcategories, each comprising a number of barriers (summarised in Table 2.1). Where useful, a quote by the GPs is given to illustrate the barrier.

\section{Barriers relating to the guideline - Risk table as an instrument}

The measuring scale of the risk factors in the risk table was found to be too crude. The scaling should have been continuous instead of categorical or dichotomous. Moreover the table suggests a relatively large health gain from lowering cholesterol levels, compared to smoking cessation. This was regarded as disadvantageous, because smoking cessation should have the highest priority.

The risk table was difficult to understand and should have been introduced by a special training. Many GPs did not noticed that hereditary predisposition for CVD was incorporated in the risk table. Its complexity called into question its value as a risk table, as a supportive tool for health education or shared decision-making.

The trouble with such a table is that you can't discuss it with patients. Patients are generally not familiar with statistics, so for nine out of ten of them reading a graph is not something they are used to. Let alone interpreting tables with red, yellow and orange colours. (GP4) 
Table 2.1 Barriers $(n=25)$ relating to the prevention of cardiovascular diseases (CVD) in primary care.

\begin{tabular}{l}
\hline Barriers \\
\hline Guideline - Risk table as an instrument \\
Scaling is too crude; should have been continuous \\
The value of cholesterol as a risk factor is overestimated \\
Difficult design at first view, need for training \\
Not a supportive tool for health education or decision-making \\
Guideline - Content of the risk table (recommendations) \\
Lack of agreement with other (inter)national risk tables \\
Cost reduction is not a doctor's task \\
Not up-to-date, especially for diabetes \\
Too rational for test ordering in daily practice \\
GP - Attitude \\
Ambivalence about prescribing statins to smokers \\
No motivation to spend extra time on explanation \\
Negative attitude towards preventive care \\
Strategic testing, rewarding weight loss or compliance \\
GP - Routines \\
Still managing single risk factors, first reaction is drug prescription \\
Flukes; accidental findings induce repeated testing \\
GP - Knowledge \\
Lack of knowledge (guideline, risk presentation, high risk approach) \\
GP - Skills \\
Risk communication is difficult \\
Shared decision-making is only useful in theory \\
Environment - Society \\
Impact of mass media, focus on emotions \\
Marketing efforts of pharmaceutical industry caused cholesterol hype \\
Mounting demand for regular health check-ups \\
Defensive medicine to prevent claims \\
Environment -Medical profession \\
Difference of primary versus secondary care \\
Greater influence of specialists \\
Environment -Practice organisation \\
Risk table is too complex for practice assistants \\
Risk profiles not fully integrated in the electronic patient record \\
\hline
\end{tabular}

\section{Barriers relating to the guideline - Content of the risk table}

The GPs were confused by the lack of agreement with other national risk tables. Although many GPs agreed that costs should be taken into account, some thought that decisions had to be based on medical grounds only, claiming that cost reduction is not the task of a doctor.

It was felt that the guideline was not up-to-date, already lagging behind current practice, especially for patients with diabetes. 
I give all diabetics a statin, regardless of when I made the diagnosis, whether they are male or female, whether they smoke or not. Because I regard diabetes mellitus as a vascular disease (secondary prevention). (GP9)

Some GPs stated that the decision-making concept underlying the recommendations for case-finding was too rational and too restrictive for daily practice. Screening large numbers of patients or repeated testing was not perceived as a problem since the cholesterol test is cheap, and can easily be done with desktop devices. A risk profile without a cholesterol level was incomplete according to them. GPs often used a cholesterol test as part of a strategy to encourage the patient to adopt a healthy life-style.

\section{Barriers relating to the GP - Attitude}

All GPs commented on the ambivalence they felt when prescribing statins to smokers since smoking cessation would make prescribing statins unnecessary in many cases. Pressure of time and high workload resulted in lack of motivation to spend extra time explaining the individual's CVD risk and counselling. After all, most patients come up with the same questions again and again.

But if I decide not to test them, it just means you spend ten minutes explaining why it's not necessary. Three months later they turn up at your office and say they want it anyway. That annoys me, especially since I've spent an extra ten minutes on them. I've given up fighting it. (GP8)

The attitude of the GPs towards primary prevention of CVD varied. It was not always perceived as their task or it was regarded as too expensive from the societal perspective. Some GPs failed to see the health gain anyhow.

If we'd really do primary prevention, you'd have to follow hundreds of people for maybe ten or thirty years to prevent one event. And you don't know who it's going to be, which is a big problem because it results in lots of tension and disappointment. Let the local health authorities take care of that, that's fine with me. (GP10)

\section{Barriers relating to the GP - Routines}

For some GPs it was difficult to accept the fact that a single risk factor, in this case cholesterol, is no longer the starting point for risk management. They were still focused on managing raised cholesterol levels instead of absolute risks of CVD. Often their first reaction was prescription of statins, as this is not time-consuming and easier than changing an unhealthy lifestyle. 
If you see a cholesterol level of 8 in a 48-year-old man, your first reaction is a statin. But then, if you check the table, it may turn out he doesn't need one. That is a different approach. But in the back of your mind you still think: what if he gets a heart attack and it then turns out he had a cholesterol level of 8 all the time and nothing was done about it? (GP6)

Some GPs justified their overuse of diagnostics with the argument that they had occasionally found low-risk people with a moderately elevated cholesterol level. According to them, such accidental findings (flukes) showed that the guideline does not offer $100 \%$ certainty.

\section{Barriers relating to the GP - Knowledge}

Understanding the epidemiological concepts incorporated in the risk table was felt to be a problem. Besides, GPs were simply not aware of some of the recommendations, such as the fact that there is a more aggressive approach to secondary prevention, or that repeated (annual) testing after a normal test result is unnecessary.

\section{Barriers relating to the GP - Skills}

Risk communication, i.e. translating the absolute 10-year CVD risk into "patient language" is difficult. The GPs' explanations were often too complex, not tailored to patients' needs, or they failed to check the patients' understanding. The CVD risk was very frequently overestimated. In some cases, this was done on purpose, as a strategy to change unhealthy behaviour.

Most GPs felt they were in the best position to evaluate the pros and cons of different interventions and to decide on the right one. Shared decision-making was regarded as a theoretical model for which there was no time in daily practice, and no patients' need to be involved in decision-making. Hence, the risk table was not seen as a supportive tool for the process of shared decisionmaking.

If you have to start explaining these numbers you have to take your time and talk about costs as well. All those arguments pro and con, and percentages and all that, that's a bit too complicated for me. What does it mean to these people if I tell them "You run a $17 \%$ risk and this treatment will reduce it to $13 \%$ "? That's not an easy one, I can tell you. (GP16)

\section{Barriers relating to the environment - Society}

The popular mass media and the marketing efforts of the pharmaceutical industry, for instance by distributing free digital risk tables and desktop 
analysers, mainly focus on emotions and less on facts. As a result, the general public have unrealistic ideas about the contribution of cholesterol to the absolute CVD risk, and the topic is fraught with anxiety.

This whole cholesterol story is based on people's anxiety. If you're anxious, get your cholesterol level tested. It used to be: get your blood pressure tested. It's all to do with anxiety. It is linked to something it shouldn't be linked to. (GP5)

Cholesterol screening is not uncommon in the business community, and insurance companies often demand it. Employees with elevated cholesterol levels, based on a single test, are premature labelled as at high risk and sent to their GPs for follow-up. The GPs then often have to reassure them, since in most cases there is nothing to worry about, as apart from the slightly elevated cholesterol level the patient has a low risk profile. Sometimes the GPs' motivation to prescribe statins or order cholesterol tests stemmed from defensive medicine, i.e., to prevent claims in the near future.

Suppose he gets a myocardial infarction in the future and then they find a cholesterol level of 8.0. There will always be someone who says: "You mean to say he never checked your cholesterol?" (GP15)

\section{Barriers relating to the environment - Medical profession}

GPs stated that specialists often ignore the existing local consensus. There seems to be a difference in current practice between primary and secondary care, especially as regards the threshold for prescribing statins, which seems to be lower in secondary care. Specialists have greater influence, in the sense that changing the treatment initiated by a specialist is very difficult for a GP.

There are lots of people who've been to see the cardiologist for an a-typical angina, who didn't actually have angina, but a transiently abnormal lipid spectrum, and who comes back with a statin. You just try and reverse that. It's impossible. (GP1)

\section{Barriers relating to the environment - Practice organisation}

Some GPs mentioned that delegating tasks to the practice assistant was not possible because of the complex character of the risk table and the lack of authority for this task.

Insight into existing data about the patient's risk profile is a prerequisite for efficient care. So far, however, reminder systems, risk tables and guideline recommendations have not been properly integrated into the electronic patient record. 


\section{Discussion}

Risk tables are intended to rationalise identification and management of people at high risk for CVD. The feasibility of risk tables is open to doubt, since many barriers to adherence to the risk table in the Dutch cholesterol guideline and its recommendations were identified. The majority of GPs regarded barriers relating to the mass media and the pharmaceutical industry as important. From the GPs viewpoint, it leads to demanding patients and increased pressure for tests and pharmaceutical interventions. A more defensive attitude towards cholesterol testing and statin prescription is another barrier. Not surprisingly, frustration was a recurrent theme in the GPs' comments. Barriers relating to the content and format of the risk table were also present. Often in discussing the various options for intervention with patients, the risk table raised more questions than it answered, with the integrated cost-effectiveness considerations in particular hampering the GPs' work. Lack of skills in risk communication were not recognised as barriers by the GPs themselves but were observed in the audiotaped consultations.

The GPs who took part in this study varied on the major personal and practice characteristics. They were possibly more experienced in CVD prevention compared to the average GP, although some of the GPs expressed that their motivation to participate was fed by a negative attitude towards cardiovascular primary prevention. We expect that the barriers in this perhaps more motivated group can be generalized to other GPs. The data saturation indicated that we seem to have covered the relevant barriers perceived by GPs in working with the guideline.

The high-risk approach to primary prevention was not always clear to the GPs, this being often a "clinically grey area" as some have called $\mathrm{it}^{11}$. Barriers relating to the GPs' attitude and the difference between primary and secondary care $^{10}$, as well as to differences in practice organisation, have also been reported by others ${ }^{12,13}$. Time constraints were indeed identified as one of the major profession-related barriers ${ }^{14}$. Complying with all guidelines on primary prevention would take several hours a day ${ }^{15}$.

What do these results mean for the implementation of the risk table? The roles of the media and the pharmaceutical industry are hard to deal with in an implementation strategy. Many GPs had difficulties with prescribing statins to persistent smokers owing to medical-ethical considerations. However these considerations are difficult to incorporate in the guidelines. Redesigning the format of the risk table and a larger focus on reducing unnecessary repeat tests rather than on reducing unnecessary diagnostic tests could be helpful, since most patients want to know their "number". The decision of when to perform a diagnostic test may also rest on considerations such as patient preferences ${ }^{16}$. 
Training GPs in risk communication is important, e.g. to neutralize the inflated risk perception and patient expectations. It might be worthwhile to try to empower the role of the patients by preparing them for the consultation by developing materials that do not induce fear ${ }^{17,18}$. This may increase the GPs perceived effectiveness in changing patient behaviour, which in turn is associated with improved preventive care efforts of patients ${ }^{19,20}$.

This qualitative study has yielded some essential input for the development of a risk communication tool that can be given to the patient to be read at home to prepare for discussing one's CVD risk during the consultation.

The present study also revealed that further research should focus on the conditions for risk communication to patients. Insight is needed into the cognitions, perceptions and preferences of patients in this respect, if we are to foster successful CVD prevention in the GP's office.

\section{Acknowledgements}

This study was supported by a grant from the Dutch Heart Association. 


\section{References}

1. Grundy SM, Pasternak R, Greenland P, Smith S, Jr., Fuster V. Assessment of cardiovascular risk by use of multiple-risk-factor assessment equations: a statement for healthcare professionals from the American Heart Association and the American College of Cardiology. Circulation 1999;100:1481-92.

2. Haq IU, Ramsay LE, Yeo WW, Jackson PR, Wallis EJ. Is the Framingham risk function valid for northern European populations? A comparison of methods for estimating absolute coronary risk in high-risk men. Heart 1999;81:40-6.

3. Wallis EJ, Ramsay LE, UI Haq I, Ghahramani P, Jackson PR, Rowland Yeo K, Yeo WW. Coronary and cardiovascular risk estimation for primary prevention: validation of a new Sheffield table in the 1995 Scottish health survey population. BMJ 2000;320:671-6.

4. Jackson R. Updated New Zealand cardiovascular disease risk-benefit prediction guide. BMJ 2000;320:709-10.

5. Anonymous. Joint British recommendations on prevention of coronary heart disease in clinical practice: summary. British Cardiac Society, British Hyperlipidaemia Association, British Hypertension Society, British Diabetic Association. BMJ 2000;320:705-8.

6. Wood D, De Backer G, Faergeman O, Graham I, Mancia G, Pyorala K. Prevention of coronary heart disease in clinical practice: recommendations of the Second Joint Task Force of European and other Societies on Coronary Prevention. Atherosclerosis 1998;140:199-270.

7. Montgomery AA, Fahey T, Peters TJ, Maclntosh C, Sharp DJ. Evaluation of computer based clinical decision support system and risk chart for management of hypertension in primary care: randomised controlled trial. BMJ 2000;320:686-90.

8. Isles CG, Ritchie LD, Murchie P, Norrie J. Risk assessment in primary prevention of coronary heart disease: randomised comparison of three scoring methods. BMJ 2000;320:690-1.

9. Peters TJ, Montgomery AA, Fahey T. How accurately do primary health care professionals use cardiovascular risk tables in the management of hypertension? $\mathrm{Br} \mathrm{J}$ Gen Pract 1999;49:987-8.

10. Freeman AC, Sweeney K. Why general practitioners do not implement evidence: qualitative study. BMJ 2001;323:1-5.

11. Fairhurst K, Huby G. From trial data to practical knowledge: qualitative study of how general practitioners have accessed and used evidence about statin drugs in their management of hypercholesterolaemia. BMJ 1998;317:1130-4.

12. Hulscher ME, van Drenth BB, Mokkink HG, van der Wouden JC, Grol RP. Barriers to preventive care in general practice: the role of organizational and attitudinal factors. $\mathrm{Br} \mathrm{J}$ Gen Pract 1997;47:711-4.

13. van Drenth BB, Hulscher ME, van der Wouden JC, Mokkink HG, Van Weel C, Grol RP. Relationship between practice organization and cardiovascular risk factor recording in general practice. Br J Gen Pract 1998;48:1054-8.

14. Beaulieu M TY, Jada AR, Xhignesse M. Enhancing prevention in primary care: are interventions targeted towards consumers' and providers' perceived needs? Health Expect 2000;3:253-62.

15. Yarnall K, Pollack Kl, Outbid T, Krause KM, Michener JL. Is there enough time for prevention. Am J Pub Health 2003;93:635-41.

16. Getz L, Nilsson PM, Hetlevik I. A matter of heart: the general practitioner consultation in an evidence-based world. Scand J Prim Health Care 2003;21:3-9.

17. Paterson JM, Llewellyn Thomas HA, Naylor CD. Using disease risk estimates to guide risk factor interventions: field test of a patient workbook for self-assessing coronary risk. Health Expect 2002;5:3-15.

18. Marteau TM, Kinmonth AL. Screening for cardiovascular risk: public health imperative or matter for individual informed choice? BMJ 2002;325:78-80. 
19. Ely JW, Goerdt CJ, Bergus GR, West CP, Dawson JD, Doebbeling BN. The effect of physician characteristics on compliance with adult preventive care guidelines. Family Med 1998;34:34-9.

20. Skolbekken JA. Communicating the risk reduction achieved by cholesterol reducing drugs. BMJ 1998;316:1956-8. 



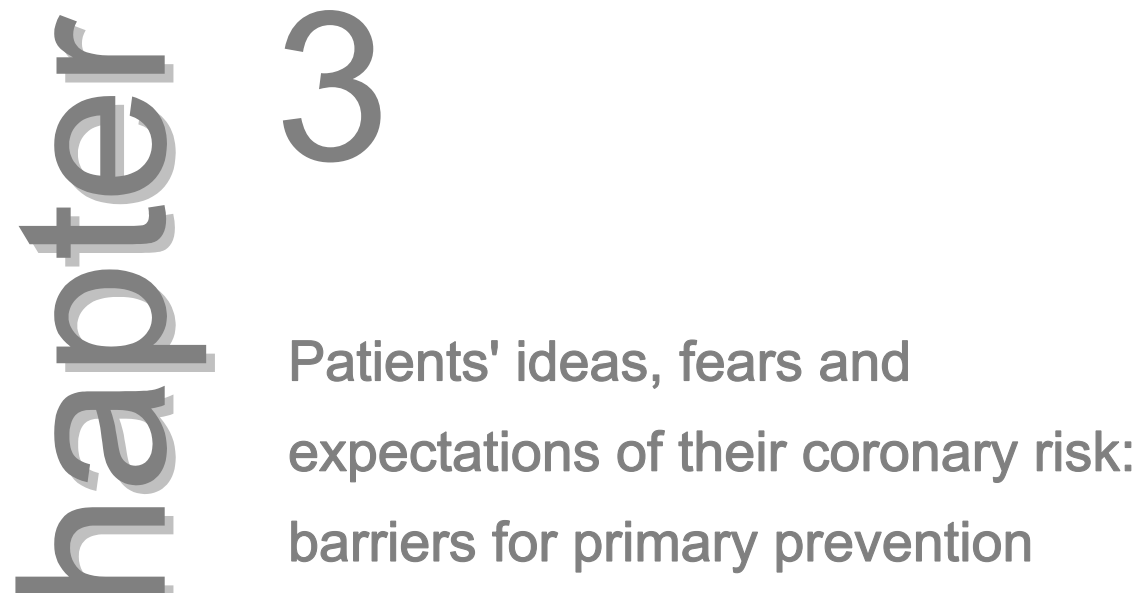

Ben van Steenkiste, Trudy van der Weijden, Daniëlle Timmermans, Jacqueline Vaes, Jelle Stoffers, Richard Grol Patient Educ Couns. 2004;55:301-7 


\section{Abstract}

\section{Background}

Risk tables are intended to estimate the absolute risk of coronary heart diseases of individuals without CVD and subsequently provide options for decisions on multiple risk management. However, the application of cardiovascular guidelines and risk tables may be impeded by many barriers.

\section{Objectives}

Exploration of the role of patients in the feasibility of cardiovascular preventive care in general practice.

\section{Methods}

Patient-related barriers were examined by means of a qualitative study. Fifteen general practitioners (GPs) audio-taped one or two consultations on primary cardiovascular preventive care. The tapes were used to guide the subsequent semi-structured in-depth interviews with patients. Twenty-two patients were interviewed.

\section{Results}

Patients' understanding of prevention of cardiovascular disease was often insufficient. The risk table and the multi-factorial approach were difficult to understand. Risk perception was often unrealistic and dichotomous, and mainly based on personal experiences. There was a demand for more information and cholesterol tests.

\section{Conclusions}

At the patient level, many barriers impede effective prevention of cardiovascular diseases. In particular the highly individualized high-risk approach needs to be explained to patients. Educational patient materials, intended to support both the GP and the patient, should take into account the ideas, fears and expectations of patients. 


\section{Introduction}

In Britain and the US, the primary prevention of cardiovascular diseases (CVD) is increasingly guided by specific risk tables and accompanying recommendations (Table 3.1, showing part of a Dutch risk table). Risk tables are intended to estimate the absolute risk of coronary heart diseases of individuals without CVD and subsequently provide options for decisions on multiple risk management such as drug treatment, life-style change or reassurance. The estimated (10-year) absolute risk of myocardial infarction is based on combined information on the risk factors age, sex, diabetes, smoking, blood pressure and cholesterol ${ }^{1,2}$. When a patient is at high risk, various treatment options may occur, and the portrayal and discussion of options is considered to be the pivotal stage of shared decision-making ${ }^{3}$.

Table 3.1 Part of the risk table of the Dutch College of General Practitioners Guideline on Cholesterol (for non-diabetic men)

Risk table: absolute risk (\%) of developing an Acute Myocardial Infarction in 10 years

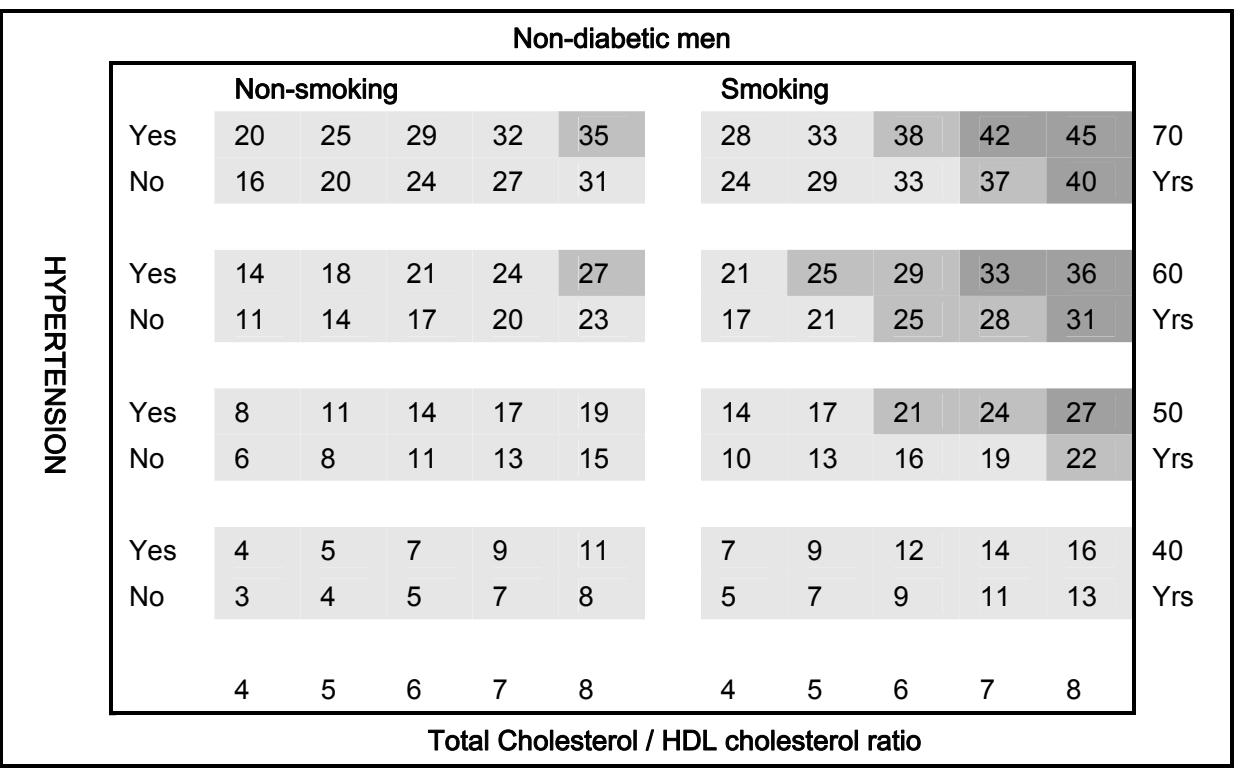

- Low-grade grey: no statin

- Medium-grade grey: statin when CVD in first degree family member before the age of 60 years

- High-grade grey: statin

General practitioners (GPs) often deviate from the guideline, resulting in problems such as repeated unnecessary diagnostic testing and over-treatment, where reassurance and explanation should perhaps have been the preferred management ${ }^{4}$. Conversely, it seems difficult to motivate high-risk patients for 
preventive strategies such as life-style change or long-term drug compliance. Many GPs experience pressure from patients who demand unnecessary testing or medical treatment ${ }^{5}$. Active participation by the patient could lead to improved patient compliance with life-style advice or pharmaceutical treatment, as well as to effective reassurance and patient satisfaction ${ }^{6,7}$. The question is whether patients correctly understand the information about their risk and the options for management. However, explaining risk factors and risks is difficult $^{8-11}$. Optimal use of cardiovascular risk tables requires a thorough insight into the barriers at patient's level that play a role during a consultation about cardiovascular disease prevention. The objective of the present study was to explore those barriers that impede effective communication on cardiovascular risk and prevention during consultations in primary care. Insight in those barriers may help to translate the risk table into the patient's concepts and language, and improve the conditions for shared decision-making.

\section{Methods}

Three hundred GPs in the southern part of the Netherlands were invited by post to participate in this qualitative study. The first twenty GPs who responded immediately were visited. During the practice visit they received additional information about the study, the use of the tape-recorder, how to obtain informed consent, the selection of patients, and to use the risk table. Each GP was asked to recruit the first two consecutive patients, between 40-70 year of age and without established CVD that he or she met in a consultation in which the risk table was applied to discuss a patients' cardiovascular risk. At the start of the consultation, the GP asked the patient to sign an informed consent form for audio-taping the consultation and a subsequent interview at the patient's home.

Each patient was interviewed by one of the authors (JV) one to two weeks after the consultation. She listened to the audio-tapes of the consultations to prepare herself for the semi-structured in-depth interviews at the patient's home. Patients were first asked to recount whatever they remembered from the consultation and then how they felt about it. Thereafter patient's knowledge and expectations related to CVD prevention, risk factors and risk management were explored, based on the events in the taped consultations. The interviews were audio-taped and lasted between 30 and 90 minutes. At the end of the interview demographic characteristics (Table 3.2) were obtained by means of a questionnaire in which the highest level of education and last occupation were items for measuring Social Economic Class (SES).

The tapes were transcribed verbatim, and the transcripts were read and coded independently by two of the authors (BvS and TvdW). The coding of themes 
consistently followed grounded theory rules, all the emerging themes were directly supported by verbatim data from the interviews or the consultations. We did not set out with the overarching aim of generating theory from the findings.

All barriers related to prevention of CVD were coded. Coding differences between authors were solved through discussion. This approach allowed both expected (from the literature) and emerging themes to be explored in subsequent interviews. This process was continued until data saturation was reached, i.e., no new themes emerged ${ }^{12}$. After the coding of all data was completed, the codes were categorized as patient's ideas, fears and expectations. This model fitted best to our data ${ }^{13}$.

The study was approved by the ethics committee of the University Hospital of Maastricht.

\section{Results}

The 15 GPs selected 30 patients. Six patients were excluded because of a missing audio-tape of the consultation and another two patients were excluded because missing interviews. Therefore the study involved 22 patients. For demographic characteristics of the patients see Table 3.2.

The barriers relating to: the patient's ideas, fears, and expectations before or at the consultation are summarized in Table 3.3. Examples of barriers are illustrated below by patient quotes.

Table 3.2 Demographic characteristics of the patients $(n=22)$

\begin{tabular}{lc}
\hline Age (yrs) & \\
mean $( \pm \mathrm{sd})$ & $52( \pm 8.6)$ \\
min-max & $36-70$ \\
Female & 5 \\
Socio-economic status & 4 \\
$\quad$ high & 15 \\
medium & 3 \\
low & \\
Risk profile & 1 \\
Diabetes & 9 \\
Positive family history of CVD $^{\mathrm{a}}$ & 10 \\
Smoking & 5 \\
Hypertension & 5 \\
BMl >30 kg/m & 5 \\
Hypercholesterolaemia & 9 \\
\hline
\end{tabular}

${ }^{a}$ Cardiovascular disease in first degree family member before the age of 60 years 
Table 3.3 Summary of patient-related barriers in the primary prevention of cardiovascular diseases

Barriers related to patients' ideas about cardiovascular diseases and risk factors
Insufficient: Cholesterol is more dangerous than high blood pressure, as a
clot may become detached and go to your brain
Incorrect: If your cholesterol is elevated, it means some blood vessel is
blocked
Fragmentary. It does not really run in our family, genetically speaking. But it
does run in my wife's family; her father died of a cardiac arrest
Faded: He did explain all that, but I can't remember now
Fatalism: If it's your fate to get it, you will get it
Difficult risk-table: That table is hard to understand; I thought that orange
meant a high risk
Risk perception (fears)
Dichotomous thinking. If your cholesterol is good, it means you no longer
Incorrect comparison: My father is 105 and he still smokes
Based on emotions: One of my friends from the sports club turned out to
have very poor coronary arteries. And there we were thinking sport was
good for us
Associated with ageing and mortality. Cardiovascular disease, that's getting
close to the idea of death, I think
Not alarmed: I didn't change my attitude until I got those black toes; that's
when I started to reduce my smoking
Head in the sand: I don't need to know; that would only worry me more

Concerning health information and education

Informed and reassured. Seeking information themselves: I don't think about that; I don't worry about it, and if want to know about it I'll find out for myself

Non-committal. On certain terms: Only if it's non-committal, or if they give me medication

Informed but not reassured, 'worried well': In fact, I should believe what the doctor says, but then I start to think maybe it's something else and then I ask for a little check-up

Concerning interventions/ management of problems

Right to a cholesterol test (among the elderly): If I want to know, I feel it's my right to know

Uniform approach: My brother also has a cholesterol level of 6 and he gets the pills

One risk factor approach: If my blood pressure is too high, I should be given medication, whether I'm in the high-risk group or not 


\section{Barriers related to patients' ideas about cardiovascular disease and risk factors}

\section{Understanding cardiovascular diseases}

Many patients showed insufficient insight in cardiovascular diseases to really understand their GPs explanation. Some patients showed a lack of knowledge about the aetiology, consequences, multiple prevention options and the influence of genetics. Some patients' knowledge was incorrect and fragmentary, based on experiences with close friends or relatives who had suffered of CVD. These experiences sometimes had a greater impact on knowledge and behaviour than the information provided by GPs. The information provided during the consultation had sometimes faded, leaving only the emotion, e.g., the feeling of reassurance following the message that 'the test result was good'.

Other persons shared a more fatalistic view of CVD as an unavoidable phenomenon, because they already had had a long history of unhealthy lifestyle. Or their fatalistic view was based on the belief that CVD is solely caused by genetic factors, not really influenced by environmental factors, and beyond personal control.

Suppose I get an infarction anyway in a few months, or in five years' time, l'd feel it's been a waste of effort. I'd think: I wish I had smoked for those five years as well.

\section{Understanding cardiovascular risk factors}

Patients often overestimated the importance of cholesterol as a risk factor or even perceived cholesterol as the most important risk factor. One patient believed that a high cholesterol level meant that somewhere in his body an artery had become blocked. Many patients seemed to know that there are good next to bad types of cholesterol.

Some patients failed to realize that smoking is the most important risk factor. One patient even thought that it was dangerous to stop smoking; he thought that nicotine had become an essential drug for his body. Hypertension as a risk factor seemed to be accepted as a routine issue. A new patient accepted without further questions that he would have to use blood pressure lowering medication for the rest of his life, although losing weight and regular exercise could have solved the problem as well.

I know so many people who stopped smoking and then died. So it makes me think, could that happen to me as well if I stopped smoking? Because my body no longer receives nicotine? 


\section{Understanding the risk table}

Only two patients reported that they had understood the GP's explanation of the risk table. It was particularly the absolute 10-year risk, a key concept in the risk table, which patients found difficult to understand.

[Interviewer:] Your GP has told you that you have a 23\% risk of getting cardiovascular disease within the next ten years. Does that number mean anything to you? [Patient:] Yes, it means l'll get cardiovascular disease within ten years.

I don't think they can conclude from a blood sample whether you'll get cardiovascular disease. l've seen it with my neighbour across the street. He had been in for a checkup and the hospital had said that everything was all right. Well, the day after that he had a heart attack and he was gone.

\section{Barriers related to patients' risk perception (fears)}

Cardiovascular risk did not seem to be a clear concept to many patients. Many of them perceived cardiovascular risk as a dichotomous variable, failing to appreciate the grey areas in between the extremes, in terms of the spectrum of disease options.

Well, I mean, if your cholesterol is OK it means there's no more risk of cardiovascular disease, isn't that right?

You may say, it's one in a hundred. But what if I'm that one? One in a hundred means nothing to me; it's always fifty-fifty in a way. I don't care by how little the risk is reduced, as long as it's reduced.

Many patients evaluated their personal risk by comparing themselves with another individual in their social environment, with emotions being given greater weight than cognition. Their risk perception was rather optimistic, since they often compared themselves with a 'bad' example from a comparable group. To them, the exception proved the rule.

I've known people who died 25 years ago, at the age of 23 or 25 . But there's also my uncle, with his great big cigars and his short walk ever day and a bottle of gin, he was 97, he broke a leg and he was dead within three months. It all contributes. But I also know lung cancer patients who have never smoked a cigarette in their lives.

The participants' cardiovascular risk perception rarely seemed to be based on facts; instead it was more often based on emotions like fear or concern related to experiences with family, close friends or colleagues who suffered from cardiovascular diseases. 
One of our friends from the sports club, aged 43, turned out to have very poor coronary arteries. And there we were thinking that sport was good for us. One after the other went to see his doctor to know how he was doing.

Some patients associated the phenomenon of CVD directly and unavoidably with ageing and death, and therefore did not want to think about CVD at all. By contrast, some of the older patients felt that they were 'on the list', which resulted in the kind of concern that drives patients to see their doctor.

Not alarmed. Some persons seemed to seek risk to some extent. Despite the fact that they were aware of the risks to their health, they challenged death and continued their unhealthy life-style as long as they were not alarmed by any negative physical sensations.

You don't just start to avoid risks; you need to have had a blow first. If l'd had to start using medication, that would have frightened me, it would mean they have to suppress it. That would really be a risk to me.

Some patients prefer to deny their risk and are not motivated to receive information; preferring instead to stick their heads in the sand.

Ignorance is bliss, as they say. The more you read about it, the more anxious you get. I know, I'm sticking my head in the sand.

\section{Expectations for information and treatment}

There were also some barriers related to the interaction with the GP during the consultation, in terms of incongruent needs and expectations. Needs (e.g. repeated testing) and expectations (e.g. prescription of drugs instead of the advice to stop smoking) that are incongruent with the GP's management or the guideline recommendations did seem to play a role. Moreover, patients' expectations were sometimes directly influenced by the information they had gathered from other sources; e.g. the World Wide Web.

\section{Expectations concerning health information and education}

The need for information varied among patients; there was a category of patients who regarded themselves as well-informed, without any further need for information. These patients felt reassured or were not really bothered by information on CVD risk.

No it is like in the traffic; if I get in the car, I don't think about that I might have an accident. 
Other patients did express a need for information, but some, who were insufficiently informed, made a proviso before accepting the information. In addition to the information, they demanded active aids or alternatives such as medicines that would help them change their life-style.

Another condition for accepting information was that they wanted noncommittal advice, refusing any appeal to their own responsibility.

I think that's wrong; you go there for some other disease and they still challenge you about your smoking. If I'm told to stop smoking they should also provide me with the means to quit.

Another category of patients, referred to as the 'worried-well' by some authors $^{14,15}$, can be characterized as having a low cardiovascular risk, and still feeling the urge to ask for diagnostic or therapeutic interventions. They might be well-informed about their low risk, but nevertheless are anxious about monitoring their cholesterol level.

I know I should believe what the doctor says, but then afterwards I start to think what if it's not OK, and then I get another blood sample tested. I think you should get a health check once a year.

\section{Expectations about interventions/management of problems}

The patient's reason for encounter was often a request (or even demand) for a cholesterol test. They felt they had a right to get one and expected the GP not only to meet their request, but also to use a uniform approach. Tailoring risk management to the individual patient, the so-called high-risk approach, as advocated in the guideline, seemed to be hard to understand. Despite the GP's explanation about the relative weight of one abnormal risk factor in the entire risk profile, some patients were not convinced and still asked for medication.

I had 6.3 ( $\mathrm{mmol} / \mathrm{l})$ serum cholesterol and my GP wouldn't give me those pills. I know, there are all kinds of other factors involved, but my uncle also had high cholesterol and no risk factors and he still had a heart attack. Give me those tablets anyway.

It appeared that elderly patients experienced a greater need for information and screening. Some patients explained that regular checkups of blood pressure and serum cholesterol reduced their fear of becoming dependent. They anticipated the threat of physical decline.

The older you get, the less risk you want to run. I never used to think about that before, but now I do. Life's too good to want to die now. Maybe I should have a 
cholesterol check-up every six months now I'm almost sixty. It doesn't mean I'm old, but the risk of getting something is increasing.

\section{Discussion and conclusion}

This study confirms that prevention of cardiovascular diseases in general practice is impeded by various barriers at patient level. We found important barriers in three areas: ideas (insufficient knowledge about CVD or CV risk factors), fears (unrealistic perception of $\mathrm{CV}$ risk and misunderstanding the $\mathrm{CV}$ risk table), and expectations about information and treatment.

To ensure sufficient depth in the interviews all patients were interviewed at home to create an informal atmosphere and stimulate them to speak freely about their recent visit to the GP, where they had discussed their cardiovascular risk. The patients were told that no feedback about the results of the interviews was given to the GPs. Data saturation was reached after interviewing about 17 men and women of different ages and different social backgrounds. Although the GPs were about to include the first two consecutive patients that fulfilled the inclusion criteria, it is possible that some kind of selection bias occurred (e.g. higher chance of including a patient known by the GP as willing to participate). It might have resulted in an under representation of barriers, although the fact that the patients were recruited by 15 different GPs minimised the possibility of selection bias.

For the ease of presentation and to gain more grip and insight in the data, we attempted to use some of the existing social cognition models (The Health Belief Model, the Theory of Reasoned Action, the Trans-theoretical Model and the Theory on Illness Representations) We wanted to see whether our data could fit in one of these models, in order to understand how individuals risk perception influences behaviour ${ }^{16-19}$. But none of them could, and, in the end the classification in ideas, fears, and expectations seemed to fit best.

\section{Discussion}

It is not easy to explain cardiovascular risk to patients with the help of a risk table. Apart from its presentation, risk perception is influenced by many factors, such as experience in the family, age, sex, locus of control, etc. ${ }^{20,21}$. It was rather striking that many persons had a dichotomous (risk/no-risk) rather than a continuous perception of the concept of risk. This was also found for prenatal screening where the perception of many counselees could often be characterized as a 'binary perception' process, and for subjects perceiving their carrier risks of Duchene muscular dystrophy ${ }^{22,23}$. People seem to translate 
numeric risks into categories in order to make the information usable and show a wide variety in interpretations ${ }^{24}$.

The comparative evaluation of cardiovascular risk we found in our study could be labelled as "unrealistic optimism" 25 , one of the defensive biases in perceiving risk information ${ }^{26}$. People tend to estimate the chance they will develop a disease as less than that an average other person will. They compare themselves with the wrong group ${ }^{27,28}$. The magnitude of this unrealistic optimism (i.e. the difference between risk estimates for oneself and for others) varies, but is particularly large for diseases that are believed to be preventable by individual action. For instance, some patients who were informed that they were running a high risk minimized the severity of the health threat by saying things like 'my father was still smoking cigarettes when he was very old' or perceived the risk factor as highly prevalent: 'everybody else runs the same risk, there are so many smokers'.

The risk of a heart attack was often experience based, assessed by recalling such occurrences among friends or relatives. Risk perceptions are shown to be influenced by several cognitive strategies while evaluating risks which explain some of the systematic errors observed in people's quantitative estimates of risk. People often evaluate a risk in terms of how easily they can recall past examples or how easily they can imagine such occurrences ${ }^{29,30}$. Some patients preferred to deny their risk and stick their heads in the sand. These coping strategies are characterized by procrastination (delaying making a decision), hypervigilance (frantically searching information) and defensive avoidance (selective forgetting and selective inattention) ${ }^{31,32}$.

The expectations for information varied among patients. Some were not interested at all, others were well informed or although well informed lacked the motivation (non-committal advice) to change their behavior. Some patients were both well informed and motivated but they did not know how to change their life-style. Perhaps the Theory of Stages of Change with precontemplation, contemplation, preparation, action and maintenance can help to tailor the information that is given by the GPs. In our study, nearly all patients expressed a need for more information. There are indications in the medical literature that patients also wish to participate in decision-making ${ }^{33}$.

\section{Practice implications}

For daily practice, proper communication and shared-decision making requires the GP to learn about patients' ideas, fears and expectations. Apart from training GPs in these skills, there is a need to develop educational material for patients ${ }^{34,35}$. Such materials could support both the communication and the decision-making process, since pressure of time also imposes its constraints on the decision-making process, possibly resulting in a sub-optimal decision 
strateg ${ }^{36}$. Shared decision-making seems a valuable approach in primary prevention, and decision aids could support the GP and the patient as well as save time $e^{37,38}$, though the effect of such decision aids remains to be investigated. A field test using a patient workbook for self-assessment of coronary risk yielded promising results ${ }^{7}$. We conclude that there are many barriers at patient level that impede effective primary prevention of cardiovascular diseases. Developing tailored educational patient materials could be a promising strategy to support the implementation of guidelines and risk tables and to help address patients' ideas, fears and expectations and facilitate shared decision-making.

\section{Acknowledgements}

This study was supported by a grant from the Dutch Heart Association. 


\section{References}

1. Grundy SM, Pasternak R, Greenland P, Smith S, Jr., Fuster V. Assessment of cardiovascular risk by use of multiple-risk-factor assessment equations: a statement for healthcare professionals from the American Heart Association and the American College of Cardiology. Circulation 1999;100:1481-92.

2. Wood D, De Backer G, Faergeman O, Graham I, Mancia G, Pyorala K. Prevention of coronary heart disease in clinical practice: recommendations of the Second Joint Task Force of European and other Societies on Coronary Prevention. Atherosclerosis 1998;140:199-270.

3. Elwyn G, Edwards A, Kinnersley P, Grol R. Shared decision making and the concept of equipoise: the competences of involving patients in healthcare choices. $\mathrm{Br} J$ Gen Pract 2000;50:892-9.

4. Weijden van der G. Evaluation of cholesterol guidelines in general practice. Thesis Maastricht: Unigraphic, 1997.

5. Steenkiste van BC, Weijden van der T, Stoffers J, Grol R. Barriers to implementing cardiovascular risk tables in routine General Practice. Scand J Prim Health Care. 2004;22: 32-7.

6. O'Connor A, Rostom A, Fiset V, Tetroe J, Entwistle V, Llewellyn-Thomas H, Holmes-Rovner $\mathrm{M}$, Barry $\mathrm{M}$, Jones $\mathrm{J}$. Decision aids for patients facing health treatment or screening decisions: systematic review. BMJ 1999;319:731-4.

7. Paterson JM, Llewellyn Thomas HA, Naylor CD. Using disease risk estimates to guide risk factor interventions: field test of a patient workbook for self-assessing coronary risk. Health Expect 2002;5:3-15.

8. Steiner JF. Talking about treatment: the language of populations and the language of individuals. Ann Intern Med 1999;130:618-22.

9. Goodman S. Probability at the bedside: the knowing of chances or the chances of knowing? Ann Intern Med 1999;130:604-6.

10. Hux J, Naylor C. Communicating the benefits of chronic preventive therapy: does the format of efficacy data determine patients' acceptance of treatment? Med Decis Making 1995; 15:152-7.

11. Naylor C, Chen E, Strauss B. Measured enthusiasm: does the method of reporting trial results alter perceptions of therapeutic effectiveness? Ann Intern Med 1992;117:916-21.

12. Glaser BG, Strauss AL. The Discovery of Grounded Theory. Chicago: Aldine, 1967.

13. Stewart M, Brown JB, Patient-centeredness in medicine. In: Edwards A, Elwyn G, eds. Evidence-based Patient choice. New York: Oxford University press Inc. , 2001:97-117.

14. Smith RC, Gardiner JC, Lyles JS, Johnson M, Rost KM, Luo Z, Goddeeris J, Lein C, Given CW, Given B. Minor acute illness: a preliminary research report on the "worried well". J Fam Pract 2002;51:24-9.

15. Garfield S. The delivery of medical care. Sci Am 1970;222:15-23.

16. Wilson DK, Purdon SE, Wallston KA. Compliance to health recommendations: A theoretical overview of message framing. Health Educ Res 1988;3:161-71.

17. Becker $\mathrm{MH}$. Theoretical models of adherence and strategies for improving adherence. In: Shumaker SA, ed. The handbook of health behavior change. New York: Springer Publishing Co, 1990:5-43.

18. Prochaska JO, DiClemente CC. Stages of change in the modification of problem behaviors. Prog Behav Modif 1992;28:183-218.

19. Edwards $\mathrm{A} B \mathrm{BH}$. Risk communication - making evidence part of patient choice. In: Edwards A, Elwyn G, eds. Evidence-based patient choice. New York: Oxford University Press, 2001: 144-60.

20. Bottorff J, Ratner P, Johnson J, Lovato C, SA. J. Communicating cancer risk informating: the challenges of uncertainly. Patient Educ Couns 1998;33:67-81.

21. Howitt A, Armstrong D. Implementing evidence based medicine in general practice: audit and qualitative study of antithrombotic treatment for arterial fibrillation. Br Med J 1999;318:1324-7. 
22. Lippman-Hand A, Fraser FC. Genetic counseling: Provision and reception of information. Am J Med Genet 1979;3:113-27.

23. Parsons E, Atkinson P. Lay constructions of genetic risk. Soc Health Illness 1993;15:437-55.

24. Wertz DC, Sorenson JR, Heeren TC. Clients' interpretation of risks provided in genetic counseling. Am J Hum Genet. 1986;39:253-64.

25. Weinstein N. Why it won't happen to me: perceptions of risk factors and susceptibility. Health Psychol 1984;3:431-57.

26. Croyle RT SY, Hart M. Processing risk factor information: Defensive biases in health-related judgments and memory. In: Petrie KJ WJ, ed. Perceptions of health and illness: current research and applications. Amsterdam: Harvard Academic Publishers 1997:267-90.

27. Weinstein ND. Unrealistic optimism about susceptibility to health problems: conclusions from a community-wide sample. J Behav Med 1987;10:481-500.

28. Weinstein ND. Why it won't happen to me: perceptions of risk factors and susceptibility. Health Psychol 1984;3:431-57.

29. Tversky A, Kahneman D. Judgements of and by representativeness. Kahneman D, Slovic P, Tversky A (Eds.) Judgment under uncertainty: heuristics and biases. Cambridge, MA: Cambridge University Press 1982:84-101.

30. Sherman,S J, Cialdini,R B, Schwartzman D F; Reynolds,-Kim-D. Imagining can heighten or lower the perceived likelihood of contracting a disease: The mediating effect of ease of imagery. Pers Soc Psycho Bull 1985;11:118-27

31. Janis IL, Mann L. Emergency decision making: a theoretical analysis of responses to disaster warnings. J Human Stress 1977;3:35-45.

32. Janis IL, Mann L. Decision making: A psychological analysis of conflict, choice, and commitment. New York: Free Press 1977.

33. Mazur DJ, Hickam DH. Patients' preferences for risk disclosure and role in decision making for invasive medical procedures. J Gen Intern Med 1997;12:114-7.

34. Beaulieu M TY, Jada AR, Xhignesse M. Enhancing prevention in primary care: are interventions targeted towards consumers' and providers' perceived needs? Health Expect 2000;3:253-62.

35. Samsa GP, Cohen SJ, Goldstein LB, Bonito AJ, Duncan PW, Enarson C, DeFriese GH, Horner RD, Matchar DB. Knowledge of risk among patients at increased risk for stroke. Stroke 1997;28:916-21.

36. Timmermans D. Decision aids for bounded rationalists: an evaluation study of multi-attribute decision support in individual and group settings. Groningen: University of Groningen 1991.

37. Edwards A, Barker J, Bloor M, Burnard P, Covey J, Hood K, Matthews E, Pill R, Russell D, Russell I, Stott N, Wilkinson C. A systematic review of risk communication - improving effective clinical practice and research in primary care. London: NHS Executive 1998.

38. Edwards A, Elwyn G. The potential benefits of decision aids in clinical medicine. JAMA 1999;282:779-80. 



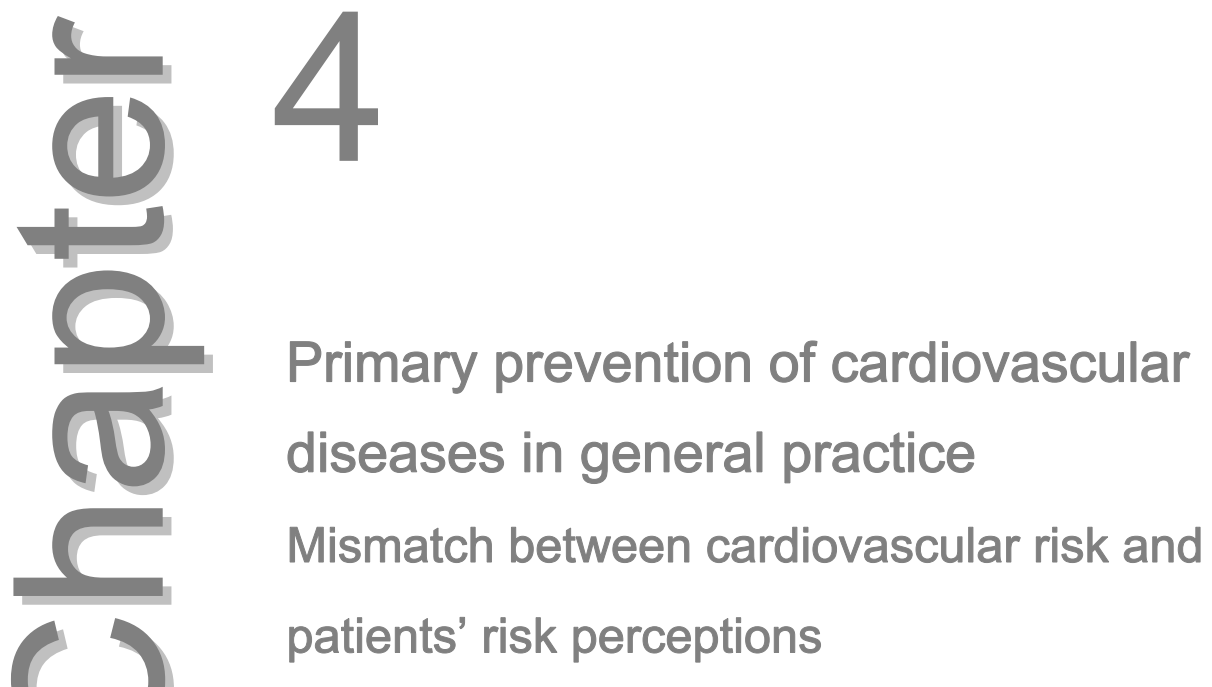

Trudy van der Weijden, Ben van Steenkiste, Jelle Stoffers, Daniëlle Timmermans, Richard Grol Med Decis Making 2007;27:754-761 


\section{Abstract}

\section{Objectives}

Guidelines on primary prevention of cardiovascular disease (CVD) emphasize identifying high-risk patients for more intensive management, but patient's misconceptions of risk hamper implementation. Insight is needed into the type of patients that general practitioners (GPs) encounter in their cardiovascular prevention activities. How appropriate are the risk perceptions and worries of patients with whom GPs discuss CVD risks? What determines inappropriate risk perception?

\section{Methods}

Cross-sectional study in 34 general practices. The study included patients aged 40-70 years with whom CVD risk was discussed during consultation. After the consultation, the GPs completed a registration form and patients completed a questionnaire. Correlations between patients' actual CVD risk and risk perceptions were analysed.

\section{Results}

During six months, 490 patients were included in the study. In $17 \%$ of the consultations, patients were actually at high risk. Risk was perceived inappropriately by nearly four in five high-risk patients (incorrect optimism), and by one in five low-risk patients (incorrect pessimism). Smoking, hypertension, and obesity were determinants of perceiving CVD risk as high, while surprisingly, diabetic patients did not report any anxiety about their CVD risk. Males were more likely to perceive their CVD risk inappropriately than females.

\section{Conclusions}

In communicating CVD risk, GPs must be aware that they mostly encounter low-risk patients, and that the perceived risk and worry does not necessarily correspond with the actual risk. Striking were the incorrect perceptions of CVD risk among men and patients with diabetes. 


\section{Introduction}

Various guidelines have been developed to support general practitioners (GPs) in their cardiovascular prevention activities. Nowadays, so-called risk score sheets structure the guidelines on primary prevention of cardiovascular diseases $(C V D)^{1,2}$. These tables allow easy assessment of an individual's absolute 10-year risk of a first CVD event, as well as suggesting options for diagnostic and therapeutic management. However, many barriers hamper the implementation of the recommendations of this so-called high-risk approach, and both overuse and unde ruse of tests and drugs are known to occur ${ }^{3}$.

One important barrier concerns patients' perception of their CVD risk ${ }^{4,5}$. Misconceptions seem to be common among primary care patients ${ }^{6-10}$. Patients may adopt an active or passive role towards CVD prevention, depending on their ideas, perceptions, fears, and expectations ${ }^{5}$. Knowing patients' fears and risk perceptions and bringing them into line with the actual risk seems a prerequisite for effective management ${ }^{11,12}$. Involving the patient in decisionmaking on the management of high risk may improve patients' satisfaction, well-being, and even lifestyle and health outcomes ${ }^{13,14}$, and probably also the GPs' adherence to the recommended high-risk approach.

Thus, it is important for effective cardiovascular risk management that GPs have a clear view of patients' actual cardiovascular risk, their risk perceptions, and their preferences and expectations regarding risk management. A mismatch between patients' actual cardiovascular risk and their risk perceptions might lead to conflicts between the GPs' intended management and patients' expectations. In this study we compared the actual risk and risk perceptions and worry of patients with whom GPs discussed cardiovascular risks. We addressed the following questions about consultations on primary prevention of cardiovascular disease in general practice:

1a) How often are GPs confronted with inappropriate risk perceptions or anxiety (i.e., mismatches between patients' actual cardiovascular risk and their perceived risk or worry)?

b) How do patients' risk perceptions and anxiety correlate with their actual cardiovascular risk?

2 What factors (i.e., demographic and cardiovascular risk factors) determine a high perceived risk or anxiety and what factors determine inappropriately perceived risk? 


\section{Methods}

\section{Setting}

The data were derived from the baseline measurements of a randomized controlled trial of the effect of strategies for the implementation of guidelines on cardiovascular risk management in a representative group of general practices $^{15}$. The 34 participating GPs were instructed to include the first 30 consecutive patients aged 40-70 years without established cardiovascular disease with whom, at any time, they discussed cardiovascular risk factors during the consultation, either at the patient's initiative or that of the physician. The ethics committee of the University Hospital of Maastricht approved the study.

\section{Variables and instruments}

The dependent variable was inappropriate risk perception. The perception of the probability of cardiovascular disease was measured by three questions, two on absolute probability and one on relative probability perception;

- Absolute probability in proportions: "How do you estimate your risk of getting a cardiovascular disease within the next 10 years?" (answering options: 1\%, 10\%, $25 \%, 50 \%,>50 \%)$

Patients were labeled as perceiving high absolute probability if they scored $50 \%$ or higher. Patients were labeled as perceiving low absolute probability if they scored $10 \%$ or lower.

- Absolute probability in narratives: "How do you estimate your risk of getting a cardiovascular disease within the next ten years?" (7-point scale, with 1 = very low, 7 = very high),

Patients were labeled as having high absolute probability perception if they scored higher than the midpoint of the scale, which was four.

- Relative probability: "How do you estimate your risk relative to that of peers?" (5-point scale, with 1 = much lower, 5 = much higher).

Patients were labeled as having high relative probability perception if they scored higher than the midpoint of the scale, which was 3.

Anxiety was assessed by two questions:

- $\quad$ "Do you ever think that you might develop a cardiovascular disease, such as a myocardial infarction or a stroke?" (6-point scale, with $1=$ never to $6=$ always) 
- $\quad$ "Are you worried about developing a cardiovascular disease? Can you indicate on a scale of 1 to 10 how worried you are?" (10-point scale, with $1=$ not at all worried, $10=$ extremely worried).

A patient was labeled as anxious if the scores on both questions were higher than the midpoints of the scales, which were three and five respectively.

Inappropriate risk perception takes two forms: it may refer to high-risk patients who underestimate the probability of CVD or are not anxious about this high risk (incorrect optimism), or to low-risk patients who overestimate the probability or are anxious about their CVD risk (incorrect pessimism).

The patients' actual CVD risk was estimated from their age, sex, actual smoking status (having smoked one or more cigarettes or other nicotine products during the preceding week yes/no), alcohol use ( $\leq 2$ units/>2 units per day), being under medical treatment for hypertension, hypercholesterolemia or diabetes (yes/no), and a family history with a first-degree relative having angina pectoris or a myocardial infarction before the age of 60 years (CHD family history yes/no). The absolute 10-year risk of a CVD was estimated by means of the Dutch risk score sheet that classifies patients who had an actual absolute 10 -year risk of $20 \%$ of higher as "high actual risk" ${ }^{1}$. In accordance with recent guidelines, all patients with diabetes were labelled as at "high actual risk"2. Each patient was dichotomized as high- or low-risk. If data were missing, blood pressure and serum cholesterol values were derived from recent population cohort data, taking the patient's age and sex into account. The risk was also calculated, for reasons of international comparison, according to the Systematic Coronary Risk Evaluation (SCORE) risk chart of the European Society of Cardiology ${ }^{16}$.

Socio-economic status (SES) was measured as a standardized combination of highest level of education and job level achieved. The patients were divided into three levels of socio-economic status: low, intermediate, or high.

At the end of each consultation, the GPs handed the patients a questionnaire, and asked them to return it to Maastricht University by prepaid post. After each consultation, the GPs recorded patient outcomes on specially designed recording forms, indicating the risk factors. The demographic and psychological characteristics were derived from the patient questionnaires, while the cardiovascular risk factors were derived from both the GPs' registration forms and the patient questionnaires.

\section{Analysis}

Mismatches between risk perception on the one hand and actual risk on the other were investigated by analyzing the scores on probability perception and anxiety for the subgroups of low- and high-risk patients. The scores on 
probability perception and anxiety were correlated with the actual risk by means of Spearman's correlation coefficients.

We built two multivariate backwards logistic regression models, one with absolute probability perception and the other with anxiety as the dependent variable, and patients' age, sex, SES, diabetes, and cardiovascular risk factors as independent variables. Two other models were built with inappropriate absolute probability perception and inappropriate anxiety as the dependent variables, and patients' age, sex, and SES as independent variables. Cardiovascular risk factors and diabetes were not included in the latter models because they were already part of the dependent variable. Cut-off level for stepwise backwards entry was $p<0.05$, and that for removal $p<0.10$.

\section{Results}

\section{Patients}

A total of 490 patients without cardiovascular disease were included by 34 GPs (mean 14.4 patients per GP, SD 7.3, range 5-29). The characteristics of the participating GPs were comparable to those of the Dutch GP population in terms of age, sex, and practice type.

Using the Dutch scoring system, 82 (76 with diabetes) out of 490 patients, which is $17 \%$, were classified as "high actual risk". The patients' cardiovascular risk and risk perception are listed in Table 4.1, which shows separate values for the total patient group and the low-risk and high-risk subgroups. The low- and high-risk groups differed significantly, and in the expected direction, for most risk factors, except for smoking. Nearly half $(10+38=48 \%)$ of the high-risk patients thought that their personal absolute 10-year risk was low, they choose for around $10 \%$ or even lower than $1 \%$, while nearly one-fifth $(14+3=17 \%)$ of the low-risk patients estimated their absolute risk to be $50 \%$ or higher (Table 4.1). The mean scores on risk perception were generally somewhat below the midpoints of the scales. There were no differences in mean risk perception scores between high- and low-risk patients. 
Table 4.1 Risk factors, risk perception and anxiety. Absolute numbers (valid \%, column percentages), or mean values (standard deviation SD). (Actual risk estimation was missing for 17 patients)

\begin{tabular}{|c|c|c|c|}
\hline Risk factors & $\begin{array}{c}\text { Total } \\
n=490\end{array}$ & $\begin{array}{l}\text { High risk } \\
\mathrm{n}=82\end{array}$ & $\begin{array}{l}\text { Low risk } \\
n=401\end{array}$ \\
\hline age & 54.1 (SD 10.1) & $57.3(\text { SD } 9.2)^{*}$ & 53.4 (SD 10.1) \\
\hline sex (male) & $219(45)$ & $43(52)^{*}$ & $173(43)$ \\
\hline hypertension & $229(47)$ & $49(60)^{*}$ & $178(44)$ \\
\hline hypercholesterolemia & $144(30)$ & $48(59)^{*}$ & $94(23)$ \\
\hline diabetes & $76(16)$ & $76(93)^{*}$ & $0(0)$ \\
\hline CHD family history & $174(36)$ & $20(24)^{*}$ & $152(38)$ \\
\hline obesity & $91(19)$ & $23(28)^{*}$ & $68(17)$ \\
\hline smoking & $141(29)$ & $27(33)$ & $112(28)$ \\
\hline high alcohol intake & $134(28)$ & $13(16)^{*}$ & $120(30)$ \\
\hline \multicolumn{4}{|l|}{ Risk perception and anxiety } \\
\hline \multicolumn{4}{|l|}{$\begin{array}{l}\text { probability perception } \\
\text { absolute probability perception as } \%\end{array}$} \\
\hline$<1 \%$ & $87(18)$ & $8(10)$ & $78(20)$ \\
\hline (19 missing values) $10 \%$ & $204(43)$ & $30(38)$ & $170(44)$ \\
\hline $25 \%$ & $99(21)$ & $24(30)$ & $74(19)$ \\
\hline $50 \%$ & $65(14)$ & $12(15)$ & $53(14)$ \\
\hline$>50 \%$ & $16(3)$ & $5(6)$ & $10(3)$ \\
\hline absolute probability perception (7-pt scale) & 3.5 (SD 1.2) & 3.7 (SD 1.2) & 3.2 (SD 1.3) \\
\hline relative probability perception (5-pt scale) & 2.9 (SD 0.7$)$ & $2.9(\mathrm{SD} 0.6)$ & 2.9 (SD 0.7) \\
\hline \multicolumn{4}{|l|}{ anxiety. } \\
\hline - ever think of CVD? (6-pt scale) & 2.9 (SD 0.9) & 2.9 (SD 0.9) & 2.9 (SD 0.9) \\
\hline - worried about developing CVD (10-pt scale) & 3.8 (SD 2.4) & 3.9 (SD 2.5) & 3.6 (SD 2.2) \\
\hline
\end{tabular}

* difference with level of significance $p<0.05$

\section{How often are GPs confronted with patients with inappropriate perception of cardiovascular risk?}

Table 4.2 shows that in the total group, the proportions of patients with high scores on absolute probability perception, relative probability perception, and anxiety were $19 \%, 14 \%$, and $15 \%$ respectively. Although one would expect these proportions to differ between the subgroups of patients with low and high risk, this was not what we found. The proportions of high perceived relative probability and high-anxiety patients were even higher in the actual low-risk than in the actual high-risk group (Table 4.2, panel 1). Applying the European risk score sheet instead of the Dutch one would have generated a higher proportion of patients with high risk, namely $35 \%$ (Table 4.2, Panel 2.). This difference is caused by cost-effectiveness considerations that were used in the Dutch risk score sheet. Using the European classification, absolute probability perception and anxiety were similar for high and low risk patients classified, but, contrary to expectations, the proportion of high-risk patients who had high 
perceived relative risk $(6 \%)$ was significantly lower than the proportion of lowrisk patients with high perceived relative risk $(19 \%, p<0.01)$.

Table 4.2 Patients' actual cardiovascular risk level and the proportions of patients perceiving their risk as high or being anxious. Absolute numbers (valid row percentages)

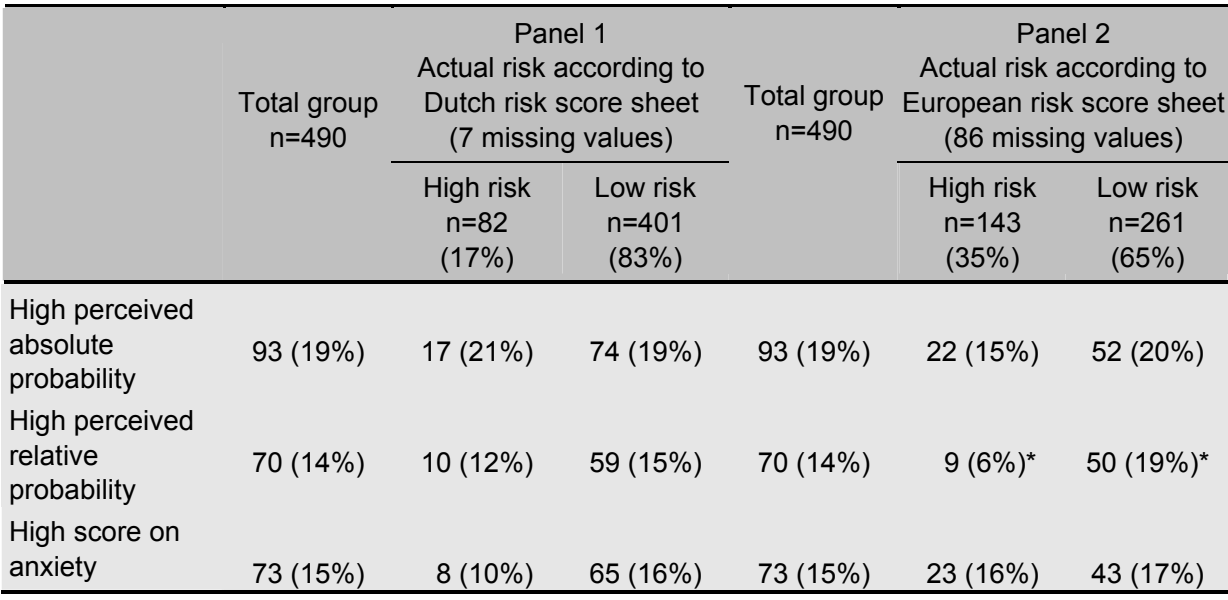

* significant difference between high-risk and low-risk subgroups, chi-square test $p<0.01$

Inappropriate risk perception consists of incorrect pessimism or incorrect optimism. Incorrect pessimism and optimism were about equally prevalent as regards probability perception (Table 4.3$)$ : $28 \%(15 \%+13 \%)$ of the patients had inappropriate perceptions of absolute probability; $27 \%(12 \%+15 \%)$ of the patients had inappropriate perceptions of relative probability. Appropriateness was also equally prevalent as regards anxiety; $29 \%(14 \%+15 \%)$ of the patients were inappropriately worried or not worried. There was much overlap between these subgroups: overall, $41 \%$ of the patients showed an inappropriate risk perception or were inappropriately worried.

From the perspective of the subgroups this means that the absolute probability of CVD was perceived inappropriately by nearly four in five high-risk patients (incorrect optimism), and by one in five low-risk patients (incorrect pessimism).

\section{How do patients' risk perceptions correlate with their actual cardiovascular risk?}

Figure 4.1 shows the correlations between the components of risk perception and actual risk according the Dutch risk score sheet. The correlation coefficients were generally low. The emotional component of risk perception, anxiety, did not correlate with the actual risk level at all. Absolute probability perception had a higher correlation with anxiety than relative probability perception. The correlation coefficients were the same or even lower when 
actual risk was calculated according the European risk score sheet (not shown in figure).

Table 4.3 Appropriateness of absolute probability perception, relative probability perception and anxiety

\begin{tabular}{|c|c|c|c|c|}
\hline \multicolumn{2}{|c|}{$\begin{array}{l}n=476, \\
14 \text { missing values }\end{array}$} & \multicolumn{2}{|c|}{ Absolute probability perception } & \\
\hline \multirow[t]{2}{*}{ Actual risk } & $\begin{array}{l}\text { High } \\
n=80\end{array}$ & $\begin{array}{c}17(4 \%) \\
\text { appropriate }\end{array}$ & $\begin{array}{c}63(13 \%) \\
\text { incorrect optimism }\end{array}$ & ->79\% $(63 / 80)$ \\
\hline & Low & $\begin{array}{l}\text { incorrect pessimism } \\
74(15 \%)\end{array}$ & $\begin{array}{c}\text { appropriate } \\
322(68 \%)\end{array}$ & \\
\hline \multicolumn{2}{|c|}{$\begin{array}{l}n=478, \\
12 \text { missing values }\end{array}$} & \multicolumn{2}{|c|}{ Relative prob. perception } & \\
\hline \multirow[t]{2}{*}{ Actual risk } & $\begin{array}{l}\text { High } \\
n=80\end{array}$ & $\begin{array}{c}10(2 \%) \\
\text { appropriate }\end{array}$ & $\begin{array}{c}70(15 \%) \\
\text { incorrect optimism }\end{array}$ & $->88 \%(70 / 80)$ \\
\hline & Low & $\begin{array}{l}\text { incorrect pessimism } \\
59(12 \%)\end{array}$ & $\begin{array}{c}\text { appropriate } \\
339(71 \%)\end{array}$ & \\
\hline \multicolumn{2}{|c|}{$\begin{array}{l}n=472, \\
18 \text { missing values }\end{array}$} & \multicolumn{2}{|c|}{ Anxiety } & \\
\hline \multirow[t]{2}{*}{ Actual risk } & $\begin{array}{l}\text { High } \\
n=79\end{array}$ & $\begin{array}{c}8(2 \%) \\
\text { appropriate }\end{array}$ & $\begin{array}{c}71(15 \%) \\
\text { incorrect optimism }\end{array}$ & $->90 \%(71 / 79)$ \\
\hline & Low & $\begin{array}{l}\text { incorrect pessimism } \\
65(14 \%)\end{array}$ & $\begin{array}{c}\text { appropriate } \\
328(69 \%)\end{array}$ & \\
\hline
\end{tabular}

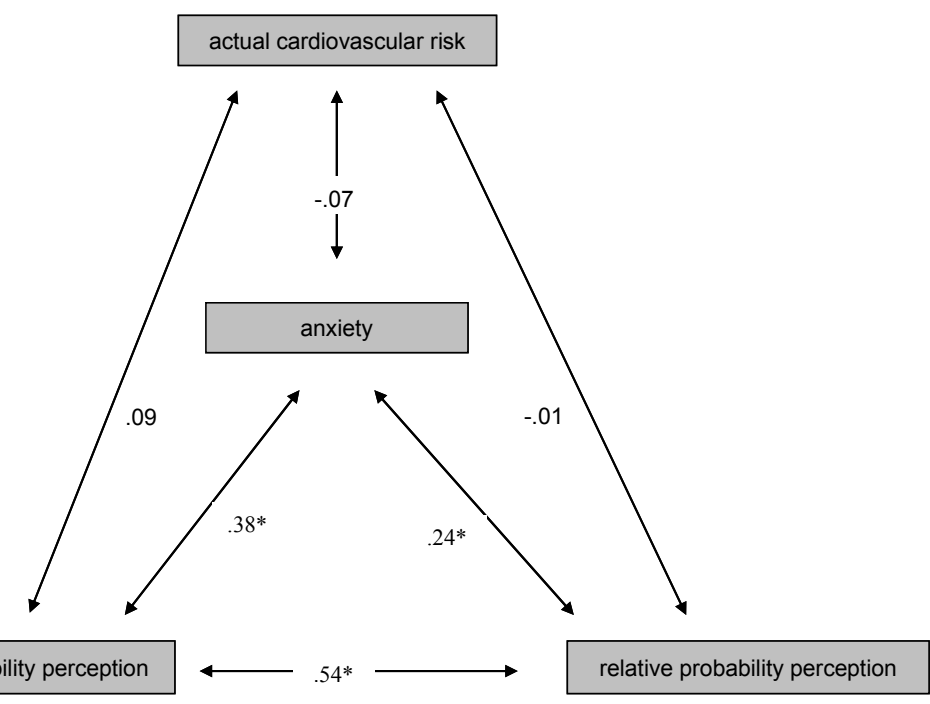

Figure 4.1 Correlations between risk perception and actual cardiovascular risk.

* Spearman's correlation coefficient significant $p<0.05$ 


\section{Determinants of high or inappropriate risk perception and high or inappropriate anxiety}

Age was negatively related to high risk perception, while smoking and being treated for hypertension were significant positive determinants of patients perceiving their absolute cardiovascular risk as high. Anxiety was only significantly influenced by obesity. Diabetes seemed to have a negative influence on anxiety, although the odds ratio was not significant. Sex did not play a role in these models (Table 4.4).

Table 4..4 Influence of demographic characteristics and cardiovascular risk factors on the odds that a patient has a high score for absolute probability perception or for anxiety about their cardiovascular risk. Adjusted odds ratios and $95 \%$ confidence intervals $(\mathrm{Cl})$. $\mathrm{n}=490$ consultations.

\begin{tabular}{|c|c|c|c|c|c|}
\hline \multicolumn{3}{|c|}{ Absolute probability perception } & \multicolumn{3}{|l|}{ Anxiety } \\
\hline \multicolumn{3}{|c|}{$\begin{array}{l}\text { dependent: } \\
0=\text { low absolute probability perception (score }<5) \\
1=\text { high absolute probability perception (score } 5-7) \\
\text { independent variables that remained in the analysis: } \\
\text { - age in years } \\
\text { - smoking }(0=\text { no, } 1=\text { yes) } \\
\text { - being treated for hypertension }(0=\text { no, } 1=\text { yes) }\end{array}$} & \multicolumn{3}{|c|}{$\begin{array}{l}\text { dependent: } \\
0=\text { not anxious } \\
1=\text { anxious } \\
\text { independent variables that remained in the analysis: } \\
\text { - obesity }(0=\mathrm{BMI} \leq 30,1=\mathrm{BMI}>30) \\
\text { - being treated for hypercholesterolemia }(0=\text { no, } 1=\text { yes }) \\
\text { - being treated for diabetes }(0=\text { no, } 1=\text { yes })\end{array}$} \\
\hline $\begin{array}{l}\text { independent } \\
\text { variables }\end{array}$ & eta (SE) & adj OR $(95 \% \mathrm{Cl})$ & independent variables & beta (SE) & adj OR $(95 \% \mathrm{Cl})$ \\
\hline intercept & $0.57(0.70)$ & & intercept & $-1.88(0.18)$ & \\
\hline age in years & $-0.48(0.01)$ & $0.95(0.93-0.98)$ & obesity & $0.84(0.30)$ & $2.31(1.28-4.17)$ \\
\hline smoking & $0.60(0.26)$ & $1.83(1.09-3.05)$ & hyperchole & $0.55(0.29)$ & $1.74(0.98-3.08)$ \\
\hline hypertension & $0.62(0.27)$ & $1.86(1.11-3.13)$ & diabetes & $-0.81(0.18)$ & $0.44(0.18-1.07)$ \\
\hline
\end{tabular}

The inappropriateness of risk perception was not determined by age or SES. Only sex seemed to have an influence, with male patients being about $70 \%$ more likely to perceive their cardiovascular risk inappropriately (Table 4.5).

Table 4.5 Influence of demographic characteristics on the odds that a patient has an inappropriate absolute probability perception or anxiety about their cardiovascular risk. Adjusted odds ratios and $95 \%$ confidence intervals $(\mathrm{Cl}) . \mathrm{n}=490$ consultations.

\begin{tabular}{|c|c|c|c|c|}
\hline \multicolumn{2}{|c|}{ Inappropriate absolute probability perception } & \multicolumn{3}{|l|}{ Inappropriate anxiety } \\
\hline \multicolumn{2}{|c|}{$\begin{array}{l}\text { dependent: } \\
0=\text { appropriate absolute probability perception } \\
1=\text { inappropriate absolute probability perception } \\
\text { independent variables that remained in the analysis: } \\
\text { - } \operatorname{sex}(0=\text { female, } 1=\text { male })\end{array}$} & \multicolumn{3}{|c|}{$\begin{array}{l}\text { dependent: } \\
0=\text { appropriate anxiety } \\
1=\text { inappropriate anxiety } \\
\text { independent variables that remained in the analysis: } \\
\text { - } \operatorname{sex}(0=\text { female, } 1=\text { male })\end{array}$} \\
\hline independent variables beta (SE) & adj OR $(95 \% \mathrm{Cl})$ & independent variables & beta (SE) & adj OR $(95 \% \mathrm{Cl})$ \\
\hline $\begin{array}{r}-1.17(0.15) \\
0.54(0.21)\end{array}$ & $1.71(1.14-2.56)$ & $\begin{array}{l}\text { intercept } \\
\text { male sex }\end{array}$ & $\begin{array}{r}-1.16(0.15) \\
0.51(0.21)\end{array}$ & $1.67(1.11-2.51)$ \\
\hline \multicolumn{2}{|c|}{$\begin{array}{l}\text { inappropriate: } \\
\text { low-risk patient with high absolute probability } \\
\text { perception OR } \\
\text { high-risk patient with low absolute probability } \\
\text { perception }\end{array}$} & \multicolumn{3}{|c|}{$\begin{array}{l}\text { inappropriate: } \\
\text { low-risk patient with anxiety OR } \\
\text { high-risk patient without anxiety }\end{array}$} \\
\hline
\end{tabular}




\section{Discussion}

There was a mismatch between the way patients perceived their 10-year CVD risk and their actual CVD risk. Risk perceptions of low- and high-risk patients did not differ. Nearly one-third of the patients were either too optimistic or too pessimistic as regards absolute probability perception. Anxiety correlated moderately well with absolute probability perception, which means that correcting inappropriate absolute probability perception might be a vehicle for correcting inappropriate anxiety. To our surprise, diabetes and a positive CVD family history were not determinants of high perceived risk, even though the patients with diabetes have a high actual risk by definition, and patients with a positive CVD family history often have a high actual risk. These findings also remain when the European risk score sheet is used. Similar underestimations of perceived risk were reported by others for persons at high risk of developing diabetes ${ }^{17}$.

One of the strengths of this study was that data was derived from real practices with real patients, who were given the questionnaire immediately after a consultation with their GP during which cardiovascular risk had been discussed. The actual cardiovascular risk was estimated on the basis of information from both the GPs and the patients' self-reports on their risk profile, rather than from standardized measurements of biological parameters only. This could be an advantage because our data reflects the reality of routine GP prevention activities, and patients would seem a more reliable source of information on lifestyle-related risk factors than GPs. The fact that we investigated both rational aspects (probability perception) and emotional aspects (anxiety) is another strong feature of this study. People seem to react to risk at two levels: they evaluate the risk cognitively, and they react to it emotionally ${ }^{18}$. The perception of a risk is influenced by the knowledge about the magnitude of the actual risk and the severity of the outcome, but also by affective factors like anxiety and worry. In other words, risk perception is based on what people think about the risk, but also on how people fee/about it ${ }^{19}$. The questions on risk perception were derived from a recent core paper on this topic $^{20}$. The analyses were not corrected for any clustering of patients within one practice, given the fact that the intra-cluster correlation coefficient in a comparable study was $0.00^{10}$.

Due to time constraints, the GPs only managed to include about half the number of patients that we had asked them to include. The missing data for the European SCORE risk chart is another limitation. A third limitation is related to the cut-offs for perceived high-risk and actual high risk. The impact of the cutoff points was explored by sensitivity analysis of the relationships described in Tables 4.2 and 4.3. It appeared that most patients had responded around the midpoint of the scale. Risk perception did improve in some cases by setting 
higher cut-off points for risk perception and anxiety, but in almost all cases coexisted to a relevant degree of mismatch.

Other recent studies investigated risk perception in patient samples regardless of the reason for encounter ${ }^{6-8}$ or in certain specifically defined high-risk groups $^{9,10}$. By contrast, we investigated risk perception in the patients that GPs are actually confronted with in discussing cardiovascular risk. The studies by Avis, Kreuter, and Marteau only measured relative probability perceptions, while the studies by Samsa and Frijling measured only absolute probability perceptions. The proportion of patients who were too optimistic was much lower in our study (15\%) than in the other studies, where it was around $40 \%$. The difference might be explained by the fact that the discussion of cardiovascular risk during the consultation sometimes took place at the patients' initiative, and many of such patients were low-risk and curious about their risk. The proportion of patients who were too pessimistic (14\%) was more comparable, being around $20 \%$ in the other studies. Smoking, obesity, hypertension, CHD family history, and hypercholesterolemia were found to be determinants of high risk perception in the three studies that reported on determinants $^{7,8,10}$. We also found smoking, obesity, and hypertension to be determinants. Diabetes was not a determinant in our study, nor in the other studies.

Any conflicts or mismatches between a rational approach (applying guidelines) and a patient-centered approach (the actual practice during the consultation) may have two different consequences: (1) a GP takes preventive action for a high-risk patient by prescribing cholesterol lowering agents, even though the patient does not perceive himself as a high-risk patient, and is therefore poorly motivated and does not comply with lifelong drug treatment; (2) a low-risk and otherwise healthy patient, who worries about her health, asks a GP for medical treatment of her slightly elevated serum lipids, a finding from an insurance screening. Both situations can lead to loss of time, superfluous prescribing, and to frustration on the part of GPs and patients. The second consequence may occur most as a surprisingly high proportion of the consultations during which issues on primary prevention of CVD were discussed (83\%), were with low-risk patients.

In conclusion, GPs need to explain both high and low CVD risk to their patients. GPs must be aware of the fact that the perceived risk is not necessarily associated with the actual risk. Effective and feasible (i.e., not time-consuming) instruments for the explanation of risk and for reassuring and counseling the relevant subgroups should be available in general practice. GPs need to learn how to handle the low-risk but anxious patient, and to be on the alert for misconceptions about CVD especially among men and patients with diabetes. This could prevent both patients and GPs from being frustrated, and could save time. 


\section{References}

1. Thomas S, van der Weijden T, van Drenth BB, Haverkort AFM, Hooi JD, van der Laan JD. NHG-standaard Cholesterol (eerste herziening). Huisarts Wet 1999;42:406-17.

2. de Backer G, Ambrosioni E, Borch Johnsen K, Brotons C, Cifkova R, Dallongeville J, Ebrahim S, Faergeman O, Graham I, Mancia G, Cats VM, Orth Gomer K, Perk J, Pyorala K, Rodicio JL, Sans S, Sansoy V, Sechtem U, Silber S, Thomsen T, Wood D. European guidelines on cardiovascular disease and prevention in clinical practice. Eur Heart J 2003;24:1601-10.

3. van der Weijden T, Dansen A, Schouten BJ, Knottnerus JA, Grol RP. Comparison of appropriateness of cholesterol testing in general practice with the recommendations of national guidelines: an audit of patient records in 20 general practices. Qual Health Care 1996;5:218-22.

4. van Steenkiste BC, van der Weijden T, Stoffers H.E.J.H., Grol R. Barriers to implementing cardiovascular risk tables in routine general practice. Scan J Prim Health Care 2004;22:32-7.

5. Steenkiste B van, Weijden T van der, Timmermans D, Vaes J, Stoffers HEJH, Grol R. Patients' ideas, fears and expectations of their coronary risk: barriers for primary prevention. Pat Educ Couns 2004;55:301-7.

6. Avis NE, Smith KW, McKinlay JB. Accuracy of perceptions of heart attack risk: what influences perceptions and can they be changed? Am J Public Health 1989;17:1608-12.

7. Kreuter MW, Strechter VJ. Changing inaccurate perceptions of health risk: results from a randomised trial. Health Psych 1995;14:56-63.

8. Marteau TM, Kinmonth AL, Pyke S, Thonpson SG. Readiness for lifestyle advice. Selfassessment of coronary risk prior to screening in the British Family Heart Study. $\mathrm{Br} J$ Gen Pract 1995;45:5-8.

9. Samsa GP, Cohen SJ, Goldstein LB, Bonito AJ, Duncan PW, Enarson C, de Friese GH, Horner RD, Matchar DB. Knowledge of risk among patients at increased risk of stroke. Stroke 1997;28:916-21.

10. Frijling BD, Lobo CM, Keus IM, Jenks KM, Akkermans RP, Hulscher MEJL, Prins A, Wouden JV van der Grol RPTM. Perceptions of cardiovascular risk among patients with hypertension or diabetes. Par Educ Couns 2004;52:47-53.

11. Lewis DK, Robinson J, Wilkinson E, Factors involved in deciding to start preventive treatment: qualitative study of clinician's and lay people's attitude. BMJ 2003;327:841-7.

12. Cockburn J, Pit S. Prescribing behaviour in general practice: patients' expectations and doctor's perceptions of patients' expectations. A questionnaire study. BMJ 1997;315:520-3.

13. Stewart M. Effective physician-patient communication and health outcomes: a review. Can Med Assoc J 1995;152:1423-33.

14. Kaplan SH, Greenfield S, Ware JE. Assessing the effects of physician-patient interactions on the outcomes of chronic disease. Med Care 1989;275:5110-27.

15. B. van Steenkiste, T. van der Weijden, H.E.J.H. Stoffers, A.D.M. Kester, D. Timmermans, R. Grol, Improving cardiovascular risk management: a randomized controlled trial on the effect of a decision support tool for patients and physicians. Eur J Cardiov Prev Rehab 2007;14: 44-50.

16. Conroy RM, Pyorala K, Fitzgerald AP, Sans S, Menotti A, De Backer G, De Bacquer D, Ducimetiere P, Jousilahti P, Keil U, Njolstad I, Oganov RG, Thomsen T, Tunstall Pedoe H, Tverdal A, Wedel H, Whincup P, Wilhelmsen L, Graham IM. Estimation of ten-year risk of fatal cardiovascular disease in Europe: the SCORE project. Eur Heart J. 2003;24:987-1003.

17. Adriaanse MC, Snoek FJ, Dekker JM, Spijkerman AMW, Nijpels G, van der Ploeg HM, Heine RJ. Perceived risk for type 2 diabetes in participants in a stepwise population-screening programme. Diabet Med 2003;20:210-5.

18. Loewenstein GF, Weber EU, Hsee CK, Welch N. Risk as feelings. Psychological Bulletin 2001;127:267-86.

19. Slovic P, Finucane ML, Peters E, MacGregor DG. Risk as analysis and risk as feelings: Some thoughts about affect, reason, risk, and rationality. Risk Analysis 2004;24:311-22. 
20. Lipkus IM, Kuchibhatla M, McBride CM, Bosworth HB, Pollak KI, Siegler IC, Rimer BK. Relationships among breast cancer patients' perceived absolute risk, comparative risk, and worries. Cancer Epid Biomarkers Prev 2000;9:973-5. 


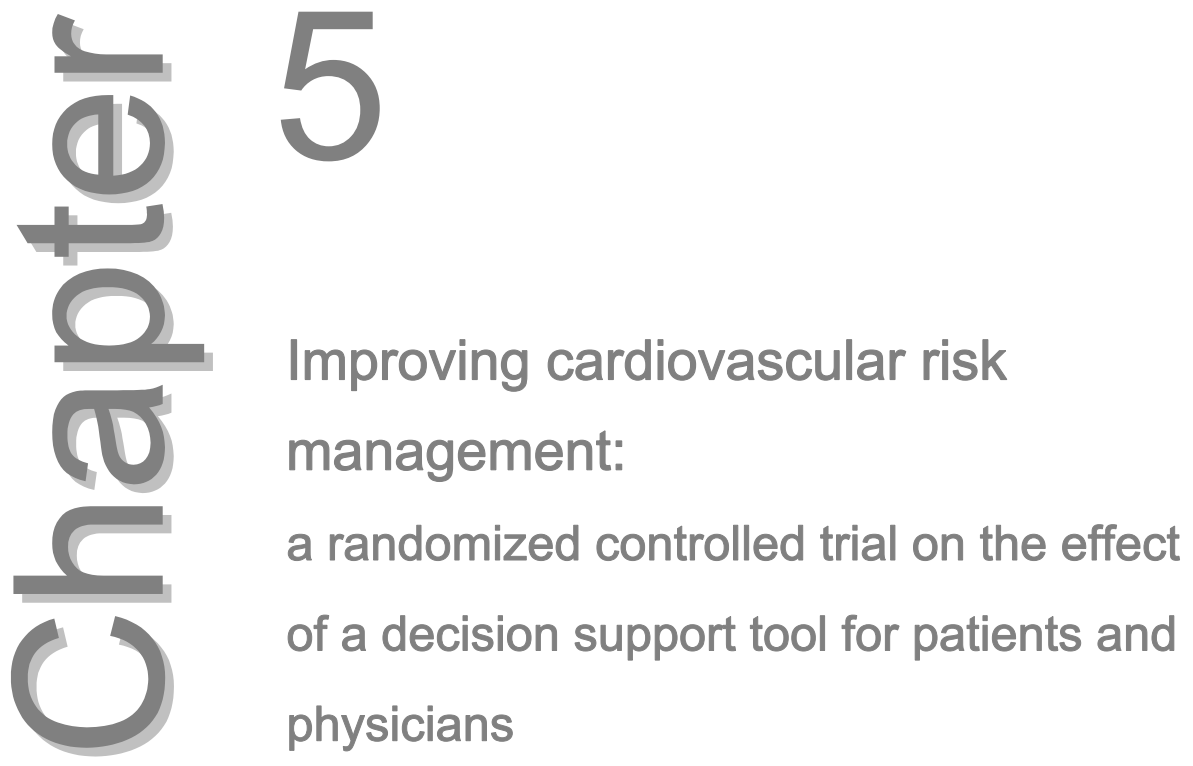

Ben van Steenkiste, Trudy van der Weijden, Jelle Stoffers, Arnold Kester, Daniëlle Timmermans, Richard Grol

Eur J Cardiovasc Prev Rehabil 2007;14:44-50 


\section{Abstract}

\section{Background}

There is non-optimal adherence of general practitioners (GPs) and patients to cardiovascular risk reducing interventions. GPs find it difficult to assimilate multiple risk factors into an accurate assessment of cardiovascular risk. In addition, communicating cardiovascular risk to patients has proved to be difficult.

\section{Objectives}

Improving primary prevention of cardiovascular diseases CVD in primary care by enhancing patient involvement in the use of a decision support tool.

\section{Methods}

Design: cluster randomized trial. Thirty-four general practitioners (GPs) included patients (40-75 yrs) without CVD. In an interactive small group training session, lasting four hours, the GPs in the intervention group were trained to use the guidelines on cardiovascular risk and the use of a decision support tool. The control group received educational materials about the guidelines on paper.

GPs' clinical performance and patients' risk perception and self-reported lifestyles were measured at baseline and after six months.

\section{Results}

Thirty-four GPs recorded 490 consultations, 276 in the intervention and 214 in the control group. After six months, no significant effect of the intervention on the GPs' performance or the patients' risk perception was found. There was only an effect on self-reported lifestyle, in that more men in the intervention group than in the control group increased their physical activity $(\mathrm{OR} 3.8,95 \% \mathrm{Cl}$ $1.7-8.7)$.

\section{Conclusions}

The 4-hour interactive small group training did not guarantee correct application of the decision support tool and as such failed to improve GPs' performance or correct patients' risk perception. The positive effect on physical activity justifies further research on patient involvement. 


\section{Introduction}

The incidence of cardiovascular diseases (CVD) remains high and the associated burden of illness is increasing. Primary prevention, an important strategy to delay the onset of CVD, is reflected in national and international guidelines for the assessment and modification of the relevant risk factors ${ }^{1-4}$. However, many barriers hamper the implementation of the recommended 'high-risk' approach. Many health professionals find it difficult to assimilate multiple risk factors into an accurate assessment of cardiovascular risk, and adherence to the guidelines is less than optimal ${ }^{5-9}$.

In addition, explaining risk to patients in order to reach a common understanding on risk level is perhaps even more difficult for both physicians and patients. General practitioners (GPs) have mentioned this as an important barrier to implementation of the high-risk approach ${ }^{9-12}$. Since it is unlikely that guidelines could incorporate the wide range of people's preferences, true dialogue between clinicians and patients before embarking on lifelong preventive treatment is very important ${ }^{13}$. The guidelines recommend optimizing patients' health status by normalizing cholesterol levels and by counselling patients on smoking, physical exercise and diet or alcohol consumption. However, patient compliance with lifestyle advice in general practice is not optimal. If GPs fail to acknowledge patients' conceptions, misconceptions and preferences, this may lead to non-compliance with medical or lifestyle advice ${ }^{14}$. Risk perception and self efficacy seem to be key factors in patients' motivation to change their behaviour.

So far, intensive implementation strategies that focused on changing professional behaviour and adjusting practice organization have resulted in limited improvement in clinical performance ${ }^{6,15}$. Since the importance of patientrelated barriers in addition to those relating to professional and organizational aspects $^{16,17}$ is now well recognized, more active patient involvement in decision-making seems a valid option to improve the quality of care ${ }^{18-20}$. We hypothesized that a decision support tool aiming to help both physicians and patients to understand the risk and options for risk management might have favourable effects in two directions: improving the physicians' performance in terms of the key recommendations of the CVD guidelines and improving patients' risk perceptions, which in turn might lead to a healthier lifestyle.

\section{Methods}

\section{General design}

A cluster-randomized trial with two arms (Figure 5.1) was used to evaluate the effect of the decision support tool on GPs (as regards clinical performance) and patients (as regards risk perception and self-reported lifestyle). 


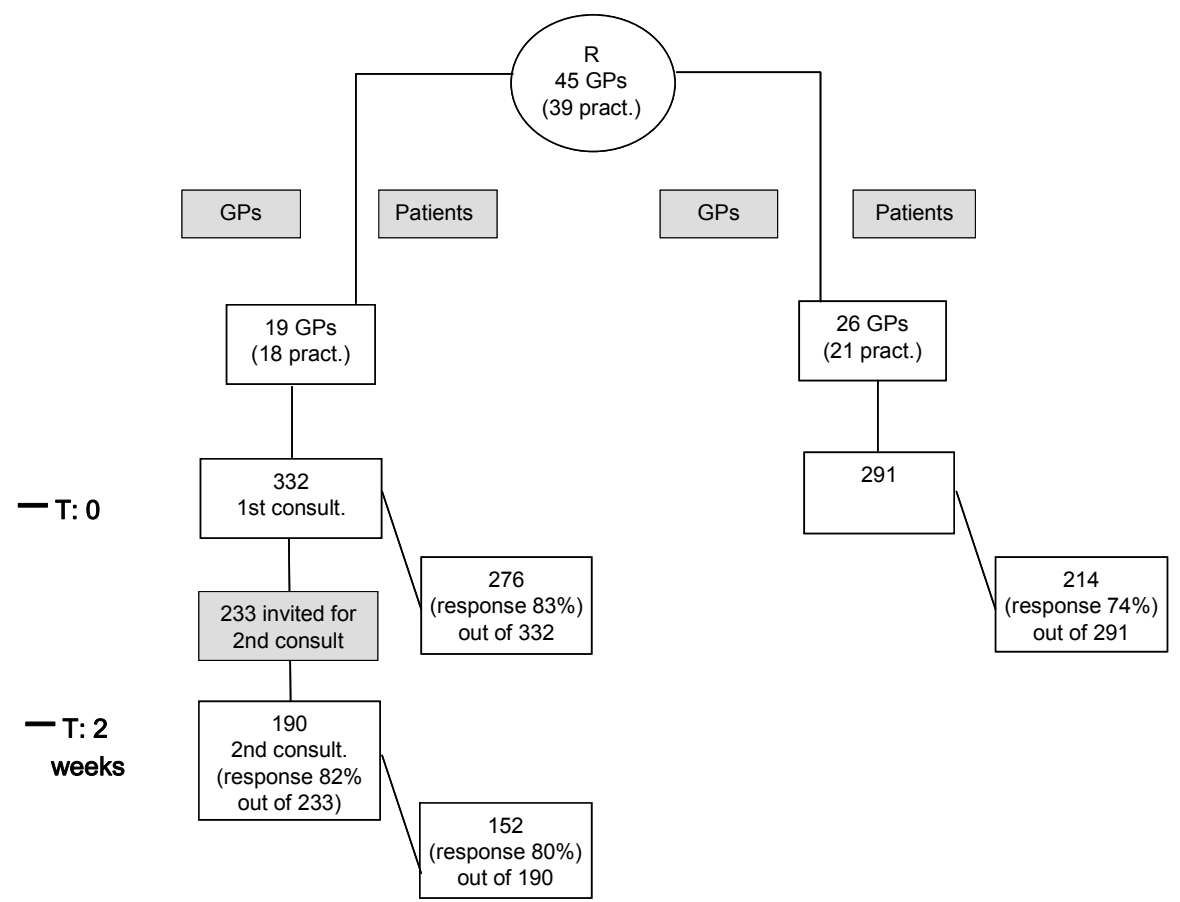

\section{- T: 26 weeks questionnaires sent at home}

Final data set:

17 GPs (16 pract.) (2 GPs excluded, no data)

TO: 276 consult registration forms + patient questionnaires

T26: 227 patient questionnaires
Final data set:

17 GPs (13 pract.) (9 GPs excluded, no data)

T0: 214 consult registration forms + patient questionnaires

T26: 200 patient questionnaires

Figure 5.1 Flowchart of trial participation.

pract., general practices; consult., = recorded consultations

\section{Participating GPs and patients}

Assuming an interclass correlation coefficient (ICC) of $0.03,16$ GPs per arm and 15 patients per GP would be needed to have an $80 \%$ chance of detecting a $15 \%$ difference $(0.5-0.65, \alpha=0.05)$ in GP performance between the intervention and control groups ${ }^{21}$. To compensate for possible dropout of patients and physicians, 45 GPs (39 general practices) in the southern and central parts of the Netherlands were recruited. 
The GPs were instructed to include the first 30 consecutive patients (men aged 40-70, women aged 40-75) without established CVD (i.e., acute myocardial infarction, stroke or peripheral arterial disease) whenever cardiovascular risk factors were discussed during the consultations, either at the initiative of the patient or that of the physician. Written informed consent was obtained from the participating patients after the consultation. The ethics committee of the University Hospital of Maastricht approved the study.

\title{
Randomization
}

A computer was used for the stratified randomization, which was at practice level to prevent contamination of the intervention within group practices. We stratified on GPs' the number of patients for which the GP was responsible (full-time equivalents (fte.) / practice size) and the availability of desktop cholesterol analysers at the practice. The latter is known to be associated with a higher level of cholesterol screening ${ }^{6}$.

\section{Interventions}

The intervention, aimed at both physicians and patients, consisted of three elements and is described in Box 5.1. The core element, the decision support tool, was systematically pilot-tested. The intervention period was eight months.

\section{Box 5.1 The intervention consisted of three elements}

\begin{abstract}
- A 4-hour interactive small group training session to instruct the physicians about the risk table and the key recommendations for management of patients at high cardiovascular risk. Role-play was used to allow the physicians to practice how the decision support tool could be used to support the consultation and to facilitate patient involvement in a time-efficient way.

- The actual use of a decision support tool, consisting of a small booklet in two versions: one for diabetic patients, using a persuasive tone on the importance of life-style changes, and one for non-diabetic patients, with a more reassuring tone. Both versions included a simplified version of the Dutch risk charts for CVD prevention. The 16-page booklets informed the patients about their absolute 10-year CVD risk, expressed in words, using natural frequencies $^{35}$, as well as percentages, including comparative data on other patient groups from the risk chart. The booklets explained the patients' absolute risk of CVD in accessible language, discussed the options for risk factor management, and invited the patients to fill out their preferences on a worksheet.

- The intervention included two consultations, to provide enough time for sharing information, discussion and answering questions. The GPs were instructed to present the booklet at the first consultation and to invite patients to do the 'homework' and return within 1-2 weeks to discuss their cardiovascular risk. The aim was to stimulate patient involvement during the second consultation, giving the patients time to consider their risk and preferences for risk reducing strategies.
\end{abstract}

The GPs in the control group received only written educational materials on the content of the Dutch guidelines on cholesterol. 


\section{Variables and instruments}

\section{Outcome at physician level}

1.1. Five performance indicators

The GPs' clinical performance was evaluated by constructing five performance indicators. Some indicators reflect the underuse and overuse of tests in the screening and classification of patients, others the management of hypercholesterolemia (Table 5.2). The numerator of the performance indicator was calculated by estimating the patients' actual risk, or potential risk in the case of an incomplete risk profile, from the available data on age, sex, diabetes, smoking, hypertension and familial predisposition to CVD. The performance indicator on lifestyle advice applied to all smoking or obese patients (irrespective of their actual risk), since these risk factors are also important in terms of the prevention of other diseases. Hence, the numerator of the performance indicator of lifestyle advice comprised all relevant patients, not only those at high cardiovascular risk.

\section{Outcome at patient level}

\subsection{Risk perception}

Risk perception is a construct with two components: absolute probability and comparative probability, each of them assessed by one question ${ }^{22}$.

Absolute probability: 'How do you estimate your risk of developing a cardiovascular disease within the next ten years?' (7-point scale, $1=$ very low, 7 = very high).

Comparative probability: 'How do you estimate your risk compared to that of your peers?' (5-point scale, $1=$ much lower, $5=$ much higher).

A patient was labelled as having high absolute or comparative probability perception if he/she scored higher than the midpoint of the scale.

\subsection{Anxiety}

Anxiety was assessed by these two questions:

'Do you ever think that you might develop a cardiovascular disease, such as an acute myocardial infarction or a stroke?' (6-point scale).

'Are you worried about developing a cardiovascular disease? Can you indicate on a scale of 1 to 10 how worried you are?'

A patient was labelled as anxious if their scores on both questions were higher than the midpoint of the scale. 


\subsection{Appropriateness of perceived risk and anxiety}

In order to judge whether the perceived risk and anxiety were appropriate (i.e. in line with actual risk), the patients' actual risk (high/low) was estimated by means of the Dutch risk table (absolute 10-year risk of a CVD, cut-off point $20 \%$ at 40 years, $40 \%$ at 60 years). Unlike recommendations by the Dutch guidelines at the time of the study, but in line with what was observed in daily practice and what is recommended in recent guidelines all patients with diabetes were labelled as at high risk $^{1,9}$. If data were missing, serum cholesterol values and blood pressure were derived from recent population cohort data, taking patients' age and sex into account ${ }^{23}$. Since we did not want to interfere with the methods used by the GPs, biological parameters such as cholesterol and blood pressure were not measured in a standardized way.

\subsection{Self-reported lifestyle}

Self-reported lifestyle involved smoking (during the past seven days), physical activity (more than two hours a week), alcohol use (more than two units a day) and obesity [bodymass index $(\mathrm{BMI})>30]$.

\subsection{Other variables}

Self-efficacy regarding favourable lifestyle changes was measured on a 5-point scale and socio-economic status (SES) was measured as a standardized combination of highest level of education and job level achieved.

\section{Measurement procedures}

After each consultation, the physicians recorded patient outcomes on specially designed recording forms ${ }^{24}$, indicating the risk factors, results of laboratory tests, management plan and whether the patient had been invited for a followup visit. At the end of each consultation, GPs handed the patients a questionnaire and asked them to return it to Maastricht University by prepaid post. A final questionnaire was sent to the patients' home 6 months after the first or second consultation (see below).

\section{Statistical analysis}

Of the patients in the intervention group, some had one and some two consecutive consultations that were recorded. Although the instruction was to delay decisions on management to the second consultation, some GPs already decided on risk management in the first consultation and used only one consultation. Therefore, physicians' performance was assessed on the data of the first consultation or the combined data for the first and second consultations. Differences in physicians' and patients' individual characteristics at baseline were tested for significance with a chi-square test. Differences in 
patients' risk perception (and its appropriateness), lifestyle, and self-efficacy were tested with a t-test for the differences between the groups, while a paired t-test or a McNemar test was used for the differences within the group. The effect of the intervention on the GPs' performance and on the patients' risk perception and lifestyle was evaluated using multilevel regression analysis with a random intercept for practice to account for possible clustering of the patient data (Stata version 8, StataCorp, College Station, Texas, USA). Patients' SES and self-efficacy were included in the model as independent variables to reduce error.

\section{Results}

\section{Participant flow (Figure 5.1)}

After randomization, the intervention group included 19 GPs (18 practices), while the control group consisted of 26 GPs (21 practices). Eleven GPs were excluded from data analysis because they failed to include any patients, resulting in 17 GPs per group. The GPs in the intervention group recorded 332 first consultations (276 patient questionnaires were returned, response $83 \%$ ) and invited 233 (70\%) patients for a second consultation, of whom 190 (57\%) actually returned to discuss their risk. The GPs in the control group recorded 291 consultations, and 214 patients returned their questionnaires (response $74 \%$ ). Analysis of characteristics of the non-responders revealed no significant differences between the groups. The response to the questionnaires sent to patients' homes after 26 weeks was $82 \%(n=227)$ in the intervention group and $93 \%(n=200)$ in the control group.

\section{Characteristics of participating physicians and patients}

Most of the GPs were male, their mean age was nearly 50 years and they had on average more than sixteen years of working experience (Table 5.1). Their practices were mostly located in urban areas, and fewer than half of them were single-doctor practices. The intervention group included more practices with specialized CVD clinics and significantly more full-time GPs.

The mean age of the patients was 54 years, and $55 \%$ were female (Table 5.1). There were some differences between the two groups in cardiovascular risk factors such as smoking and hypercholesterolemia, resulting in slightly more patients at high risk in the intervention group (19\%) than in the control group (15\%). 
Table 5.1 Characteristics of the general practitioners (GPs), their practices and the patients (valid percentages)

\begin{tabular}{|c|c|c|c|c|}
\hline Physicians & \multicolumn{2}{|c|}{$\begin{array}{c}\text { Intervention } \\
\mathrm{n}=17\end{array}$} & \multicolumn{2}{|c|}{$\begin{array}{c}\text { Controls } \\
n=17\end{array}$} \\
\hline Mean age & \multirow{2}{*}{\multicolumn{2}{|c|}{$\begin{array}{l}49 \pm 5 \\
19 \pm 7\end{array}$}} & \multicolumn{2}{|c|}{$47 \pm 7$} \\
\hline Mean working experience (years) & & & & \\
\hline Sex (male) & 13 & (38) & 12 & $(35)$ \\
\hline Full-time employment (fte) & 13 & (38) & 7 & $(21)^{\prime}$ \\
\hline Practices & \multicolumn{2}{|c|}{16} & \multicolumn{2}{|c|}{13} \\
\hline Single-doctor & 7 & (21) & 7 & (21) \\
\hline Location: Urban ( $\geq 1000$ addresses per $\left.\mathrm{km}^{2}\right)$ & 12 & $(35)$ & 9 & (26) \\
\hline Desk-top cholesterol analysers & 3 & (9) & 2 & (6) \\
\hline With specialized CVD clinics & 8 & $(24)$ & 4 & (12) \\
\hline Patients & \multicolumn{2}{|c|}{$\mathrm{n}=276$} & \multicolumn{2}{|c|}{$\mathrm{n}=214$} \\
\hline Age & \multicolumn{2}{|c|}{$54 \pm 10$} & \multicolumn{2}{|c|}{$54 \pm 10$} \\
\hline Sex (male) & 124 & $(45)$ & 96 & $(45)$ \\
\hline Estimation of high CVD risk ${ }^{a}$ & 51 & (19) & 31 & (15) \\
\hline Potentially at high CVD risk ${ }^{\mathrm{b}}$ & 166 & $(60)$ & 121 & $(57)$ \\
\hline Diabetes & 49 & (18) & 29 & (21) \\
\hline Smoking & 92 & (33) & 49 & $(23)^{\star}$ \\
\hline Hypertension & 123 & (45) & 106 & $(50)$ \\
\hline Family history of CVD ${ }^{c}$ & 126 & (46) & 83 & (39) \\
\hline Hypercholesterolemia & 27 & (27) & 8 & $(11)^{\star}$ \\
\hline \multicolumn{5}{|l|}{ Socio-economic status (SES) } \\
\hline High & 32 & $(12)$ & 20 & (10) \\
\hline Intermediate & 118 & (44) & 96 & (46) \\
\hline Low & 116 & $(44)$ & 95 & $(45)$ \\
\hline
\end{tabular}

${ }^{a}$ High cardiovascular risk according to the Dutch guidelines, with all diabetic patients labelled as high-risk. ${ }^{b}$ Possibility of high cardiovascular risk according to the Dutch guidelines. risk assessment is recommended. ${ }^{\mathrm{C}} 1^{\text {st }}$ degree relative with $\mathrm{CHD}$ before the age of 60 . * $p<0.05$

\section{Effects of the intervention}

\section{Physician level}

The performance indicators of the GPs revealed good performances (Table 5.2). The results for the first indicator show a tendency towards an intervention effect: $86 \%$ of the patients at high risk in the intervention group were actually tested, compared to $76 \%$ in the control group. But this difference was only $10 \%$ and thus not significant. 
Table 5.2 Performance of the GPs in terms of the key recommendations of the cholesterol guidelines (Box 5.1, page 69). Multi-level logistic regression analysis, adjusted for clustering of the data at GP level $(95 \% \mathrm{Cl})$

\begin{tabular}{|c|c|c|}
\hline & \multicolumn{2}{|c|}{ Probability, adjusted for clustering $(95 \% \mathrm{Cl})$} \\
\hline & $\begin{array}{l}\text { Intervention } \\
\text { n=17 GPS, } \\
276 \text { patients }\end{array}$ & $\begin{array}{c}\text { Control } \\
n=17 \text { GPS, } \\
214 \text { patients }\end{array}$ \\
\hline \multicolumn{3}{|l|}{ Classification } \\
\hline Appropriate risk classification $\mathrm{I}^{\mathrm{a}}$ & $0.86(0.75-0.92)$ & $0.76(0.62-0.86)$ \\
\hline Appropriate risk classification $\mathrm{II}^{\mathrm{b}}$ & $0.64(0.50-0.76)$ & $0.63(0.55-0.72)$ \\
\hline \multicolumn{3}{|l|}{ Assessment } \\
\hline Appropriate assessment & $0.85(0.71-0.93)$ & $0.82(0.64-0.92)$ \\
\hline \multicolumn{3}{|l|}{ Management } \\
\hline Appropriate smoking advice & $0.82(0.66-0.91)$ & $0.91(0.68-0.98)$ \\
\hline Appropriate dietary advice & $0.69(0.55-0.81)$ & $0.79(0.58-0.91)$ \\
\hline
\end{tabular}

$\mathrm{Cl}$ confidence interval.

${ }^{a}$ I, indicates underuse: all patients at high risk having a cholesterol test / all patients at high risk.

${ }^{\mathrm{b}}$ II, indicates overuse: all patients at high risk having a cholesterol test / all patients having a cholesterol test.

\section{Patient level}

For each component of patients' perceived risk, only small non-significant changes between and within the groups were observed (Table 5.3). In the intervention group, $18 \%$ of the patients estimated their absolute probability of developing CVD as high and $15 \%$ estimated their risk as higher than that of their peers; the corresponding figures for the control group were $21 \%$ and $14 \%$.

Table 5.3 Description of risk perception and self-reported lifestyle. Total $n=490$; intervention $n=276$; controls $n=214$; valid percentage $(\%)$

\begin{tabular}{|c|c|c|c|c|c|c|}
\hline \multirow{2}{*}{\multicolumn{2}{|c|}{ Risk perception }} & & \multicolumn{2}{|c|}{$T=0$} & \multicolumn{2}{|c|}{$\mathrm{T}=26$ (wks) } \\
\hline & & & Intervention & Controls & Intervention & Controls \\
\hline \multirow{2}{*}{\multicolumn{2}{|c|}{ Abs. probability perception }} & - high & $49(18)$ & $44(21)$ & $37(16)$ & $36(18)$ \\
\hline & & - appropriate ${ }^{a}(A)$ & $194(72)$ & $145(70)$ & $154(70)$ & $140(71)$ \\
\hline \multicolumn{7}{|c|}{ Comparative probability perception } \\
\hline & & - higher than peers & $40(15)$ & $30(14)$ & $27(12)$ & $34(17)$ \\
\hline & & - appropriate (B) & $193(72)$ & $156(74)$ & $163(74)$ & $143(73)$ \\
\hline \multirow{2}{*}{\multicolumn{2}{|c|}{ Anxiety }} & - anxious & 45 (17) & $28(13)$ & $35(16)$ & $32(16)$ \\
\hline & & - appropriate ${ }^{\mathrm{b}}(\mathrm{C})$ & $181(69)$ & $155(74)$ & $152(69)$ & $141(73)$ \\
\hline Appropriate on a & & $A+B+C$ & $146(53)$ & $128(60)$ & $126(46)$ & $114(53)$ \\
\hline \multirow[t]{4}{*}{ Lifestyle } & Smoking & & $92(33)^{*}$ & $49(23)^{*}$ & $66(29)$ & $45(23)$ \\
\hline & Insufficier & physical activity $^{c}$ & $84(31)^{*}$ & $47(22)^{*}$ & $53(24)^{\star *}$ & $51(26)$ \\
\hline & $\mathrm{BMI}>30$ & & 52 (19) & 39 (18) & 35 (16) & 30 (15) \\
\hline & Alcohol > & units per day & 75 (27) & $59(28)$ & $52(24)$ & $47(25)$ \\
\hline
\end{tabular}

Missing data are not reported. Number of missing data varied per outcome from 0 to 59 at $T_{0}$ and from 0 to 56 at $\mathrm{T}_{26 \mathrm{wks}} \mathrm{BMI}$, bodymass index.

${ }^{a}$ High probability perception + high actual risk or low perceived risk + low actual risk. ${ }^{b}$ Anxious + high actual risk or not anxious + low actual risk. ${ }^{*} p<0.05$ between groups. ${ }^{* *} p<0.05$ within groups. 
In the intervention group, $17 \%$ of the patients were anxious, compared to $13 \%$ in the control group. Although the reduction in anxiety over time was larger in the intervention group, it was too small to be significant.

Evaluation of the appropriateness of the perceived risk revealed only small inconsistent changes over time on both components. There was no significant change in appropriateness of anxiety. After 26 weeks, the proportion of patients with appropriate scores on risk perception and anxiety had decreased from 53 to $46 \%$ in the intervention group and from 60 to $53 \%$ in the control group. Subgroup analysis of the patients at high risk revealed the same findings; no effects were seen.

After six months, more patients in the intervention group had stopped smoking than in the control group but the difference was not significant. There was a significant intervention effect on physical activity (Mac Nemar, $p<0.05$ ). More patients in the intervention group $(+31)$ had sufficiently increased their physical activity than in the control group (-4). The effect differed between men [odds ratio (OR) 3.8] and women (OR 0.9). Self-efficacy and SES contributed to physical activity as well, as men of high SES were doing less well in terms of physical activity than those of low SES (Table 5.4).

Table 5.4 Multi-level regression analysis, clustered at GP level, of patients' physical activity, odds ratio, $(95 \% \mathrm{Cl})$

\begin{tabular}{lrc}
\hline & & $\begin{array}{c}\text { Physical activity }^{\text {a }} \\
\text { at T 26 weeks }\end{array}$ \\
\hline Physical activity at T0 (yes vs no) & 12.5 & $\begin{array}{c}(7.0-22.4)^{*} \\
(0.14-0.88)^{*}\end{array}$ \\
Sex (men vs women) & 0.4 & \\
Intervention (training vs control) & & $(1.7-8.7)^{*}$ \\
- for men & 3.8 & $(0.4-2.0)$ \\
- for women & 0.9 & $(1.1-2.0)^{*}$ \\
Self-efficacy (yes vs no) & 1.5 & $(0.40-1.63)$ \\
SES (medium vs low) & 0.8 & $(0.16-0.78)^{*}$ \\
\hline
\end{tabular}

SES, socio economic status.

${ }^{a}$ Physical activity: 0 = less than two hours walking, cycling or sports per week. ${ }^{*} p<0.05$

\section{Discussion}

The present cluster-randomized study evaluated whether provision of and training in the use of a decision support tool in primary care would improve the quality of the cardiovascular preventive care offered by GPs and would result in a more realistic risk perception by patients, which in turn might lead to a healthier lifestyle. 
Contrary to our expectations of this innovative intervention, we found no substantial changes in GP performance in the intervention group compared to the control group, even though the GPs in the intervention group had more contacts with their included patients. Nor did we find any effect of the intervention on the appropriateness of patients' risk perception, and inducement of fear was not observed either. Regarding patients' lifestyle, we observed only a significant improvement in self-reported physical activity among men in the intervention group compared to the men in the control group. Self-efficacy and, surprisingly, low SES contributed to this effect as well. Showing that appropriate risk perception might not be the only condition that attributes to a change of lifestyle.

In this effectiveness trial, the selection of patients to be included was implicitly generated by the GPs' routines and habits, thus reflecting real practice conditions. Most of the GPs had a special interest in cardiovascular prevention, which ensured a minimum attitude and performance level. The intervention was not entirely applied as intended, and we lost some GPs between randomization and follow-up, diminishing the power to detect small but relevant differences ${ }^{25}$. The GPs included fewer patients than intended, and only $70 \%$ of the patients in the intervention group were actually invited for a second consultation. Since the decision support tool was well accepted by the patients, this study may have underestimated the potential effect of the intervention on the outcome.

In developing the intervention, we tried to address the most important barriers and to use proven strategies. During the training, the GPs welcomed the decision support tool as something they had lacked so far. Nevertheless, it seems that we may have made life more complicated for the GPs. What we tried to do is to introduce two new features at the same time. The first was the application of the high-risk approach by using the risk tables, and the second was the use of a decision support tool that, in our view, demanded a different approach to patient care by spreading it over two consultations instead of one. Apparently, this is quite a complex innovation and our implementation strategy, consisting of a 4-hour training, may not have been powerful enough to meet this implementation challenge.

Time pressure was an important barrier to the use of the decision support tool, as has been recognized by others ${ }^{26}$. More intensive training in patient involvement and the use of decision support tools seems advisable but is no guarantee for success ${ }^{13,27-29}$. Using practice nurses instead of the GPs seems a more promising approach to cardiovascular prevention in primary care ${ }^{30,31}$.

The patients seemed eager to learn or become involved, since more than $80 \%$ of the invited patients returned to discuss their risk. Nevertheless, this did not result in a more realistic risk perception, as has also been found by others $^{19,32,33}$. Extending the decision support to include better preparation of patients for involvement in decision-making and a greater focus on 
implementation of the decision tool might have yielded more favourable effects $^{34}$.

\section{Conclusion}

Introduction of the high-risk approach, namely using a risk table and a decision support tool to enhance patient involvement, demands an intensive implementation strategy. The decision support tool used in our study did not affect patients' risk perception. However, there seemed to be a beneficial effect of the decision support tool on the patients' self-reported lifestyle. We feel that this type of intervention deserves more research. 


\section{References}

1. De Backer G, Ambrosioni E, Borch Johnsen K, Brotons C, Cifkova R, Dallongeville J, Ebrahim S, Faergeman O, Graham I, Mancia G, Cats VM, Orth Gomer K, Perk J, Pyorala K, Rodicio JL, Sans S, Sansoy V, Sechtem U, Silber S, Thomsen T, Wood D. European guidelines on cardiovascular disease and prevention in clinical practice. Atherosclerosis 2003;171:145-55.

2. Jackson R. Updated New Zealand cardiovascular disease risk-benefit prediction guide. BMJ 2000;320:709-10.

3. Anonymous. Joint British recommendations on prevention of coronary heart disease in clinical practice: summary. British Cardiac Society, British Hyperlipidaemia Association, British Hypertension Society, British Diabetic Association. BMJ 2000;320:705-8.

4. Thomas S, van der Weijden T, van Drenth BB, Haverkort AFM, Hooi JD, van der Laan JD. NHG-Standaard Cholesterol (eerste herziening). Huisarts Wet 1999;42:406-17.

5. Hobbs FD, Erhardt L. Acceptance of guideline recommendations and perceived implementation of coronary heart disease prevention among primary care physicians in five European countries: the Reassessing European Attitudes about Cardiovascular Treatment (REACT) survey. Fam Pract 2002;19:596-604.

6. van der Weijden T, Grol RP, Knottnerus JA. Feasibility of a national cholesterol guideline in daily practice. A randomized controlled trial in 20 general practices. Int J Qual Health Care 1999;11:131-7.

7. Peters TJ, Montgomery AA, Fahey T. How accurately do primary health care professionals use cardiovascular risk tables in the management of hypertension? $\mathrm{Br} \mathrm{J}$ Gen Pract 1999;49:987-8.

8. Isles CG, Ritchie LD, Murchie P, Norrie J. Risk assessment in primary prevention of coronary heart disease: randomised comparison of three scoring methods. BMJ 2000;320:690-1.

9. Steenkiste van B, Weijden van der T, Stoffers HEJH, Grol R. Barriers to implementing cardiovascular risk tables in routine general practice. Scand J Prim Health Care 2004;22: 32-37.

10. Elwyn G, Edwards A, Kinnersley P, Grol R. Shared decision making and the concept of equipoise: the competences of involving patients in healthcare choices. $\mathrm{Br} \mathrm{J}$ Gen Pract 2000;50:892-9.

11. Elwyn G. Shared decsion making Patient involvement in clinical practice (thesis). Centre for Quality of Research (WOK), Nijmegen, The Netherlands, 2001.

12. Montgomery AA, Fahey T. How do patients' treatment preferences compare with those of clinicians? Quality in health care Qual Health Care 2001;10 Suppl 1:39-43.

13. Lewis DK, Robinson J, Wilkinson E. Factors involved in deciding to start preventive treatment: qualitative study of clinicians' and lay people's attitudes. BMJ 2003;327:841.

14. Barry CA, Bradley CP, Britten N, Stevenson FA, Barber N. Patients' unvoiced agendas in general practice consultations: qualitative study. BMJ 2000;320:1246-50.

15. Lobo CM, Frijling BD, Hulscher ME, Braspenning JC, Grol RP, Prins A, van der Wouden JC. Organizing cardiovascular preventive care in general practice: determinants of a successful intervention. Prev Med 2002;35:430-6.

16. Grol R, Grimshaw J. From best evidence to best practice: effective implementation of change in patients' care. Lancet 2003;362:1225-30.

17. Steenkiste van B, Weijden van der T, Timmermans D, Vaes J, Stoffers HE, Grol R. Patients' ideas, fears and expectations of their coronary risk: barriers for primary prevention. Patient Educ Couns 2004;55:301-7.

18. Edwards A, Unigwe S, Elwyn G, Hood K. Effects of communicating individual risks in screening programmes: Cochrane systematic review. BMJ 2003;327:703-9.

19. O'Connor AM, Legare F, Stacey D. Risk communication in practice: the contribution of decision aids. BMJ 2003;327:736-40. 
20. McAlister FA, O'Connor AM, Wells G, Grover SA, Laupacis A. When should hypertension be treated? The different perspectives of Canadian family physicians and patients. CMAJ 2000;163:403-8.

21. Eccles M, Grimshaw J, Campbell M, Ramsay C. Research designs for studies evaluating the effectiveness of change and improvement strategies. Qual Saf Health Care 2003;12:47-52.

22. Lipkus IM, Kuchibhatla M, McBride CM, Bosworth HB, Pollak KI, Siegler IC, Rimer BK. Relationships among breast cancer perceived absolute risk, comparative risk, and worries. Cancer Epidemiol Biomarkers Prev 2000;9:973-5.

23. Blokstra A, Seidell JC, Smit HA, Bueno de Mesquita HB, Verschuren WMM. The Monitoring Project on Risk Factors for Chronic Diseases (MORGEN project) Annual Report 1997. Bilthoven, RIVM,1998. [Report No.: 263200007].

24. Spies TH, Mokkink HGA, De Vries Robbe PF, Grol RPTM. Which data source in clinical performance assessment? A pilot study comparing self-recording with patient records and observation. Int J Qual Health Care 2004;16:65-72.

25. Puffer S, Torgerson D, Watson J. Evidence for risk of bias in cluster randomised trials: review of recent trials published in three general medical journals. BMJ 2003;327:785-9.

26. Edwards A, Matthews E, Pill R, Bloor M. Communication about risk: the responses of primary care professionals to standardizing the 'language of risk' and communication tools. Fam Pract 1998;15:301-7.

27. Edwards A, Elwyn G, Hood K, Atwell C, Robling M, Houston H, Kinnersley P, Russell I. Patient-based outcome results from a cluster randomized trial of shared decision making skill development and use of risk communication aids in general practice. Fam Pract 2004;21: 347-54.

28. Elwyn G, Edwards A, Hood K, Robling M, Atwell C, Russell I, Wensing M, Grol R. Achieving involvement: process outcomes from a cluster randomized trial of shared decision making skill development and use of risk communication aids in general practice. Fam Pract 2004;21:337-46.

29. Hollnagel $\mathrm{H}$. Explaining risk factors to patients during a general practice consultation. Conveying group-based epidemiological knowledge to individual patients. Scand J Prim Health Care 1999;17:3-5.

30. Horrocks S, Anderson E, Salisbury C. Systematic review of whether nurse practitioners working in primary care can provide equivalent care to doctors. BMJ 2002;324:819-23.

31. Steptoe A, Doherty S, Rink E, Kerry S, Kendrick T, Hilton S. Behavioural counselling in general practice for the promotion of healthy behaviour among adults at increased risk of coronary heart disease: randomised trial. BMJ 1999;319:943-7.

32. Coulter A. Partnerships with patients: the pros and cons of shared clinical decision-making. $J$ Health Serv Res Policy 1997;2:112-21.

33. Edwards A, Unigwe S, Elwyn G, Hood K. Personalised risk communication for informed decision making about entering screening programs. Cochrane Database Syst Rev 2003:Cd001865.

34. Sepucha KR, Mulley AG. Extending decision support: preparation and implementation. Patient Educ Couns 2003;50:269-71.

35. Gigerenzer G, Edwards A. Simple tools for understanding risks: from innumeracy to insight. BMJ 2003;327:741-4. 



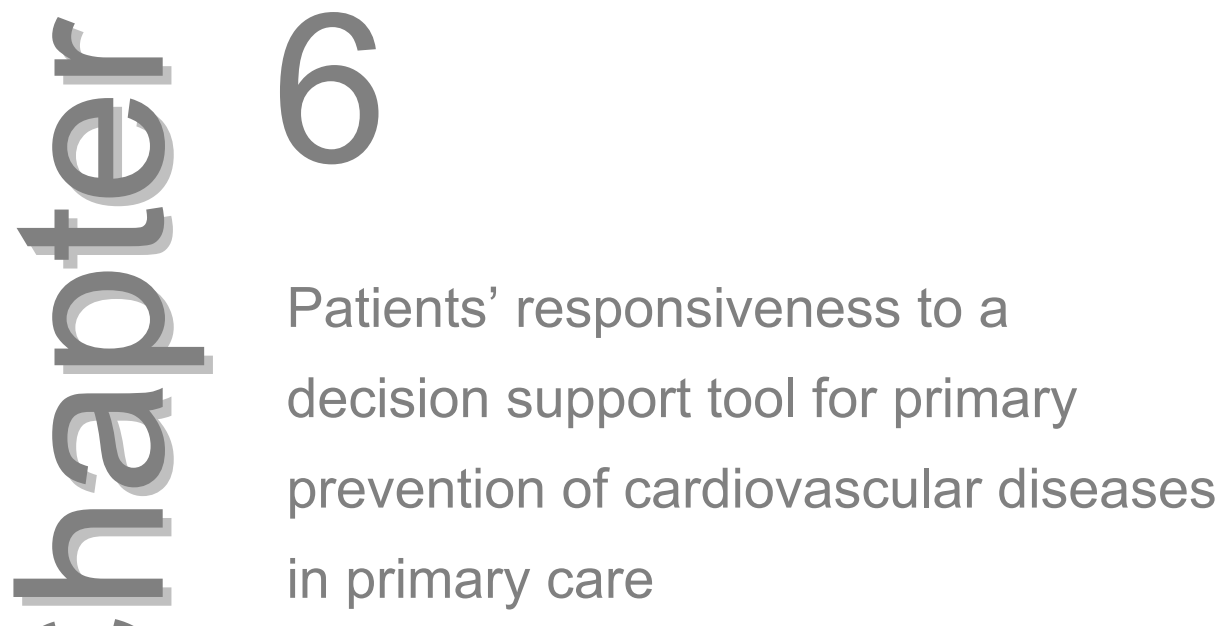

Ben van Steenkiste, Trudy van der Weijden, Jelle Stoffers, Richard Grol Patient Educ Couns (2008), doi10.1016/j.pec. 2008.02.009 


\section{Abstract}

\section{Background}

Many patients lack of understanding of cardiovascular risk and have unrealistic expectations with respect to medical interventions. To facilitate informed decisions about cardiovascular risk the use of a decision support tool seemed a valuable strategy to help patients determine what is personally relevant to them, so that they can participate in the decision about their cardiovascular risk management to the extent that they would like to.

\section{Objectives}

Assessment of patients' responsiveness to a decision support tool for primary prevention of cardiovascular diseases. The booklet focuses on barriers at patient level.

\section{Methods}

Process evaluation of an intervention in primary care. Patients at high or potentially-high cardiovascular risk were asked by their general practitioner (GP) to prepare themselves for a second consultation in order to participate in decisions on risk management.

Outcomes: patients' actually having read the booklet and returning for the second consultation; comprehension and perceived relevance of the information; perceived reassurance.

\section{Results}

Seventheen GPs, in the inetervention arm of a cluster RCT, issued 276 decision support tools during the first consultation and were instructed to ask them to return for a second consultation to discuss their CVD risk. Patients had a mean age of 54 years, $47 \%$ were male and $19 \%$ actually had a high cardiovascular risk.

Data on 239 patients, a mixture of returnees and non-returnees, showed that they all read the booklet; comprehension was fair to good; $85 \%$ perceived the information as relevant, and $68 \%$ of the patients felt reassured by the information. Satisfaction with the first consultation was higher in the non-returnees.

\section{Conclusions}

Cardiovascular prevention spread over two consultations with use of a decision support tool for patients is not easily applicable for GPs. However, based on the findings of good patients' responsiveness, we recommend further development and implementation of decision support tools in primary care.

Practice Implications: decision support for primary CVD-prevention is welcomed by patients but needs further adjustment of both the GP and the organization of CVD prevention in primary care. Sharing information between professional and patient on a personal cardiovascular risk management plan is difficult, more training is needed. 


\section{Introduction}

Prevention of cardiovascular diseases in primary care is hampered by many barriers at various levels. Major problems at patient level are a lack of understanding of cardiovascular risk, unmet information needs and unrealistic expectations with respect to medical interventions ${ }^{1}$. The high-risk approach advocates focusing on patients at high cardiovascular risk. An individual's risk is determined by risk tables and the patient's risk profile, including the most important risk factors, which is still not common in daily practice ${ }^{2,3}$. However, being at high risk is often not perceived and understood as such by patients, while conversely, patients without high CVD risk often inappropriately perceive themselves as being at high risk $^{4,5}$. In addition to risk perception, risk management involves many other factors, such as emotions, personal values, social pressure, environmental barriers, and economic constraints ${ }^{6}$.

Discussing risks and benefits of health interventions with low- or high-risk patients is increasingly becoming an essential part of modern health care $e^{7-9}$. Although the format in which risks are presented is known to affect people's perception, the evidence on the most effective format is incomplete and contradictory ${ }^{10-13}$. Appropriate and effective risk communication has proved to be a difficult task, and is perceived as such by GPs ${ }^{14-16}$. To facilitate informed decisions about cardiovascular risk based on factual information, we have developed a decision support tool, as this seemed a valuable strategy to help patients determine what is personally relevant to them, so that they can participate in the decision about their cardiovascular risk management to the extent that they would like to ${ }^{17}$. To this end, patients need to understand their cardiovascular risk and all reasonable options to address it, including the potential benefits, harms and side effects of each option ${ }^{6,18,19}$. Recent review work indicates that decision aids might contribute to increased knowledge, a more realistic perception of the probability of benefits and harms, less decisional conflict, active involvement in decision making, and improved agreement between what a patient prefers and the option which is chose ${ }^{20}$. This might also be relevant to an inappropriately worried patient who needs to understand that a healthy lifestyle is the only valid option, while there is no indication for drugs ${ }^{21}$.

In our system, after the patients had read the decision support booklet at home, they returned as informed patients for the second consultation, where they were invited to discuss their cardiovascular risk and to take part in the decisions about a risk-reducing management plan in a way that takes account of personal preferences. To facilitate this follow-up consultation, the information in the decision aid booklet had to be read, well understood, perceived as relevant, and reassuring. 
However, it was unclear how patients would respond when they were asked to read the booklet, do some homework and then return and discuss their cardiovascular risk, instead of getting a test or drugs immediately ${ }^{9}$.

The present paper reports on the patients' responsiveness to this innovative decision support tool, examined in the intervention arm of a cluster RCT in the Netherlands. First we assessed the response, in terms of actually reading the booklet and returning for a second consultation, comprehension and perceived relevance of the information, and sense of reassurance. Secondly, we explored factors that contributed to a positive or negative response by the patients to the decision support tool, in order to learn about ways to improve the decision aid or the circumstances in which it can be most helpful.

\section{Methods}

\section{Design and population}

We designed a cross-sectional study among patients (aged 40-75 years.) without established CVD who were at high, or at potentially high cardiovascular risk, based on an estimate of the absolute 10-year CVD-risk that was calculated on the available risk factors, such as age, sex, serum cholesterol, and blood pressure as described in the Dutch risk tables, being part of the national guideline on cholesterol. The risk tables precisely define which

patients are at high-risk (with an indication for medical treatment) ${ }^{22}$. The participating GPs were instructed to invite patients for the trial whenever cardiovascular risk factors were discussed during the first consultation, either at the patient's initiative or that of the physician. The patients received the decision support booklet from their GP in order to prepare themselves for a second consultation, in which they would be involved in decisions on cardiovascular risk management. This intervention was evaluated in a cluster RCT with 17 GPs in the intervention $a^{23}$. Written informed consent was obtained from the participating patients after the first consultation. The medical research ethics committee of the University Hospital of Maastricht approved the study.

\section{The decision support tool}

The actual decision support tool for the prevention of CVD consisted of a small booklet, in two versions. One for non-diabetic patients with a neutral tone on the importance of lifestyle changes, and one for diabetic patients, using a more persuasive tone, since all diabetic patients are believed to be at high-risk and have as such much health to gain. The booklets explained ones' absolute risk 
of CVD in accessible language (literacy level 3), discussed the options for risk management, and optimized the conditions for shared-decision making.

- Section one defibned who was eligible to use the booklet, and defined cardiovascular diseases and the concept op cardiovascular risk.

- Section two explained the Dutch risk charts for CVD prevention. The risk charts were printed on fold-out pages, one for men and one for women . They were showing the absolute 10-year risk of acute myocardial infarction (AMI). The risk was derived from the Framingham risk equation, using sex, age, diabetes, smoking, hypertension, and the total cholesterol/HDL cholesterol ratio as input. Two case histories, one for a man and one for a woman were used to help the reader navigate through the risk charts in order to calculate one's own risk. To support the reader in the interpretation of his/her CVD risk, the absolute 10-year CVD risk was presented and framed in different ways. In words using natural frequencies including uncertainty as well as percentages, including comparative data on other patient groups from the risk chart, and positively as well as negatively framed $^{24}$. The risk-reducing effect of the various treatment options were explained, with the aim of providing users with certain insights, such as that smoking cessation is more effective than life-long treatment with statins in the case of a slightly elevated cholesterol level.

- Section three provided information about the most important cardiovascular risk factors, the contribution of each risk factor within the risk profile and various options for risk reduction. Smokers were questioned about their smoking behaviour in order to assist the GP in applying the minimal intervention strategy to stop smoking.

- Section four was a worksheet for summarizing the patient's risk assessment, recording additional questions, preferences for risk reduction, and an invitation to participate in the decision making process on a personal risk management plan. It was meant to help th e patients prepare him/herself for a second consultation with the GP in which CVD risk was discussed.

The structure of the 16-page booklets in A5-format was founded on the early work of O'Connor et al. ${ }^{18}$ The content was based on the key recommendations of the Dutch guidelines on cholesterol. The booklets also included addresses and websites of health organizations where patients could find more in-depth information.

The decision-support tool was developed in a systematic procedure by a panel of experts from the fields of research, general practice, health education, copywriting, illustrating and publishing. They developed an initial draft of the booklet using an iterative process, after which patients and representatives of the Dutch College of General Practitioners and the Dutch Heart Foundation examined the content and quality of the written health information in the tool, 
using generally accepted instruments ${ }^{25,26}$. These pilot studies resulted in minor revisions to the lay-out and wording of the decision-support tool, after which the tool was evaluated in a cluster RCT in primary care ${ }^{23}$.

\section{Instructions for use}

The GPs were instructed about the risk table and the key recommendations for cardiovascular risk management in a 4-hour interactive small group training session. Role-play was used to allow the GPs to practice how the decision support tool could be used to support the consultation and to facilitate patient involvement in a time-efficient way. To optimize patient involvement and reinforce the process of decision-making, we instructed the GPs to spread their work on cardiovascular risk management over two consultations. At the first consultation, the GPs presented the booklet and invited the patients to do the homework (i.e. study the booklet and fill out the worksheet) and to return within 1-2 weeks to discuss their cardiovascular risk and their preferences for riskreducing options. The aim was to stimulate patient involvement during the second consultation, giving the patients time to consider their risk and preferences for risk management.

\section{Variables and instruments}

The patients completed a questionnaire on the decision support tool, issued by the GP, after the second consultation, while the same questions relating to patients' responsiveness were administered by telephone for the nonreturnees. The GPs recorded their activities at the first and second consultations on specially developed consultation registration forms.

The patients' response was regarded as positive if they (a) actually returned for a second consultation to discuss the information (yes/no on the consultation registration form), (b) read the booklet (yes/no, number of minutes), (c) understood the information, (d) perceived the information as relevant, and (e) felt reassured by the information in the booklet.

The questions on perceived understanding, relevance, and reassurance are listed below:

- " Do you understand the risk table for cardiovascular diseases on the foldout pages? " (3-point scale, 1 = unsatisfactory, 2 = fair, 3 = good)

- " Do you understand the clarification of the risk factors such as, age, sex, smoking, hypertension, and cholesterol? " (3-point scale, 1 = unsatisfactory, 2 = fair, 3 = good)

- "Do you feel that the information is suitable for you? " (yes/no)

- " Does the information on your risk on cardiovascular diseases put your mind at rest? " (yes/no) 
Possible explanations for differences in patients' responsiveness were explored by looking at age, sex, cardiovascular risk, satisfaction with the consultation, self-efficacy, socio-economic status (SES), lifestyle (healthy/non-healthy), anxiety, and whether patients had actually been invited for the second consultation (yes/no).

Data on cardiovascular risk were extracted from the GPs' consultation recording forms for the first consultation. The risk level, high vs. low, was determined by means of the risk tables. Patients' satisfaction with the consultation was measured by the Satisfaction with Consultation Questionnaire (21 items, 5 -point scale with $1=$ highly dissatisfied, $5=$ highly satisfied $)^{27}$. Selfefficacy regarding favorable lifestyle changes was measured on a 5-point scale ( $1=$ not at all, $5=$ very well), and SES was measured as a standardized combination of highest level of education and job level achieved, and accordingly classified as high, medium or low. A healthy lifestyle was defined as no smoking, less than two alcoholic drinks per day, no obesity (body mass index $<30$ ), and sufficient physical activity ( $>2 \mathrm{hrs}$. of sports activities a week). Anxiety was assessed by two questions:

- "Do you ever think that you might develop a cardiovascular disease, such as an acute myocardial infarction or a stroke? " (6-point scale, 1 = never, $6=$ always).

- "Are you worried about developing a cardiovascular disease? Can you indicate on a scale of 1 to 10 how worried you are? " $(1=$ not at all worried, $10=$ extremely worried).

A patient was labeled as anxious if the scores on both questions were higher than the midpoint of the scale.

\section{Analysis}

1) Descriptive statistics were used to describe a patient's responsiveness in terms of actually returning for the second consultation, reading, comprehension, perceived relevance and reassurance.

2) To explore the factors that might account for patients' actual return, a logistic regression analysis was done with patients' return as the dependent variable and age, sex, SES, satisfaction with the consultation, self-efficacy, risk group (high/low), lifestyle (healthy/unhealthy), anxiety (anxious/not anxious), and invitation for a second consultation (yes/no) as independent variables in the model.

3) We further explored the patients' responsiveness regarding the decision aid with comprehension, perceived relevance, and reassurance as the dependent variables in each model and adding patients' actual return to the set of independent variables, which otherwise was the same as in analysis 2. 


\section{Results}

\section{GPS}

Most of the GPs (76\%) were male and worked full-time in their practice. They recorded 332 first consultations, invited 233 patients $(70 \%)$ for a second consultation and actually recorded 190 (57\%) second consultations (Figure 6.1).

\section{GPs}

recorded 332 first consultations

$276(83 \%)$ returned first questionnaires on:

- informed consent

- demographic data

- risk profile (cardiovascular risk)

- satisfaction with the consultation

- social economic status (SES)

- self-efficacy

- lifestyle

$152(80 \%)$ returned second questionnaires on:

- responsiveness

- time spent on reading of the booklet

- comprehension of risk tables and risk factors

- perceived relevance

- perceived reassurance

Figure 6.1 Flowchart of the intervention arm of the trial 


\section{Patients}

The mean age of the patients that could be contacted $(n=239,152$ returned questionnaires, 87 interviewed by telephone) was 54 years; $47 \%$ were male and $42 \%$ had a low SES. Hypertension $(51 \%)$ was the most prevalent risk factor, while $17 \%$ of the patients were anxious about getting a cardiovascular disease, and $19 \%$ actually had a high cardiovascular risk (Table 6.1). After the first consultation, 276 ( $83 \%$ of 332 ) patients who had been given the decision support tool returned their questionnaires, and $152(80 \%$ of 190$)$ returned their questionnaires after the second consultation (Figure 6.1).

Table 6.1 Characteristics of the patients, valid percentage (\%) based on the $1^{\text {st }}$ patient questionnaire. (152 returnees and 87 interviewed by telephone

\begin{tabular}{lr}
\hline & $\mathrm{n}=239$ \\
\hline Age, mean \pm std. & $54 \pm 10$ \\
Sex, male & $111(47)$ \\
Socio-economic status (SES) & \\
$\quad$ - high & $29(13)$ \\
- medium & $102(45)$ \\
- low & $94(42)$ \\
Cardiovascular risk factors & \\
- diabetes & $41(18)$ \\
- smoking & $71(30)$ \\
- hypertension & $107(46)$ \\
- family history of CHD & $89(41)$ \\
- hypercholesterolemia & $61(26)$ \\
- alcohol >2 drinks daily & $66(29)$ \\
- obesity, BMl>30 & $40(17)$ \\
Anxious & $37(17)$ \\
High cardiovascular risk & $44(19)$ \\
Healthy lifestyle ${ }^{\mathrm{c}}$ & $39(17)$ \\
Self-efficacy regarding changing an unhealthy lifestyle $^{\mathrm{b}}$ & $3.8 \pm 0.8$ \\
Satisfaction with the consultation $^{\mathrm{d}}$ & $3.9 \pm 0.6$ \\
\hline
\end{tabular}

a $1^{\text {st }}$ degree relative with $\mathrm{CHD}$ before the age of $60 .{ }^{\mathrm{b}}$ Scale: $1=$ definitely, $5=$ not at all. ${ }^{\mathrm{c}}$ Healthy lifestyle $=$ alcohol $<2$ drinks daily and no smoking and $\mathrm{BMl}<30$ and $>2 \mathrm{hrs}$ of sports a week. ${ }^{\mathrm{d}}$ Scale: $1=$ highly dissatisfied , $5=$ highly satisfied.

\section{Responsiveness}

a) Actual return: of the 276 patients who returned the first questionnaire, 176 $(64 \%)$ actually returned for a second consultation, 152 of whom returned their questionnaire and 24 did not because no questionnaire had been handed out to them $(n=13)$ or no cardiovascular risk had been discussed $(n=11)$. The telephone interview revealed that 49 patients felt no need to go back and discuss their risk, and 14 stated that they had not been invited for a second consultation (Figure 6.2). 
b) Reading: all patients who could be contacted had read the booklet. An average of $22(S D \pm 12)$ minutes was spent on reading it (Table 6.2).

c) Comprehension: the patients' comprehension of the information on risk tables and cardiovascular risk factors in the decision aid was fair to good.

d) Relevance: the information was perceived as relevant by $85 \%$ of the patients.

e) Reassurance: almost $70 \%$ of the patients felt reassured by the information in the booklet.

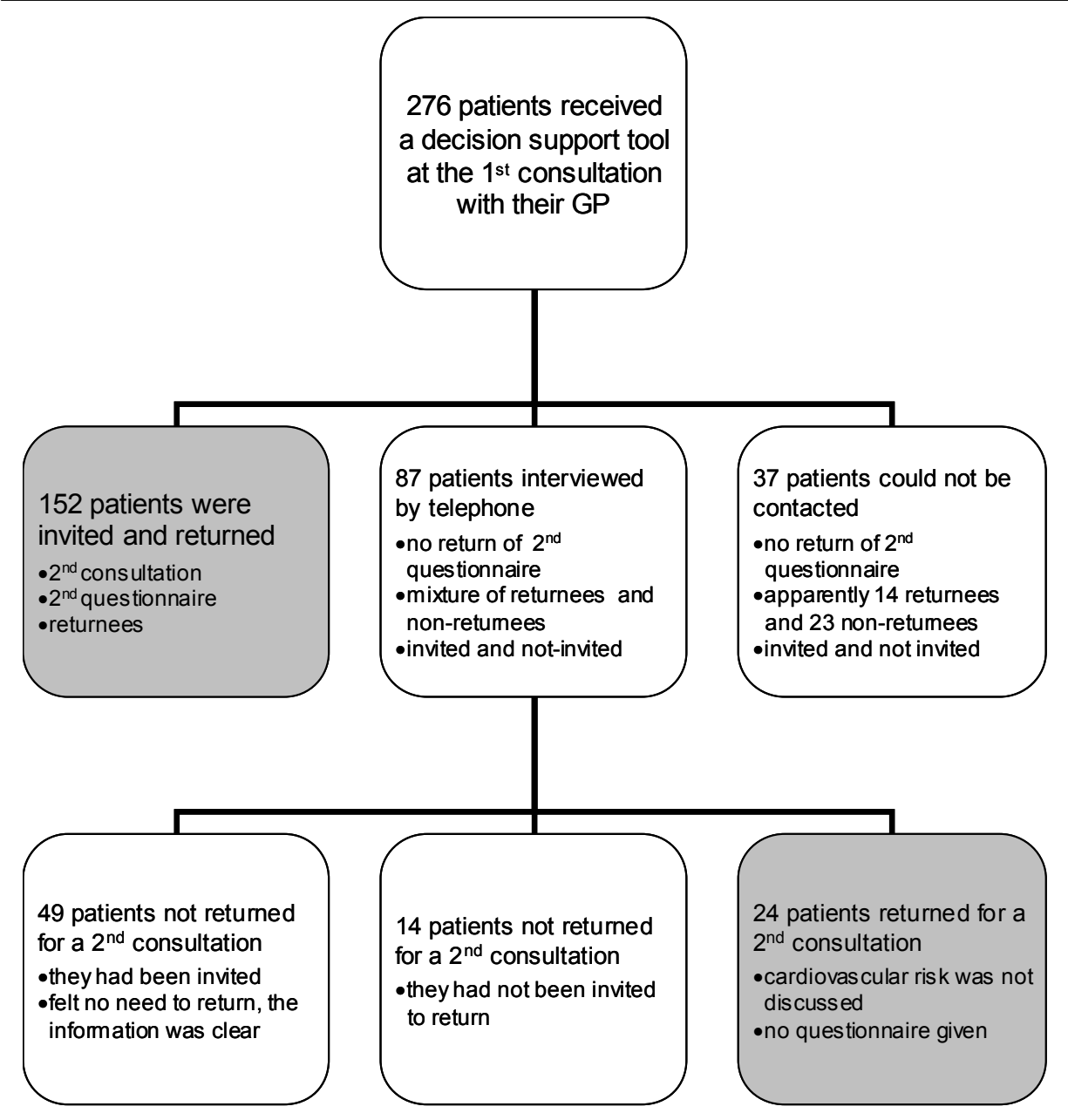

Figure 6.2 Response to additional data collection in the intervention arm of the trial for the process evaluation; understanding the decision support tool and reasons for nonreturn 
Table 6.2 Patients' responsiveness regarding the decision support tool. Information based on questionnaires (152) or telephone interviews (87) after the second consultation

\begin{tabular}{lccc}
\hline & $\begin{array}{c}\text { Non-Diabetic } \\
\mathrm{n}=190 \\
\text { mean } \pm \mathrm{sd}\end{array}$ & $\begin{array}{c}\text { Diabetic } \\
\mathrm{n}=41 \\
\text { mean } \pm \mathrm{sd}\end{array}$ & $\begin{array}{c}\text { All } \\
\mathrm{n}=239 \\
\text { mean } \pm \mathrm{sd}\end{array}$ \\
\hline Read booklet & $190(100)$ & $41(100)$ & $239(100)$ \\
Time spent on reading (min.) & $22 \pm 12$ & $22 \pm 8$ & $22 \pm 12$ \\
Given to others to read & $84(45)^{*}$ & $9(24)$ & $95(42)$ \\
Comprehension $^{*}$ & & & \\
$\quad$ - the risk table & $2.2 \pm 0.9$ & $2.2 \pm 0.8$ & $2.2 \pm 0.9$ \\
$\quad$ - the risk factors & $2.1 \pm 0.9$ & $2.2 \pm 0.8$ & $2.2 \pm 0.9$ \\
Perceived relevance & $156(87)$ & $28(80)$ & $186(85)$ \\
Feeling reassured & $126(69)$ & $24(67)$ & $152(68)$ \\
\hline
\end{tabular}

$\mathrm{n}=239$, (valid percentage) number of missing data varied per outcome from 0 to 6

${ }^{a}$ scale 1 - 3 ( 1 =insufficient, $2=$ fair, $3=$ good); $p=<0.05$, difference between groups

\section{Determinants of actual return}

Logistic regression analysis with actual return as the dependent variable revealed that of the above-mentioned set of independent variables, only satisfaction with the (first) consultation appeared to be a determinant of patients' actual return. The patients who had not returned were more satisfied than the returnees $(\mathrm{OR}, 95 \% \mathrm{Cl} 0.60(0.37-0.970))$.

\section{Determinants of responsiveness, controlling for actual return}

Further exploratory logistic regression analyses (Table 6.3) of patients' responsiveness regarding the decision aid while controlling for their actual return showed that the returnees had understood the risk factors better than the non-returnees, and that patients with medium SES understood it better than low-SES patients.

Women perceived the information as significantly less relevant to them than men, and the returnees felt more reassured by the information than the nonreturnees. 
Table 6.3 Logistic regression analysis of patients' responsiveness to the decision aid, OR, $95 \%$ $\mathrm{Cl}$

\begin{tabular}{|c|c|c|c|c|c|c|}
\hline \multirow[b]{2}{*}{ Group (returnees vs non- returnees) } & \multicolumn{2}{|c|}{$\begin{array}{l}\text { Understanding } \\
\text { the risk factors }\end{array}$} & \multicolumn{2}{|c|}{$\begin{array}{c}\text { Perceived } \\
\text { relevance } \\
\text { of the information }\end{array}$} & \multicolumn{2}{|c|}{$\begin{array}{l}\text { Being reassured } \\
\text { by the information }\end{array}$} \\
\hline & $579.3^{*}$ & 109.2- 3072.7 & 0.4 & $0.2-1.1$ & $3.2^{*}$ & $1.8-5.8$ \\
\hline Sex (female vs male) & & & $0.3^{*}$ & $0.1-0.6$ & & \\
\hline $\begin{array}{c}\text { SES (medium vs low) } \\
\text { (high vs low) }\end{array}$ & $\begin{array}{l}8.9^{*} \\
4.9\end{array}$ & $\begin{array}{l}1.7-47.5 \\
0.5-44.0\end{array}$ & & & & \\
\hline Satisfaction with the consultation & & & & & & \\
\hline Age & & & & & & \\
\hline Anxiety & & & & & & \\
\hline Self-efficacy & & & & & & \\
\hline Lifestyle (healthy vs unhealthy) & & & & & & \\
\hline Cardiovascular risk (high vs low) & & & & & & \\
\hline Invited for $2^{\text {nd }}$ consultation (yes vs no) & & & & & & \\
\hline
\end{tabular}

$n=239,152$ returnees and 87 non-returnees. ${ }^{*} p<0.05$

The dependent variable of "understanding the risk table" was found to interact with general satisfaction with the consultation. It appeared that satisfaction with the consultation accounted for the better comprehension of the risk table by the returnees, who were more satisfied with the consultation than the nonreturnees. The difference in comprehension increased with increasing satisfaction (Table 6.4).

Table 6.4 Logistic regression analysis of patients' comprehension of the risk table in the decision aid; OR, $(95 \% \mathrm{Cl})$

\begin{tabular}{|c|c|c|}
\hline & \multicolumn{2}{|c|}{$\begin{array}{l}\text { Understanding the risk table at a mean level } \\
\text { of satisfaction with the consultation }\end{array}$} \\
\hline & $\begin{array}{l}\text { returnees } \\
(n=152)\end{array}$ & $\begin{array}{l}\text { non- returnees } \\
(n=87)\end{array}$ \\
\hline $\begin{array}{l}\text { Group } \\
\text { Sex (female vs male) } \\
\text { SES (medium vs low) } \\
\quad \text { (high vs low) }\end{array}$ & $70.8(25.6-196.3)$ & $0.0(0.0-0.0)$ \\
\hline $\begin{array}{l}\text { Satisfaction with the consultation, by group } \\
\text { Satisfaction with the consultation } \\
\text { Age } \\
\text { Anxiety } \\
\text { Self-efficacy regarding changing an unhealthy lifestyle } \\
\text { Lifestyle (healthy vs unhealthy) } \\
\text { Cardiovascular risk (high vs low) } \\
\text { Invited for } 2^{\text {nd }} \text { consultation (yes vs no) }\end{array}$ & $\begin{array}{l}6.5(1.5-28.7) \\
0.3(0.1-0.9)\end{array}$ & $\begin{array}{l}0.2(0.0-0.7) \\
1.2(0.7-5.5)\end{array}$ \\
\hline
\end{tabular}

$\mathrm{n}=239,152$ returnees and 87 non-returnees. 


\section{Discussion}

The present paper evaluated patients' responsiveness to a decision aid for the primary prevention of cardiovascular diseases. In general, responsiveness was satisfactory; the booklet was read by all patients, their comprehension of the risk factors and risk tables was fair to good, and the information was perceived by the majority as relevant and reassuring. The booklet was best understood by those who returned for the second consultation and by patients with a medium SES. The returnees also felt more reassured. Women perceived the information as less relevant than men. Patients who did not have a good understanding of the risk table were more dissatisfied with the consultation and less likely to return for a second consultation to discuss their risk. Considering the large $95 \%$ confidence intervals these findings have to be confirmed in further studies. Others reported on comparable or slightly worse results ${ }^{28}$. The DA in that study was highly tailored which normally tend to be more effective in risk perception and value clarification but not consistently for knowledge and decisional conflict ${ }^{19}$.

In this process evaluation of the implementation of a decision aid in normal practice, we learned from the non-returnees that their "non-return" was sometimes due to the GPs' failure to instruct them in the proposed way, missing the opportunity for more sustained patient involvement in the discussion and decisions. We know that adopting a new approach to improve the quality of care is often hard in daily practice, especially in primary care, resulting in underutilization of interventions ${ }^{29}$. Apparently, the new approach of cardiovascular prevention spread over two consultations with use of a decision support tool did not fit in well with the GPs' daily routine. They forgot about it or felt some aversion towards the new approach because it was perceived as time-consuming, a feeling that was sometimes increased by the GPs' low perceived self-efficacy as regards changing patients' lifestyle. We think that our counter-intuitive finding that the non-returnees reported even greater satisfaction than the returnees might be explained by the quality of the consultation in terms of information, attention, and time. The GPs might thus appear to be able to save time, but the patients had not understood the information handed out to them, and have missed the opportunity for more sustained involvement in a personal cardiovascular risk management plan. Only reading the booklet is not enough, it will seldom bring the often necessary lifestyle change in case of high-CV risk. The booklet, as all decision aids, has to be embedded in a series of (at least two) consultations in which the patients' understanding is checked, options for change are discussed, and a riskreducing strategy and follow-up is decide upon.

The strength of our study is that our data stemmed from real practice, with large numbers of respondents, while other authors have reported on pilot 
testing only ${ }^{17,30}$. We did not formally measure the patients' understanding of the booklet by means of a knowledge test, which acan be considered as a weakness. Another weakness might be that our tool does not meet all the criteria for a decision aid, according to the latest IPDAS criteria (http://www.ipdas.ohri.ca) ${ }^{31}$, although at the start of the project our tool was in line with current views at that time. To become a decision aid the decision support tool needs to be revised taking all the IPDAS criteria and the recommendation in the new guideline on CVRM into account.

Decision aids reduce uncertainty abiut the decision, improve knowledge without increasing anxiety and so far have little apparent impact on actual choices made ${ }^{19}$. Applying formal decision analysis, by supporting the patient in using a decision tree, could strengthen thes effects ${ }^{32-34}$. Further improvement of the risk presentation is needed and could be achieved by putting CVD risk in perspective and by adding visual formats and simple tabular data on drug benefit and harm ${ }^{35-37}$.

The decision support tool incorporates a self-completed cardiovascular risk calculator that tailors the impact of multiple therapeutic options to each patient. An electronic version of this decision support tool, presented on the Internet with more in-depth information on cardiovascular risk management could be supportive to GPs and patients alike. An electronic version could be made more sophisticated by using multimedia techniques. Patient experiences with a computerized version were recently evaluated ${ }^{38}$. The patients' limited knowledge about their CHD risk and effective risk reduction option was confirmed. The decision aid stimulated patients to discuss their CVD risk and a specific plan for risk reduction with their doctors. Moreover, it helped patients to communicate their needs to their doctor.

We feel that a paper version and an electronic version of the decision aid could be complementary. The basic information in the paper version could be discussed to check if it is clearly understood and to reveal patients' preferences for interventions, while the electronic version could then be used for more indepth information. Checking patients' comprehension and identifying their preferences for risk-reducing strategies could be delegated to a trained practice nurse. This strategy is a subject of research in the current IMPALA trial, in which a risk communication tool and a decision aid are issued to patients for preparation at home, and in which the practice nurse applies an adapted motivational interviewing technique to discuss the risk and options for risk reduction $^{39}$. 


\section{Conclusions}

We recommend further development and implementation of the decision aid as an important tool to reassure patients and inform them about their cardiovascular risk. Since this implementation is difficult for GPs, they require additional training for this first step to be successful. Delegating cardiovascular prevention to practice nurses might be a valuable option.

\section{Practice Implications}

Decision support for primary CVD-prevention is welcomed by patients but needs further adjustment of both the GP and the organization of VCDprevention in primary care. Discussion of a personal cardiovascular risk management plan is difficult, more training is needed. 


\section{References}

1. van Steenkiste B, van der Weijden T, Timmermans D, Vaes J, Stoffers J, Grol R. Patients' ideas, fears and expectations of their coronary risk: barriers for primary prevention. Patient Educ Couns. 2004;55:301-7.

2. Manuel DG, Lim J, Tanuseputro P, Anderson GM, Alter DA, Laupacis A, Mustard C. Revisiting Rose: strategies for reducing coronary heart disease. Brit Med J. 2006;332:659-62.

3. Brindle P, Beswick A, Fahey T, Ebrahim S. The accuracy and impact of risk assessment in the primary prevention of cardiovascular disease: A systematic review. Heart. 2006;92: 1752-59.

4. Erhardt L, Hobbs FD. Public perceptions of cardiovascular risk in five European countries: the react survey. Int J Clin Pract. 2002;56:638-44.

5. Weijden van der T, Steenkiste van B, Coenen J, Stoffers HEJH, Timmermans D, Grol R. Primary prevention of cardiovascular diseases in General Practice: mismatch between cardiovascular risk and the patients' risk perception. Med Decis Making. 2006;in press.

6. Weinstein ND. What does it mean to understand a risk? Evaluating risk comprehension. $J$ Natl Cancer Inst Monogr. 1999(25):15-20.

7. Coulter A. Paternalism or partnership? Patients have grown up-and there's no going back. Brit Med J. 1999;319:719-20.

8. Pignone M, Mulrow CD. Evidence based management of hypertension: Using cardiovascular risk profiles to individualise hypertensive treatment. Brit Med J. 2001;322:1164-6.

9. Ford S, Schofield T, Hope T. What are the ingredients for a successful evidence-based patient choice consultation?: A qualitative study. Soc Sci Med. 2003;56:589-602.

10. Feldman Stewart D, Kocovski N, McConnell BA, Brundage MD, Mackillop WJ. Perception of quantitative information for treatment decisions. Med Decis Making. 2000;20:228-38.

11. Edwards A, Elwyn G, Covey J, Matthews E, Pill R. Presenting risk information--a review of the effects of "framing" and other manipulations on patient outcomes. J Health Commun. 2001;6:61-82.

12. Edwards A, Elwyn G, Mulley A. Explaining risks: turning numerical data into meaningful pictures. Brit Med J. 2002;324:827-30.

13. Edwards A, Unigwe S, Elwyn G, Hood K. Effects of communicating individual risks in screening programmes: Cochrane systematic review. Brit Med J. 2003;327:703-9.

14. Steenkiste van B, Weijden van der T, Stoffers HEJH, Grol R. Barriers to implementing cardiovascular risk tables in routine general practice. Scand J Prim Health Care. 2004;22: 32-7.

15. Kedward J, Dakin L. A qualitative study of barriers to the use of statins and the implementation of coronary heart disease prevention in primary care. $\mathrm{Br} \mathrm{J}$ Gen Pract. 2003;53:684-9.

16. Gwyn R, Elwyn G, Edwards A, Mooney A. The problematic of decision-sharing: deconstructing 'cholesterol' in a clinical encounter. Health Expect. 2003;6:242-54.

17. Paterson JM, Llewellyn Thomas HA, Naylor CD. Using disease risk estimates to guide risk factor interventions: field test of a patient workbook for self-assessing coronary risk. Health Expect. 2002;5:3-15.

18. O'Connor A, Tugwell P, Wells G, Elmslie T, Jolly E, Hollingworth G, McPherson R, Bunn H, Graham I, Drake E. A decision aid for women considering hormone therapy after menopause: decision support framework and evaluation. Patient Educ Cons. 1998;33:267-79.

19. O'Connor AM, Stacey D, Entwistle V, Llewellyn Thomas H, Rovner D, Holmes Rovner M, et al. Decision aids for people facing health treatment or screening decisions. Cochrane database of systematic reviews Online Update Software ISE: 1469 493X. 2003(2):Cd001431.

20. O'Connor AM, Legare F, Stacey D. Risk communication in practice: the contribution of decision aids. Brit Med J 2003;327:736-40.

21. van der Weijden T, Grol RP, Knottnerus JA. Feasibility of a national cholesterol guideline in daily practice. A randomized controlled trial in 20 general practices. Int J Qual Health Care. 1999;11:131-7. 
22. Thomas S, van der Weijden T, van Drenth BB, Haverkort AFM, Hooi JD, van der Laan JD. NHG-Standaard Cholesterol (eerste herziening). Huisarts Wet. 1999;42:406-17.

23. van Steenkiste B, van der Weijden T, Stoffers HE, Kester AD, Timmermans DR, Grol R. Improving cardiovascular risk management: a randomized, controlled trial on the effect of a decision support tool for patients and physicians. Eur J Cardiovasc Prev Rehabil. 2007;14: 44-50.

24. Gigerenzer G, Edwards A. Simple tools for understanding risks: from innumeracy to insight. Brit Med J. 2003;327:741-4.

25. Charnock D, Shepperd S, Needham G, Gann R. DISCERN: an instrument for judging the quality of written consumer health information on treatment choices. J Epidemiol Community Health. 1999;53:105-11.

26. Coulter A, Entwistle V, Gilbert D. Informing patients. An assessment of the quality of patient information materials London: King's Fund; 1998.

27. Baker R. Development of a questionnaire to assess patients' satisfaction with consultations in general practice. Br J Gen Pract. 1990;40:487-90.

28. Col NF, Ngo L, Fortin JM, Goldberg RJ, O'Connor AM. Can computerized decision support help patients make complex treatment decisions? A randomized controlled trial of an individualized menopause decision aid. Med Decis Making 2007;27:585-98.

29. Meehan TP, Wang Y, Tate JP, Curry M, Elwell A, Petrillo MK, Holmboe, ES. Improving the quality of preventive cardiovascular care provided by primary care physicians: insights from a US Quality Improvement Organization. Int. J Qual Health Care. 2006;18:186-94.

30. Lalonde L, O'Connor AM, Drake E, Duguay P, Lowensteyn I, Grover SA. Development and preliminary testing of a patient decision aid to assist pharmaceutical care in the prevention of cardiovascular disease. Pharmacotherapy. 2004;24:909-22.

31. Elwyn G, O'Connor A, Stacey D, Volk R, Edwards A, Coulter A, Thomson R, Barratt A, Barry $M$, Bernstein S, Butow P, Clarke A, Entwistle V, Feldman Stewart D, Holmes Rovner M, Llewellyn Thomas H, Moumjid N, Mulley A, Ruland C, Sepucha K, Sykes A, Whelan T. Developing a quality criteria framework for patient decision aids: online international Delphi consensus process. Brit Med J. 2006;333:417.

32. Montgomery AA, Fahey T, Peters TJ. A factorial randomised controlled trial of decision analysis and an information video plus leaflet for newly diagnosed hypertensive patients. $\mathrm{Br} \mathrm{J}$ Gen Pract 2003;53:446-53.

33. Pignone M. Incorporating decision analysis in decision aids. Med Decis Making 2007;27: 547-9.

34. Protheroe J, Bower P, Chew-Graham C, Peters TJ, Fahey T. Effectiveness of a computerized decision aid in primary care on decision making and quality of life in menorrhagia: results of the MENTIP randomized controlled trial. Med Decis Making 2007;27:575-84.

35. Lipkus IM. Numeric, verbal, and visual formats of conveying health risks: suggested best practices and future recommendations. Med Decis Making 2007;27:696-713.

36. Covey J. A meta-analysis of the effects of presenting treatment benefits in different formats. Med Decis Making 2007;27:638-54.

37. Schwartz LM, Woloshin S, Welch HG. The drug facts box: providing consumers with simple tabular data on drug benefit and harm. Med Decis Making 2007;27:655-62.

38. Sheridan SL, Shadle J, Simpson Jr RJ, Pignone MP. The impact of a decision aid about heart disease prevention on patients' discussions with their doctor and their plans for prevention: a pilot randomized trial. BMC Health Serv Res 2006;6:121.

39. Koelewijn-van Loon MS, van Steenkiste B, Ronda G,Wensing M, Stoffers HE, Elwyn G, Grol $R$, van der Weijden T. Improving patient adherence to lifestyle advice (IMPALA): a clusterrandomised controlled trial on the implementation of a nurse-led intervention for cardiovascular risk management in primary care protocol. BMC Health Serv Res 2008;8:9. 



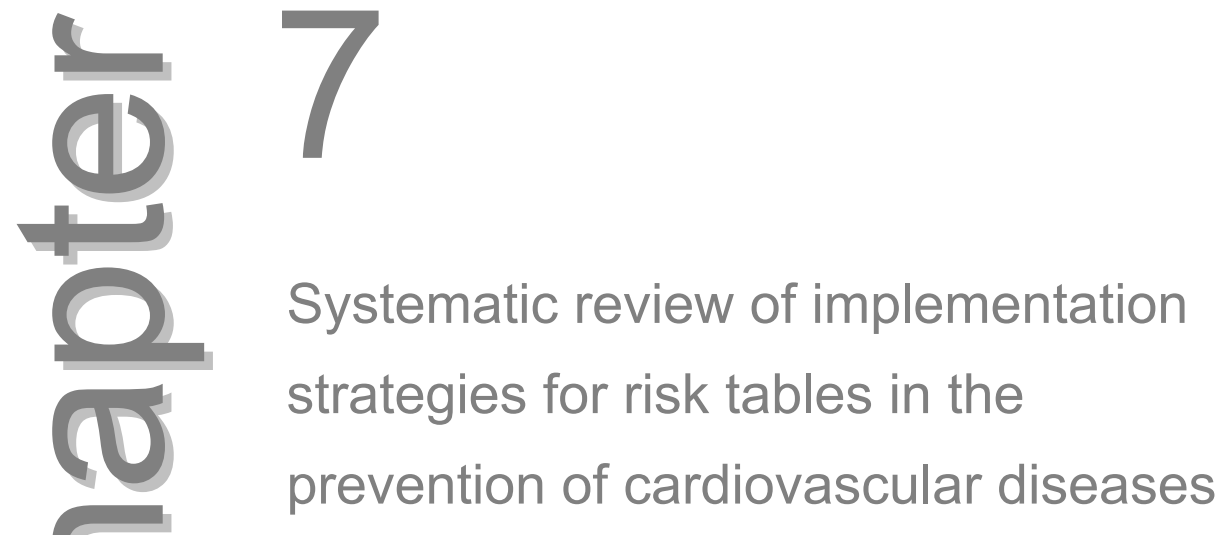

Ben van Steenkiste, Richard Grol, Trudy van der Weijden Vascular Health and Risk Management, in press 


\section{Abstract}

\section{Background}

Cardiovascular disease prevention is guided by so-called risk tables for calculating individual's risk numbers. However, they are not widely used in routine practice and it would be important to understand the conditions for their use.

\section{Objectives}

Systematic review of the literature on professionals' performance regarding cardiovascular risk tables, in order to develop effective implementation strategies.

\section{Methods}

Selection criteria: studies were eligible for inclusion if they reported quantitative empirical data on the effect of professional, financial, organizational or regulatory strategies on the implementation of cardiovascular risk tables. Participants were physicians or nurses.

Primary outcome measure: professionals' self-reported performance related to actual use of cardiovascular risk tables. Secondary: patients' cardiovascular risk reduction.

Data collection \& analysis: an extensive strategy was used to search MEDLINE, EMBASE, CINAHL, and PSYCHINFO from database inception to February 2007.

\section{Results}

The review included nine studies, covering three types of implementation strategies (or combinations). Reported effects were moderate, sometimes conflicting and contradictory. Although no clear relation was observed between a particular type of strategy and success or failure of the implementation, promising strategies for patient selection and risk assessment seem to be teamwork, nurse led-clinics and integrated IT support.

\section{Conclusions}

Implementation strategies for cardiovascular risk tables have been sparsely studied. Future research on implementation of cardiovascular risk tables needs better embedding in the systematic and problem-based approaches developed in implementation science. 


\section{Introduction}

Reducing levels of modifiable cardiovascular risk factors is a key goal in the prevention of cardiovascular diseases (CVD), and guidelines are an important means of achieving this goal ${ }^{1}$. Primary preventive treatment is targeted at patients who are asymptomatic but are at elevated absolute 10-year CVD risk. Identification of persons at high risk is guided by so-called risk tables, which are tools designed for the assessment of an individual's risk score. Numerous CVD-risk tables are available ${ }^{2,3}$. Risk tables differ in many respects, e.g. in the way risks are framed and presented, the number of risk factors included, outcome measures, interpretation, and indications for medical treatment ${ }^{2,4,5}$. These differences, and the validity of the prediction function, are still subjects of study and debate ${ }^{1,6,7}$.

Despite certain weaknesses or restrictions, there is no doubt about the value of risk tables for preventive treatment in everyday patient care. However, extensive efforts to publish and disseminate such tables have not yet resulted in the desired level of implementation in routine practice ${ }^{8}$. A systematic review of the effectiveness of cardiovascular risk tables as regards risk reduction in daily practice was inconclusive in terms of the effect on patients' risk reduction, because application of the risk tables by the professionals was not optimal. It became clear that a serious implementation problem needed to be addressed. The poor uptake of risk tables by the physicians was confirmed in observational studies $^{6}$. A risk calculator for risk management was only routinely used by $17 \%$ of American family physicians ${ }^{9}$, and less than half of the physicians in two European studies ${ }^{1,10}$. Moreover, Australian GPs reported that - if they used cardiovascular risk assessment tools at all - they used them in a restricted manner, only as an aid to patient education ${ }^{11}$. Apparently, there is a gap between the high risk approach advocated in the prevention of CVD and the actual use of risk tables in routine practice. A high-risk approach supported by risk tables seems to be an innovation that is not easy to implement. It is important to investigate what implementation strategies are most effective to ensure a good uptake of the risk tables in normal practice.

The literature reports on many different methods, strategies, and measures to introduce innovations, guidelines, best practices, or new procedures into clinical practice ${ }^{12}$. Effective implementation of innovations seems to be more successful with strategies for implementation that are tailored to the specific goals, target group and setting ${ }^{13-16}$. Therefore, the objective of our study was to systematically review the literature on health professionals' performance with respect to cardiovascular risk tables, in order to search for implementation strategies that enable professionals to use cardiovascular risk tables effectively in the prevention of CVD. 


\section{Methods}

\section{Design}

Systematic literature review.

\section{Studies included}

A study was eligible for inclusion in the review if it met the following inclusion criteria:

- quantitative empirical data were reported;

- a professional, financial, organizational or regulatory strategy was used to implement a CVD-risk table (Table 7.1);

- participants were physicians or nurses;

- the primary outcome measure was professionals' performance regarding the actual use of cardiovascular risk tables, and the secondary outcome measure was patients' cardiovascular risk reduction by improving one or more modifiable risk factors, e.g. blood pressure, cholesterol, smoking, etc.

No restrictions were used as regards setting.

\section{Search strategy}

We elaborated on the extensive search strategy used by Brindle, who recently reviewed the accuracy and impact of risk assessment in the primary prevention of $\mathrm{CVD}^{6}$. We added free-text search terms related to the implementation of cardiovascular risk tables. Table 7.2 details the terms used to search MEDLINE. Appropriate adaptations of the search syntax were made when searching EMBASE, CINAHL, and PSYCHINFO. We covered the period from database inception to February 2007. Reference lists of included articles were scanned to identify additional study reports. Languages were restricted to Dutch, English, and German.

\section{Data extraction}

Titles and abstracts of all retrieved references were scanned by one author (BvS), after which two reviewers (BvS and $T \mathrm{v} / \mathrm{d} W$ ) independently assessed the remaining set of articles for definitive inclusion or exclusion. The final set of included studies was assessed by one of the authors (BvS) on the basis of the following methodological aspects; study design, type of intervention, participants (profession), setting (location of care and country), and methods (unit of allocation and quality criteria); his findings were checked by another author (TvdW). The final decisions on inclusion and data extraction per study were made by consensus. 


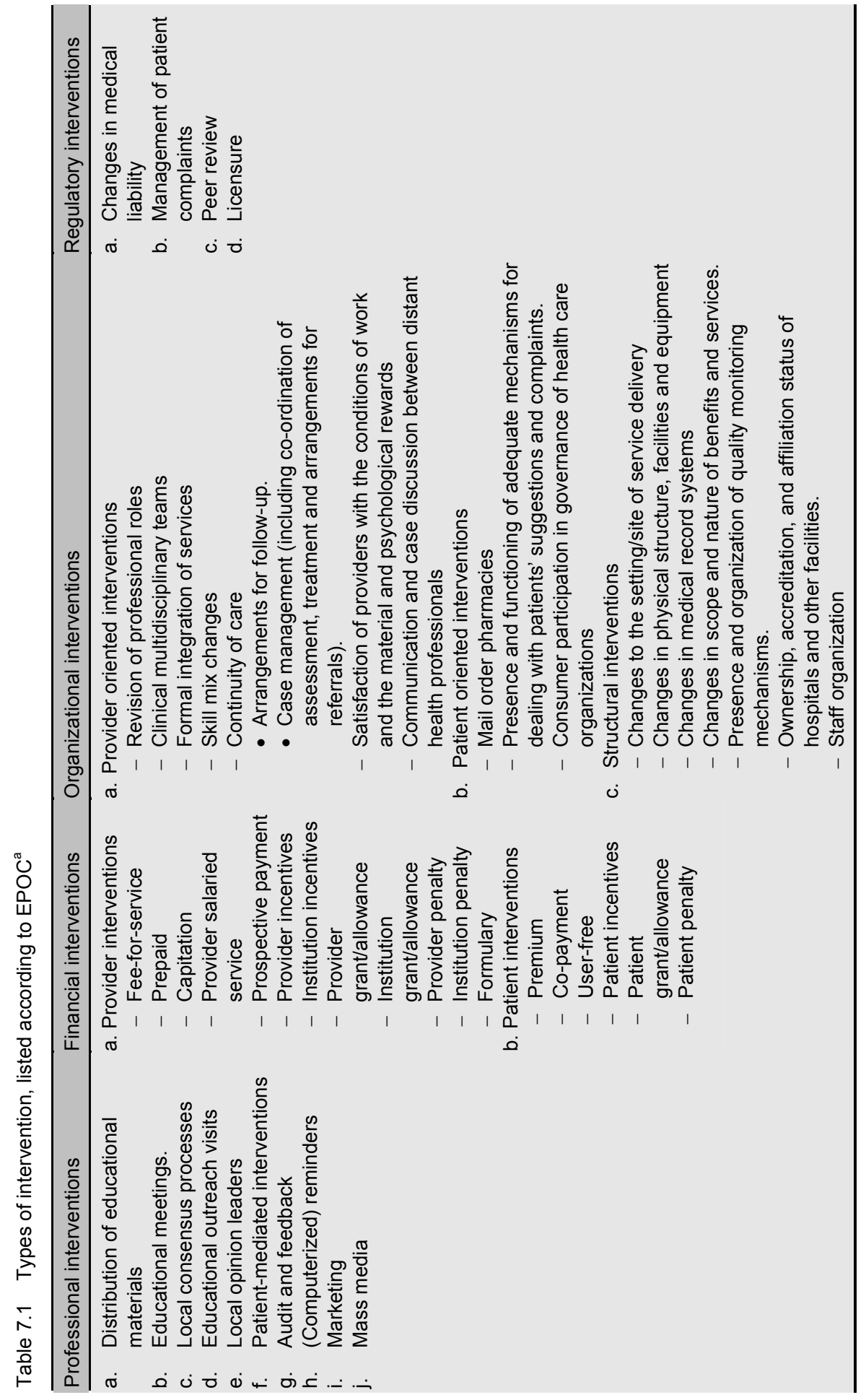


Table 7.2 Medline search terms and strategy

\begin{tabular}{|c|c|c|}
\hline \multicolumn{3}{|l|}{ Basic search strategy (Brindle) } \\
\hline \#1 chd risk assessment\$ & \#37 risk calculation\$ & \#72 (busselton adj2 score $\$$ ) \\
\hline \#2 cvd risk assessment\$ & \#38 risk calculator\$ & \#73 erica risk score\$ \\
\hline \#3 heart disease risk assessment\$ & \#39 risk factor\$ calculator\$ & \#74 framingham scor\$ \\
\hline $\begin{array}{l}\text { \#4 coronary disease risk } \\
\text { assessment\$ }\end{array}$ & $\# 40$ risk factor $\$$ calculation $\$$ & \#75 dundee scor\$ \\
\hline $\begin{array}{l}\text { \#5 cardiovascular disease risk } \\
\text { assessment\$ }\end{array}$ & \#41 risk engine\$ & \#76 brhs scor\$ \\
\hline \#6 cardiovascular risk assessment\$ & \#42 risk equation\$ & $\begin{array}{l}\text { \#77 British Regional Heart study risk } \\
\text { scor\$ }\end{array}$ \\
\hline \#7 cv risk assessment\$ & \#43 risk table\$ & \#78 brhs risk scor\$ \\
\hline $\begin{array}{l}\text { \#8 cardiovascular disease } \$ \text { risk } \\
\text { assessment\$ }\end{array}$ & \#44 risk threshold\$ & \#79 dundee risk scor\$ \\
\hline \#9 coronary risk assessment\$ & \#45 risk disc? & \#80 framingham guideline\$ \\
\hline$\# 10$ coronary risk scor $\$$ & \#46 risk disk? & \#81 framingham risk? \\
\hline$\# 11$ heart disease risk scor\$ & \#47 risk scoring method? & \#82 new zealand table\$ \\
\hline$\# 12$ chd risk scor\$ & \#48 scoring scheme? & \#83 ncep guideline? \\
\hline \#13 cardiovascular risk scor\$ & \#49 risk scoring system? & \#84 smac guideline? \\
\hline $\begin{array}{l}\text { \#14 cardiovascular disease\$ risk } \\
\text { scor\$ }\end{array}$ & $\# 50$ risk prediction? & \#85 copenhagen risk? \\
\hline \#15 cvd risk scor\$ & \#51 predictive instrument? & \#86 or/57-85 \\
\hline \#16 cv risk scor\$ & $\# 52$ project\$ risk? & \#87 56 or 86 \\
\hline \#17 or/1-16 & \#53 cdss & \#88 exp decision support techniques/ \\
\hline \#18 cardiovascular diseases/ & \#54 or/28-53 & \#89 Diagnosis, Computer-Assisted/ \\
\hline \#19 coronary disease/ & \#55 27 and 54 & $\begin{array}{l}\text { \#90 Decision Support Systems, } \\
\text { Clinical/ }\end{array}$ \\
\hline \#20 cardiovascular disease $\$$ & \#56 17 or 55 & \#91 algorithms/ \\
\hline \#21 heart disease\$ & \#57 new zealand chart\$ & \#92 algorithm? \\
\hline \#22 coronary disease $\$$ & \#58 sheffield table\$ & \#93 algorythm? \\
\hline \#23 cardiovascular risk? & \#59 procam & \#94 decision support? \\
\hline \#24 coronary risk? & $\begin{array}{l}\text { \#60 General Rule to Enable } \\
\text { Atheroma Treatment }\end{array}$ & \#95 predictive model? \\
\hline \#25 exp hypertension/ & \#61 dundee guideline\$ & \#96 treatment decision? \\
\hline \#26 exp hyperlipidemia/ & \#62 shaper scor\$ & \#97 scoring method\$ \\
\hline \#27 or/18-26 & \#63 (brhs adj3 score\$) & \#98 (prediction\$ adj3 method\$) \\
\hline \#28 risk function & \#64 (brhs adj3 risk\$) & \#99 or/88-98 \\
\hline \#29 Risk Assessment/mt (Methods) & \#65 copenhagen risk & \#100 Risk Factors/ \\
\hline \#30 risk functions & \#66 precard & \#101 exp Risk Assessment/ \\
\hline \#31 risk equation\$ & $\begin{array}{l}\text { \#67 (framingham adj1 (function or } \\
\text { functions)) }\end{array}$ & \#102 (risk? adj1 assess\$) \\
\hline \#32 risk chart? & \#68 (framingham adj2 risk) & \#103 risk factor? \\
\hline \#33 (risk adj3 tool\$) & \#69 framingham equation & \#104 or/100-103 \\
\hline \#34 risk assessment function? & \#70 framingham model\$ & \#105 27 and 99 and 104 \\
\hline \#35 risk assessor & \#71 (busselton adj2 risk\$) & \#106 87 or 105 (448.950) \\
\hline \#36 risk appraisal\$ & & \\
\hline
\end{tabular}




\begin{tabular}{|c|c|c|}
\hline \multicolumn{3}{|l|}{ Adjustments for the current review } \\
\hline \#107 106 and quality* health care & \#116 115 and clin* trial & \#129 128 and cardio* risk $^{*}$ \\
\hline \multicolumn{2}{|c|}{$\begin{array}{l}\text { \#108 } 106 \text { and practice pattern* health \#117 } 115 \text { and rand* trial } \\
\text { care }\end{array}$} & $\# 130128$ and risk tables \\
\hline \#109 106 and implement* strateg $^{*}$ & \#118 115 and randomised trial & $\# 131128$ and cardio* risk? \\
\hline \#110 106 and implement* & \#119 115 and randomized trial & \#132 128 and risk manag* \\
\hline \#111 106 and dissemination & \#120 115 and clinical trial & \\
\hline \#112 106 and diffus* & \#121 115 and cohort & \#133 115 and process assessment \\
\hline \#113 106 and guideline ${ }^{*}$ & \#121 115 and control* trial & $\# 134115$ and process evaluation \\
\hline \#114 106 and implementation? & \#122 115 and comparat* study & \#135 115 and \#17 \\
\hline \multirow[t]{6}{*}{ \#115 107 - 114 (18607) } & \multicolumn{2}{|c|}{ \#123 115 and random* ${ }^{*}$ control* $^{*}$ trial } \\
\hline & \multicolumn{2}{|l|}{ \#124 115 and observat* study } \\
\hline & \multicolumn{2}{|l|}{ \#125 115 and rand* clin* trial $^{*}$} \\
\hline & \multicolumn{2}{|l|}{ \#126 115 and control* study } \\
\hline & \multicolumn{2}{|l|}{ \#127 115 and rand* study } \\
\hline & \multicolumn{2}{|l|}{ \#128 116-127 } \\
\hline
\end{tabular}

\section{Data analysis}

The examination of the methodological quality of the studies was guided by the Data Collection Template (July 2002) of The Cochrane Effective Practice and Organisation of Care (EPOC) group, www.epoc.uottawa.ca/tools.htm.

\section{Results}

Over 1800 titles and abstracts were scanned, and the full text of 37 articles was assessed. Ten of these articles (two articles reporting on the same study) met our inclusion criteria, resulting in nine studies being included. The included studies were categorized according to their main type of intervention(s) in EPOC terms. These are summarized in Table 7.3A-C.

\section{Participants and setting}

Nearly all participants in the included studies were medical doctors, either general practitioners or internal medicine residents, while three studies involved practice nurses or practice assistants in the implementation strategy. The location of care included hospital outpatient clinics in the UK and the USA $^{17,18}$ and GP surgeries in Norway, the UK, the Netherlands, and New Zealand $^{19-24}$. 


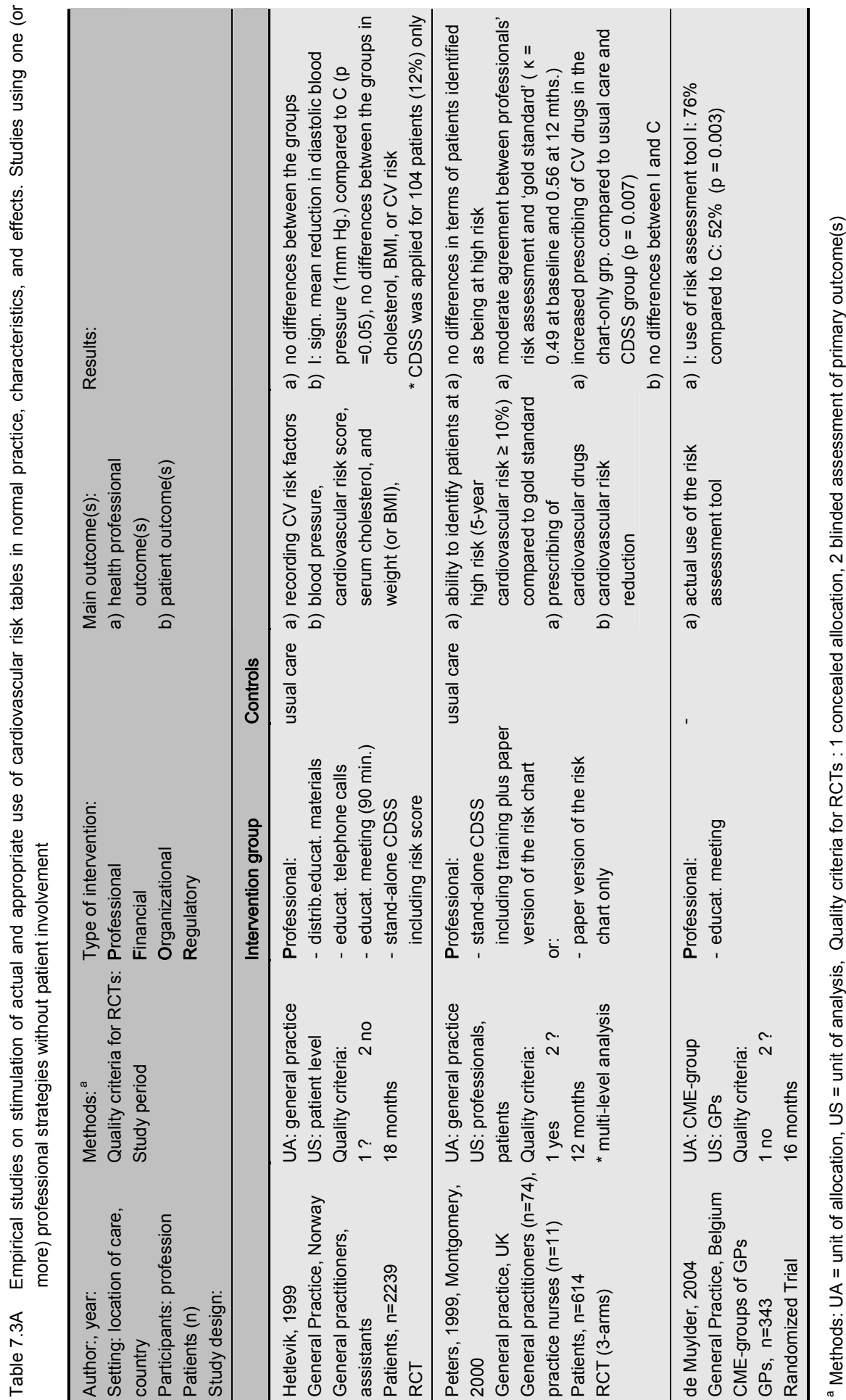




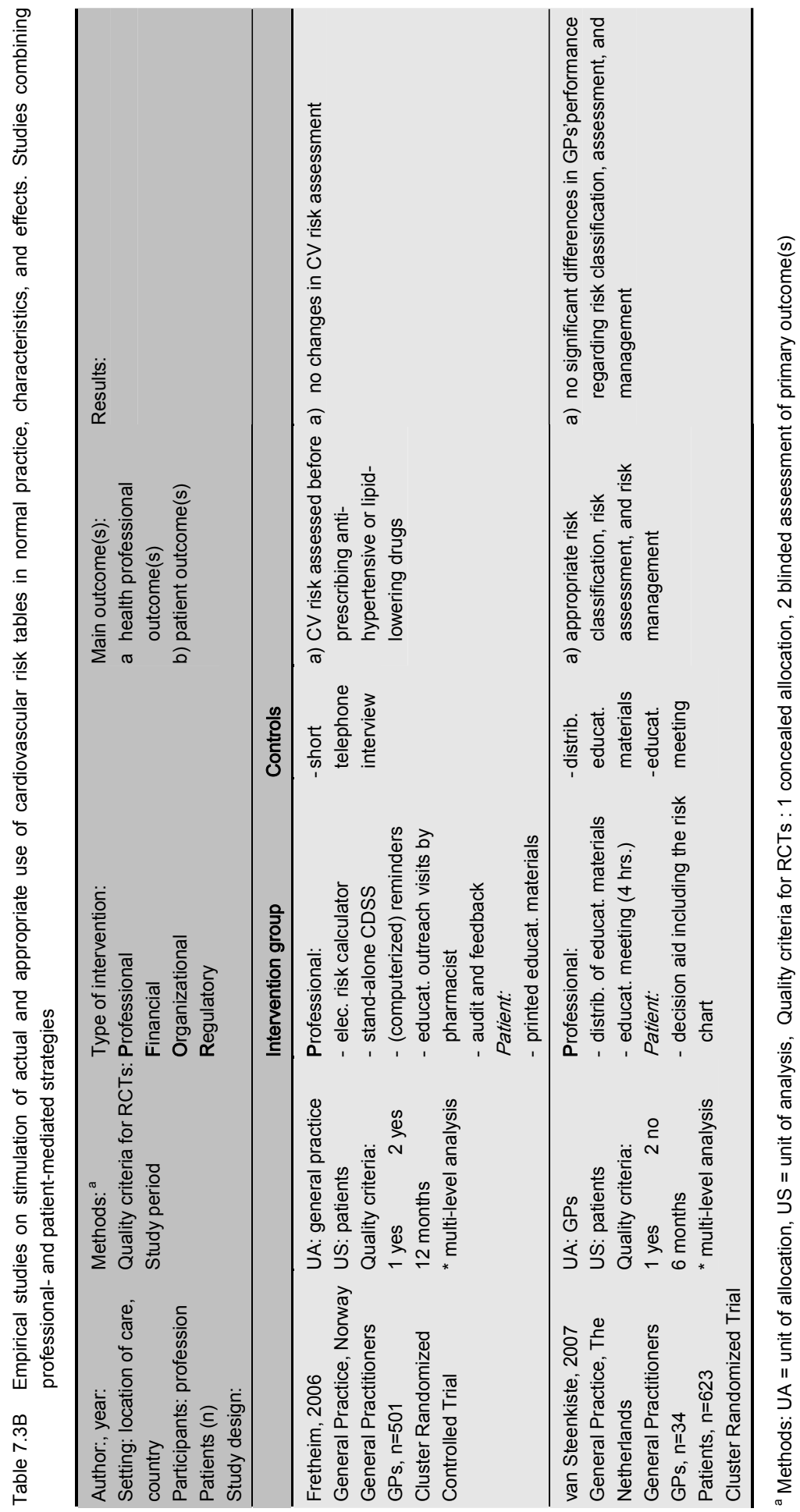




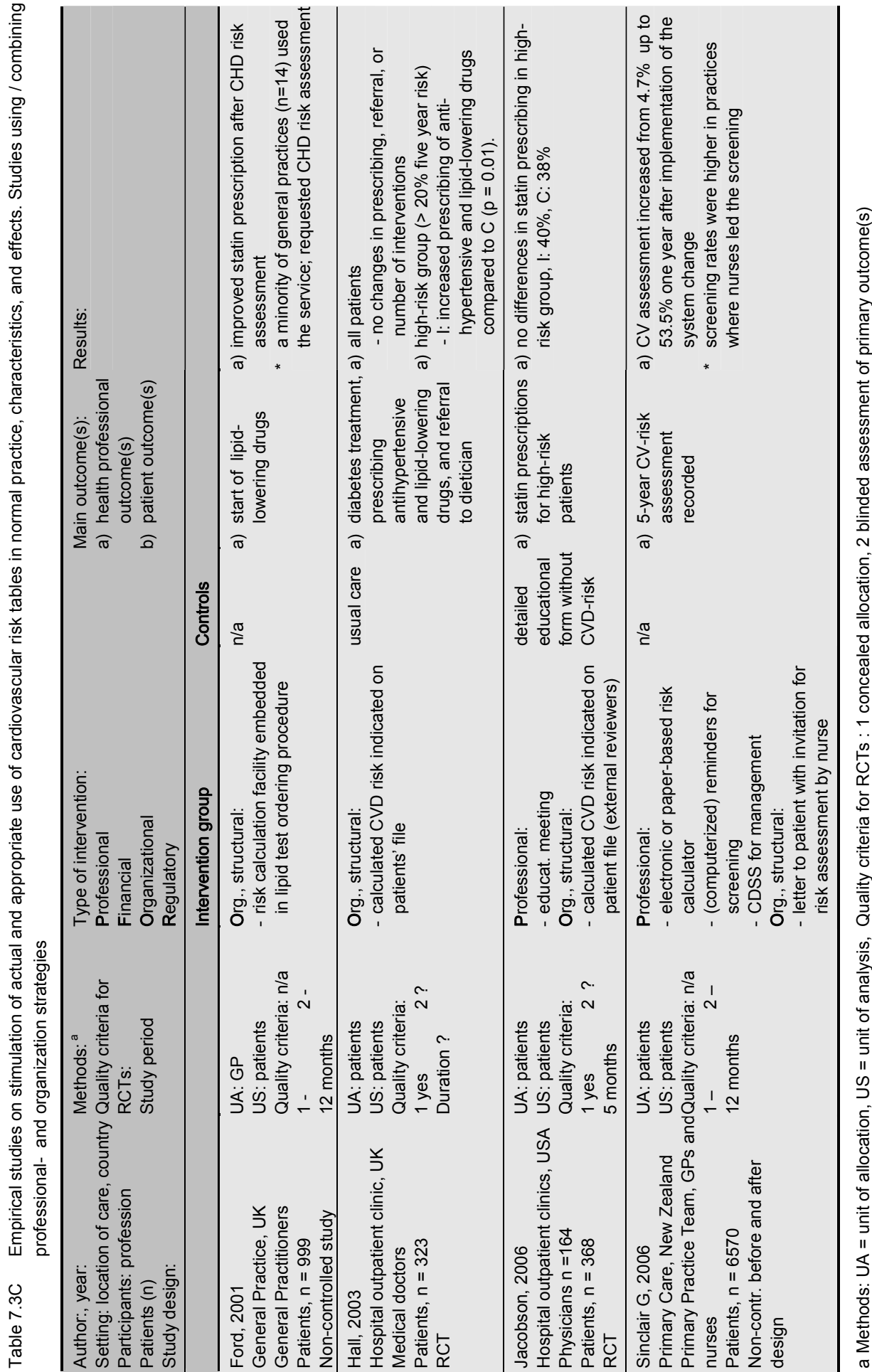




\section{Characteristics of the studies}

The trials differed considerably in size: the smallest trial included 323 patients, while a bigger trial included 2239 patients. In this large study, however, the risk table was only applied to $12 \%(n=104)$ of the eligible patients ${ }^{25}$. In the majority of the studies, the proportion of patients who completed the proposed study protocol was small. One trial included no patients, but 343 GPs were asked to evaluate the intervention strategy ${ }^{26}$. This trial, as well as five other studies, may have suffered from a unit of allocation problem, particularly, a difference between the unit of allocation and the unit of analysis, without controlling for this by means of clustered data analysis.

Seven randomized controlled trials (RCT) were found, one of them a prospective RCT without follow-up ${ }^{17}$, the others varying in time until follow-up assessment from 6 to 18 months ${ }^{18-21}$. One study reported on blinded assessment of the primary outcomes ${ }^{20}$, while five studies mentioned concealment of intervention allocation. Primary outcomes relating to the health professionals were the recording of $\mathrm{CV}$ risk and risk factors, the ability to identify patients at high risk, and appropriate indications for treatment (prescribing of cardiovascular drugs). Secondary, patient-related outcomes concerned $\mathrm{CV}$ risk and risk reduction, blood pressure, serum cholesterol, body mass index, and self-reported lifestyle.

\section{Type of intervention and effects}

We found that the interventions in the included studies were basically limited to three types: (A) professional strategies or combinations of them (without patient involvement); (B) combinations of professional- and patient-mediated strategies; (C) organizational strategies or combinations of professional and organizational strategies. In general, the effects of the interventions on primary outcomes were small, absent or contradictory for the same outcome.

\section{A) - Professional strategies}

Education was the single intervention in one of the three 'professional-oriented' trials. This was found to significantly increase the use of the risk tables ${ }^{26}$. The other two studies involved one or more educational meetings for transfer of knowledge, in combination with training in the use of a stand-alone computerized decision support system (CDSS) ${ }^{19,21}$. In the 3 -armed trial by Montgomery, the use of the CDSS plus a paper version of the risk tables, or a paper version only versus usual care, had no effect on the ability to identify patients at high cardiovascular risk or on more accurate use of the risk tables. Although increased prescribing of $\mathrm{CV}$ drugs and a significantly lower systolic blood pressure was seen in the 'risk chart only' group, no differences in risk 
reduction were found compared to usual care ${ }^{21,22}$. Interventions in which the educational meetings and the use of a CDSS were supplemented with educational materials, follow-up telephone calls and feedback on actual performance had no effect on the recording of risk factors, cholesterol level, $\mathrm{BMI}$, or $\mathrm{CV}$ risk. However, a significant mean reduction in diastolic blood pressure $(1 \mathrm{mmHG})$ was reported ${ }^{19}$.

\section{B) - Professional- and patient-mediated strategies}

Two trials combined professional interventions, such as education plus audit and feedback, with a patient-mediated intervention, involving new information on patients' $\mathrm{CV}$ risk being made available at the consultation ${ }^{20}$, and introducing a decision aid for patients ${ }^{23}$. The trial by Fretheim et al. used an outreach visit to educate GPs on CV prevention and risk communication, as well as to give feedback on actual performance, and train them to use a CDSS. The CDSS generated 'pop-ups' on screen whenever an elevated blood pressure or cholesterol level was recorded, had a CV-risk calculator, generated treatment advice, and could be used to print patient-education materials. It had no effect on CV-risk assessment prior to prescribing ${ }^{20}$. The trial by Van Steenkiste et al. used a combination of a 4-hour training session in the use of the risk tables, risk communication, and a decision aid for patients, which was to be used in two consultations to ensure patient involvement in the second consultation. Neither resulted in improved performance of the GPs in terms of risk classification, assessment, or management ${ }^{23}$.

\section{C) - Organizational}

The focus of the interventions in this group of four studies (two of which were non-controlled) was a change in facilities and equipment. In one of the two controlled trials, patients' CV risk was clearly indicated (by the researcher) on the front page of the patients' file. This had no effect on prescribing behavior, treatment or referral, except that a significant increase in the use of CV - drugs was observed for the high-risk group ${ }^{17}$. The other controlled trial involved adding an educational meeting of the professionals, and contrasted a low-detail educational form including CV risk on the patients' file in the intervention group with a more detailed form without $\mathrm{CV}$ risk in the control group. This resulted in overuse of statins in the moderate-risk group and no effect in the high-risk group $^{18}$.

One of the two non-controlled studies evaluated a risk-calculating facility embedded in a lipid test ordering procedure. Statin prescribing was found to be improved after risk assessment, but only 14 GPs used the laboratory service involved in the study ${ }^{27}$. The other study used a CDSS with risk calculator, integrated in the practice management system, which linked pop-up alerts to 
pre-selected files that appeared whenever the patient file was opened. In addition, the eligible patients were sent a letter explaining the value of screening for $\mathrm{CV}$ risk and inviting them for a risk assessment. CV-risk assessment had increased from $4.7 \%$ to $53.5 \%$ one year after implementation of the system change. Screening rates were higher in practices where nurses were responsible for the screening.

\section{Discussion}

The small number of studies that could be included in this systematic review shows that the development of effective strategies for the implementation of cardiovascular risk tables in primary prevention has been sparsely studied so far, and that our understanding of ways to speed up the uptake of such new tools remains limited. The most common type of strategy was organizational, involving methods like presenting $\mathrm{CV}$ risk on the front page of patients' files or as a laboratory facility, and pro-active screening by pop-up alerts on the computer screen with invitations sent to patients' homes for risk assessment. Patient-mediated implementation strategies have hardly been studied. Although no clear relation between a particular type of strategy and the success or failure of implementation was observed, promising strategies seemed to be those involving teamwork, nurse-led clinics and integrated IT support.

This review used a sensitive search, with language restricted to Dutch, English, and German publications. Although a restriction to randomized controlled trials is often desirable in systematic literature reviews, as it yields studies with the highest level of evidence, we chose to include non-controlled and quasicontrolled intervention studies as well, because of the expected low number.

Most of the studies we found do not seem to be theory-driven or problemdriven (i.e. tailored to barriers and facilitators), although in two studies, the strategy was guided by a systematic survey of barriers and facilitators before implementation was started ${ }^{20,23}$. Despite this, no effects were found in these studies. Apart from a qualitative process evaluation, there is a need for more in-depth qualitative methods, e.g. in-depth interviews or focus groups with health professionals, to increase our understanding of this lack of effect ${ }^{28}$. Ideally, this should be done along the lines of established planning models for implementation processes. It seems that insufficient attention has been given to the various phases in the process of change for care providers and teams $^{15,29}$.

Although the theories and models on organizational determinants of innovation of care processes overlap, and the empirical evidence behind their assumptions about human behavior or organizational change is limited, we 
tried to apply our findings to some of the many available theories. The Theory on Innovative Organizations tells us to take the type of organization into account. Decentralized decision making about innovations is crucial and good teamwork is one of the main keys for successful change. Process Reengineering Theory advises to focus on multidisciplinary care processes and collaboration instead of individual decision making. The theory aims to analyze and redesign the work process related to CVD prevention. The lessons learnt from this review, such as task delegation to a practice nurse and sending invitational letters to patients for screening, could be part of it. Theories on Organizational Culture stress that changes in the culture can stimulate changes in performance; more teamwork, flexibility and external orientation. Organizational Learning Theory advises to create conditions within the (practice) organization for continuous learning at all levels ${ }^{30}$.

Although financial incentives are an effective way of changing professional behavior, none of the studies we found used a financial incentive for the implementation of risk tables. It might be a powerful strategy, since most professionals might in the near future encounter financial incentives that are linked to the quality of care, as is already customary in the UK. Many indicators of the Quality and Outcomes Framework are related to prevention of CVD. It appears that significant health gains could result from achieving these quality targets ${ }^{31-34}$.

Ideally, implementation strategies should be tailored to support physicians' needs, and as such should be based on the problems they are actually facing ${ }^{15,29}$. We distinguished five needs related to CVD prevention, and propose recommendations for implementation based on the review:

1. Supporting physicians in the process of case-finding of potential high-risk patients.

This is an essential step in successful application of the risk tables. Active support can be provided by pop-up alerts linked to pre-selected files that appear whenever a patient file is opened. Letters sent to patients' homes, explaining the value of screening for CV risk and with an invitation for risk assessment, can further improve screening rates, especially in those practices with an established culture of practice-nurse led clinics and teamwork between the practice nurses and the GPs.

2. Supporting physicians in completing the risk profile.

A CDSS proved to be effective only when the decision support system was integrated in the practice management system.

3. Supporting physicians in calculating the risk.

Most of the studies promoted the use of a risk table, either paper-based or computerized, for risk calculation. The main problem seemed to be the actual use of the risk calculation tools, which many of the physicians failed to do. Initially, it was suggested that risk tables would be useful for 
clinicians to help them master concepts relating to CHD prevention, i.e. as a kind of educational tool rather than a practice instrument for risk calculation and management. ${ }^{35}$ Since nurses are likely to be the future consumers $^{3}$, GPs could be supported by nurses in this task.

Presenting the actual risk to the GPs, e.g. by indicating the risk on the front page of patients' files, only had a minor effect on physicians' behavior in terms of prescribing CV drugs. Nevertheless, confronting GPs with their patients' actual risk may have corrected their misperceptions and could as such help to generate a better performance, as misperception of cardiovascular risk is not uncommon among health professionals ${ }^{1,10,22,36-38}$.

4. Supporting physicians in risk communication.

Once the risk has been calculated the next challenge is how to present it in an effective way. Most patients have a hard time understanding CVD risks $^{39,40}$. Perception of risks tends to be inaccurate and people find it difficult to handle risks ${ }^{41}$. The format (framing) in which risk information is presented affects people's perception of risks and decision-making ${ }^{42}$. For example, framing in relative risk or loss framing are more persuasive compared to framing in absolute risk or gain framing respectively. This is reported for doctors, ${ }^{43}$, and patients ${ }^{44-46}$. Risk communication should include weighing up of risks and benefits of a treatment choice, and address the patient's perception of probability of an event as well as the value of the event for that individual ${ }^{44}$. To achieve this, health professionals need training to increase their competences in risk communication.

5. Supporting physicians in deciding, jointly with the patient, on appropriate action for management.

The use of a computerized decision support system to help physicians decide on appropriate management may result in some small favorable effects on prescribing behavior and blood pressure. So far, involving patients in the decision on appropriate management with the help of educational materials (including the risk table) has had no effect. Although patient involvement seems to be an effective prevention strategy, it is still unclear how this can be achieved ${ }^{47,48}$. A successful strategy might be to delegate this task to a nurse or health coach, who has more time to explain $\mathrm{CV}$ risk and for patient involvement in decisions on management and follow-up ${ }^{49-51}$. Such a strategy is a subject of research in the current IMPALA trial (ISRCTN51556722), in which a risk communication tool and a decision aid are issued to patients for preparation at home, and in which the practice nurse applies an adapted motivational interviewing technique to discuss the risk and options for risk reduction (see www.trialregister.nl). 


\section{Conclusion}

Effective primary prevention of cardiovascular diseases is not easy, and research on effective strategies for the implementation of risk tables has been sparse. Nevertheless, good teamwork, nurse-led clinics, and smart software programs, integrated in the practice management system, seem to be promising strategies for patient selection and risk assessment. Achieving patient involvement, a precondition for successful CV-risk management, is a challenge for future research that, together with the development of other professional- and organization implementation strategies, needs to be embedded in the methodology of implementation science. 


\section{References}

1. Graham IM, Stewart M, Hertog MG. Factors impeding the implementation of cardiovascular prevention guidelines: findings from a survey conducted by the European Society of Cardiology. Eur J Cardiovasc Prev Rehabil 2006;13:839-45.

2. Sheridan S, Pignone M, Mulrow C. Framingham-based tools to calculate the global risk of coronary heart disease: a systematic review of tools for clinicians. J Gen Intern Med 2003;18:1039-52.

3. Will CM. Arguing about the evidence: readers, writers and inscription devices in coronary heart disease risk assessment. Soc Health and Illn 2005;27:780-801.

4. Conroy RM, Pyörälä K, Fitzgerald AP, Sans S, Menotti A, De Backer G, De Bacquer D, Ducimetière $P$, Jousilahti $P$, Keil $U$, Njølstad I, Oganov RG, Thomsen T, Tunstall-Pedoe $H$, Tverdal A, Wedel H, Whincup P, Wilhelmsen L, Graham IM; SCORE project group. Estimation of ten-year risk of fatal cardiovascular disease in Europe: the SCORE project. Eur Heart J 2003;24:987-1003.

5. Thomas S, van der Weijden T, van Drenth BB, Haverkort AFM, Hooi JD, van der Laan JD. NHG-Standaard Cholesterol (eerste herziening). Huisarts Wet 1999;42:406-17.

6. Brindle P, Beswick A, Fahey T, Ebrahim S. The accuracy and impact of risk assessment in the primary prevention of cardiovascular disease: A systematic review. Heart 2006;92: 1752-59.

7. Wang TJ, Gona P, Larson MG, Tofler GH, Levy D, Newton-Cheh C, Jacques PF, Rifai N, Selhub J, Robins SJ, Benjamin EJ, D'Agostino RB, Vasan RS. Multiple biomarkers for the prediction of first major cardiovascular events and death. N Engl J Med 2006;355:2631-9.

8. de Koning JS, Klazinga NS, Koudstaal PJ, Prins A, Dippel DW, Heeringa J, Kleyweg RP, Neven AK, Van Ree JW, Rinkel GJ, Mackenbach JP. Quality of care in stroke prevention: results of an audit study among general practitioners. Prev Med 2004;38:129-36.

9. Eaton CB, Galliher JM, McBride PE, Bonham AJ, Kappus JA, Hickner J. Family physician's knowledge, beliefs, and self-reported practice patterns regarding hyperlipidemia: a National Research Network (NRN) survey. J Am Board Fam Med 2006;19:46-53.

10. De Muylder R, Lorant V, Paulus D, Nackers F, Jeanjean M, Boland B. Obstacles to cardiovascular prevention in general practice. Acta Cardiol 2004;59:119-25.

11. Torley D, Zwar N, Comino EJ, Harris M. GPs' views of absolute cardiovascular risk and its role in primary prevention. Aust Fam Physician 2005;34:503-4, 7.

12. Grimshaw J, McAuley LM, Bero LA, Grilli R, Oxman AD, Ramsay C, Vale L, Zwarenstein M. Systematic reviews of the effectiveness of quality improvement strategies and programmes. Qual Saf Health Care 2003;12:298-303.

13. Grol R. Beliefs and evidence in changing clinical practice. BMJ 1997;315:418-21.

14. Grol R. Improving the quality of medical care: building bridges among professional pride, payer profit, and patient satisfaction. JAMA 2001;286:2578-85.

15. Grol R, Grimshaw J. From best evidence to best practice: effective implementation of change in patients' care. Lancet 2003;362:1225-30.

16. Shaw B, Cheater F, Baker R, Gillies C, Hearnshaw H, Flottorp S, Robertson N. Tailored interventions to overcome identified barriers to change: effects on professional practice and health care outcomes. Cochrane database of systematic reviews Online Update Software ISE: 1469 493X 2005:Cd005470.

17. Hall LM, Jung RT, Leese GP. Controlled trial of effect of documented cardiovascular risk scores on prescribing. BMJ 2003;326:251-2.

18. Jacobson TA, Gutkin SW, Harper CR. Effects of a global risk educational tool on primary coronary prevention: the Atherosclerosis Assessment Via Total Risk (AVIATOR) study. Curr Med Res Opin 2006;22:1065-73.

19. Hetlevik I, Holmen J, Kruger O. Implementing clinical guidelines in the treatment of hypertension in general practice. Evaluation of patient outcome related to implementation of a computer-based clinical decision support system. Scand J Prim Health Care 1999;17:35-40. 
20. Fretheim A, Oxman AD, Havelsrud K, Treweek S, Kristoffersen DT, Bjorndal A. Rational Prescribing in Primary care (RaPP): a cluster randomized trial of a tailored intervention. PLoS Med 2006;3:e134.

21. Montgomery AA, Fahey T, Peters TJ, Maclntosh C, Sharp DJ. Evaluation of computer based clinical decision support system and risk chart for management of hypertension in primary care: randomised controlled trial. BMJ 2000;320:686-90.

22. Peters TJ, Montgomery AA, Fahey T. How accurately do primary health care professionals use cardiovascular risk tables in the management of hypertension? $\mathrm{Br} \mathrm{J}$ Gen Pract 1999;49:987-8.

23. van Steenkiste B, van der Weijden T, Stoffers HE, Kester AD, Timmermans DR, Grol R. Improving cardiovascular risk management: a randomized, controlled trial on the effect of a decision support tool for patients and physicians. Eur J Cardiovasc Prev Rehabil 2007;14: 44-50.

24. Sinclair G, Kerr A. The Bold Promise Project: a system change in primary care to support cardiovascular risk screening. N Z Med J 2006;119:U2312.

25. Hetlevik I, Holmen J, Kruger O, Kristensen P, Iversen H, Furuseth K. Implementing clinical guidelines in the treatment of diabetes mellitus in general practice. Evaluation of effort, process, and patient outcome related to implementation of a computer-based decision support system. Int J Technol Assess Health Care 2000;16:210-27.

26. De Muylder R, Tonglet R, Nackers F, Boland B. Randomised evaluation of a specific training of general practitioners in cardiovascular prevention. Acta Cardiol 2005;60:199-205.

27. Ford DR, Walker J, Game FL, Bartlett WA, Jones AF. Effect of computerized coronary heart disease risk assessment on the use of lipid-lowering therapy in general practice patients. Coronary Health Care 2001;5:4-8.

28. Fretheim A, Havelsrud K, Oxman AD. Rational Prescribing in Primary care (RaPP): process evaluation of an intervention to improve prescribing of antihypertensive and cholesterollowering drugs. Implement Sci 2006;1:19.

29. Grol R, Wensing M. What drives change? Barriers to and incentives for achieving evidencebased practice. Med J Aust 2004;180:S57-60.

30. Grol RP, Bosch MC, Hulscher ME, Eccles MP, Wensing M. Planning and studying improvement in patient care: the use of theoretical perspectives. Milbank Q 2007;85:93-138.

31. Roland M. Linking physicians' pay to the quality of care--a major experiment in the United kingdom. N Engl J Med 2004;351:1448-54.

32. Sutton M, McLean $G$. Determinants of primary medical care quality measured under the new UK contract: cross sectional study. BMJ 2006;332:389-90.

33. McElduff $P$, Lyratzopoulos $G$, Edwards R, Heller RF, Shekelle $P$, Roland M. Will changes in primary care improve health outcomes? Modelling the impact of financial incentives introduced to improve quality of care in the UK. Qual Saf Health Care 2004;13:191-7.

34. Campbell S, Reeves D, Kontopantelis E, Middleton E, Sibbald B, Roland M. Quality of primary care in England with the introduction of pay for performance. $\mathrm{N}$ Engl J Med 2007;357:181-90.

35. Jackson R, Beaglehole R. Evidence-based management of dyslipidaemia. Lancet 1995;346: 1440-2.

36. Frijling BD, Lobo CM, Keus IM, Jenks KM, Akkermans RP, Hulscher ME, Prins A, van der Wouden JC, Grol RP. Perceptions of cardiovascular risk among patients with hypertension or diabetes. Patient Educ Couns 2004;52:47-53.

37. Van der Weijden T, Steenkiste van B, Stoffers HE, Timmermans D, Grol R. Primary prevention of cardiovascular diseases in general practice; mismatch between cardiovascular risk and patients' risk perceptions. Med Decis Making 2007;27:754-61

38. Mosca L, Linfante AH, Benjamin EJ, Berra K, Hayes SN, Walsh BW, Fabunmi RP, Kwan J, Mills T, Simpson SL. National study of physician awareness and adherence to cardiovascular disease prevention guidelines. Circulation 2005;111:499-510.

39. Erhardt L, Hobbs FD. Public perceptions of cardiovascular risk in five European countries: the react survey. Int J Clin Pract 2002;56:638-44. 
40. van Steenkiste B, van der Weijden T, Timmermans D, Vaes J, Stoffers J, Grol R. Patients' ideas, fears and expectations of their coronary risk: barriers for primary prevention. Patient Educ Couns 2004;55:301-7.

41. Elwyn G, Edwards A, Eccles M, Rovner D. Decision analysis in patient care. Lancet 2001;358:571-4.

42. Timmermans D, Molewijk B, Stiggelbout A, Kievit J. Different formats for communicating surgical risks to patients and the effect on choice of treatment. Patient Educ Couns 2004;54:255-63.

43. Rakow T. Differences in belief about likely outcomes account for differences in doctors' treatment preferences: but what accounts for the differences in belief? Qual Health Care 2001;10 Suppl 1:i44-9.

44. Edwards A, Elwyn G, Covey J, Matthews E, Pill R. Presenting risk information--a review of the effects of "framing" and other manipulations on patient outcomes. Health Commun 2001;6:61-82.

45. Feldman Stewart D, Kocovski N, McConnell BA, Brundage MD, Mackillop WJ. Perception of quantitative information for treatment decisions. Medical decision making an international journal of the Society for Medical Decision Making 2000;20:228-38.

46. Lipkus IM, Klein WM, Rimer BK. Communicating breast cancer risks to women using different formats. Cancer Epidemiol Biomarkers Prev 2001;10:895-8.

47. Edwards A, Elwyn G. The potential benefits of decision aids in clinical medicine. JAMA 1999;282:779-80.

48. Edwards A, Unigwe S, Elwyn G, Hood K. Personalised risk communication for informed decision making about entering screening programs. Cochrane Database Syst Rev 2003:Cd001865.

49. Vale MJ, Jelinek MV, Best JD, Dart AM, Grigg LE, Hare DL, et al. Coaching patients On Achieving Cardiovascular Health $(\mathrm{COACH})$ : a multicenter randomized trial in patients with coronary heart disease. Arch Intern Med 2003;163:2775-83.

50. Edelman D, Oddone EZ, Liebowitz RS, Yancy WS Jr, Olsen MK, Jeffreys AS, Moon SD, Harris AC, Smith LL, Quillian-Wolever RE, Gaudet TW. A multidimensional integrative medicine intervention to improve cardiovascular risk. J Gen Intern Med 2006;21:728-34.

51. Sol BG, van der Bijl JJ, Banga JD, Visseren FL. Vascular risk management through nurse-led self-management programs. J Vasc Nurs 2005;23:20-4. 



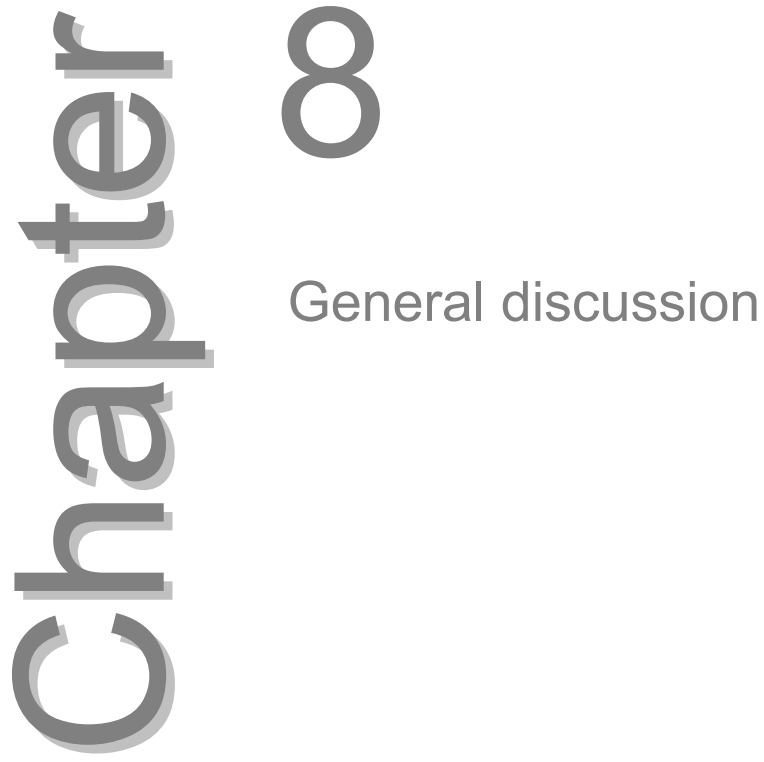




\section{General discussion}

\section{Outline of the study}

Primary prevention of cardiovascular diseases (CVD) is seen as an important strategy to delay their onset, and is recommended in national and international guidelines on CVD management ${ }^{1-4}$. The 1999 guideline on cholesterol by the Dutch College of General Practitioners (DCGP) incorporated risk tables for the calculation of individualised CVD risk. It was the first guideline in the Netherlands to include such a 'risk table', introducing a new approach to the prevention of CVD (Box 1.1) $)^{4}$. The risk table showed the (10-year) absolute risk of fatal and non-fatal acute myocardial infarction for individuals not previously suffering from CVD. It also provided options for decisions on multiple risk management such as drug treatment, life-style change or reassurance. ${ }^{*}$

Since we knew that 'simple' diffusion and dissemination of the guideline and risk tables would not result in sufficient change in clinical practice, it was our aim to develop and test a strategy to improve the adoption of the recommendations of the guideline and the risk tables by professionals. A crucial precondition for the development of effective implementation strategies is a systematic survey of the barriers preventing their adoption. We therefore examined the barriers that prevent GPs from adopting the guideline and risk tables, and the barriers that impede effective communication with patients about cardiovascular risk and prevention. We also investigated how often GPs were confronted with inappropriate risk perceptions or anxiety, because a mismatch between patients' actual cardiovascular risk and their risk perceptions might lead to conflicts between the GPs' intended management and patients' expectations.

Guided by the results of the survey of barriers, we developed an implementation strategy centring on the use of a decision support tool for both GPs and patients. In a cluster RCT, we evaluated whether the decision support tool had favourable effects on the physicians' performance in terms of the key recommendations of the cholesterol guideline, as well as on the patients' risk

\footnotetext{
* The revised guideline on cholesterol, published in 1999, holds a central position in this thesis. It describes the recommendations and targets for professional performance. Meanwhile, an update to the 1999 guideline has recently been published, describing the concept of Cardiovascular Risk Management (CVRM) and establishing a complete integration of the previous single risk factor guidelines on hypertension and cholesterol ${ }^{5}$. The 1999 cholesterol guideline could be regarded as a forerunner of the 2006 CVRM guideline, as the single risk factor perspective was already shifting towards the multiple risk factor perspective in 1999.
} 
perceptions, which in turn might lead to a healthier lifestyle. In fact we tried to introduce two new features at the same time. First, the implementation of the CVD risk tables. An innovation that demanded new skills of the GPs' that had to be thoroughly exercised in order to become part of GPs' normal practice. Second, the use of a decision support tool by patients, a proven strategy to help them gain insight in their CVD risk profile, and decide about risk reducing lifestyle. Both aspects were evaluated in the trial. In the intervention arm of the trial, we also evaluated the patients' responsiveness to the innovative decision support tool. Finally, we described, by means of a systematic review of the literature, the current state of affairs as regards the implementation of CVD risk tables, in order to recommend effective implementation strategies for appropriate application in the context of cardiovascular risk management (CVRM).With the review we aimed to reflect on what others had done on the implementation of CVD risk tables in the light of the results of our study.

\section{Results}

A qualitative survey of the barriers to cardiovascular prevention, obtained by interviewing GPs and patients, revealed 25 barriers identified by the GPs as being specific to CVRM, some of which are mentioned here. Barriers were related to the guideline and the risk table itself, to the GPs' competencies or to the patients' expectations. The risk table was regarded as difficult to understand and respondents called into question its value as a supportive tool for health education or shared decision-making. The cost-effectiveness considerations incorporated in the risk table were not seen as relevant to the doctor's task. Moreover, GPs perceived their skills in getting patients to change their lifestyle as very limited. A final major barrier that was identified was that patients are becoming more demanding as a result of the impact of mass media that mainly focus on emotions rather than on facts.

Interviewing patients who had recently consulted a GP on primary prevention of CVD yielded better insights into patients' ideas, fears and expectations related to cardiovascular diseases. Lack of understanding among patients of the cardiovascular risk factors and the concept of the integrated cardiovascular risk profile appeared to be major barriers hampering GPs in their attempts to provide effective CVRM. Mismatches between perceived risk and actual risk were found in nearly one-third of the patients who participated in our cluster $\mathrm{RCT}$; $28 \%$ were either too optimistic or too pessimistic relative to absolute probability perception. Whereas age or socioeconomic status did not determine the inappropriateness of perceptions, men and patients with diabetes underestimated their 10-year risk of CVD. To our surprise, diabetes and a positive family history of CVD were not determinants of high perceived risk. 
Others have reported similar underestimations of perceived risk for persons at high risk of developing diabetes ${ }^{6}$.

The application of an innovative decision support tool, part of a broad implementation strategy for the cholesterol guideline, was evaluated in a cluster RCT. No significant effect was found on the GPs' performance regarding key recommendations of the guideline. Although risk classification tended to be more appropriate among the GPs in the intervention group, this was not significantly different compared to the control group. No significant effects were observed either as regards patients' risk perception. There was a reduction in anxiety over time that was somewhat larger in the intervention group, but this difference was too small to be significant. After six months, more men in the intervention group had stopped smoking, and significantly more patients in the intervention group had increased their self-reported physical activity compared to those in the control group.

Patients' response to the decision support tool was fair to good. Most patients did return for a second consultation to discuss their CVD risk, as intended. Their understanding of the risk table and the risk factors was fairly good. The information in the decision support tool was perceived as relevant and reassuring. However, the subgroup of patients who did not return did appear to have lower scores on understanding. In addition, it proved to be difficult for GPs to adhere to the interventions of the implementation strategy: cardiovascular risk was not always discussed and in about $15 \%$ of the cases, the patient was not invited for a second consultation.

Our systematic review of effective implementation strategies for the use of cardiovascular risk tables in CVD prevention included only 9 studies, covering three types of implementation strategies. Reported effects were moderate, sometimes conflicting and contradictory. Although no clear relation was observed between a particular type of strategy and the success or failure of the implementation, promising strategies for patient selection and risk assessment seem to be teamwork, nurse led-clinics and integrated information technology support.

\section{Discussion}

\section{Barriers to the use of risk tables in daily practice}

Risk tables are intended to rationalise the identification and management of people at high risk of CVD. The feasibility of risk tables remains unproven, since we identified many barriers to adherence to the risk table in the Dutch cholesterol guideline and its recommendations.

In discussions by GPs with patients on the various options for intervention, the risk table raised many questions, with the integrated cost-effectiveness 
considerations in particular hampering the GPs' work. The risk tables in the new CVRM guideline use a different outcome. Instead of figures on morbidity, the outcome in the risk table is now cardiovascular mortality. These figures are generally low, and the health gain achieved by adopting a healthier lifestyle is even smaller. This may represent a new barrier to the appropriate use of the risk tables as an instrument that could help GPs in their risk communication to motivate people to adopt a healthy lifestyle ${ }^{5}$.

Inadequate risk communication skills were not reported as a barrier by the GPs themselves, but were observed in the audiotaped consultations. GPs need training in risk communication, since this is increasingly acknowledged to be part of modern medicine and everyday practice. Patients want to know their 'numbers', and because GPs have an important role in informing their patients, they have to be aware how risks are perceived and understood by their patients $^{7}$. In addition, GPs have to become familiar with the various ways of framing risks, with effective ways of communicating options for risk reducing strategies, and with the use of decision support tools for patients ${ }^{8-12}$. Barriers relating to the GPs' attitude and the difference between primary and secondary care $^{13}$, as well as to differences in practice organisation, have also been reported by others ${ }^{14,15}$. Time constraints were indeed identified as one of the major 'professional-related' barriers ${ }^{16}$ as complying with all guidelines on primary prevention would take several hours a day ${ }^{17}$.

\section{Patients' ideas, fears and expectations}

Information expectations varied among patients, as some were not interested or already well-informed. Some patients were both well-informed and motivated to reduce their CVD risk, but did not know how to change their lifestyle. However, most patients expressed a need for more information, and there are indications in the medical literature that patients also wish to participate in decision-making $^{18}$. Moreover, it is not easy to explain cardiovascular risk to patients with the help of a risk table. Apart from its presentation, risk perception is influenced by many factors, such as experience of disorders in the family, age, sex, locus of control, etc. ${ }^{19,20}$. The perceived risk of a heart attack is also often experience-based and determined by recalling such occurrences among friends or relatives. People often evaluate a risk in terms of how easily they can recall past examples or how easily they can imagine such occurrences ${ }^{21,22}$.

It was rather striking that many persons had a dichotomous (risk/no-risk) rather than a continuous perception of the concept of risk, a finding also found for prenatal screening, where the perception of many counselees could often be characterised as a 'binary perception' process ${ }^{23,24}$. People seem to translate numeric risks into categories in order to make the information usable, and show a wide variety of interpretations ${ }^{25}$. 
The scores on the comparative evaluation of cardiovascular risk ( $2.9 \pm 0.6$ on a 5-point scale: 1 much smaller, 3 equal, 5 much larger) that we found in our study could be labelled as 'unrealistic optimism, ${ }^{26}$, one of the defensive biases in perceiving risk information ${ }^{27}$. Many people tend to estimate the risk that they will develop a disease as lower than the risk for a comparable other person ${ }^{26,28}$. The magnitude of this unrealistic optimism (i.e. the difference between risk estimates for oneself and for others) varies, but is particularly large for diseases that are believed to be preventable by individual action. People may thus underestimate their risk, but overestimation is also possible, and GPs have to be aware of this: their risk communication should focus on neutralising the risk perception and patient expectations that are often inflated by the mass media. Empowering patients by preparing them for the consultation with educational materials that do not induce fear could help patients correct their misperceptions and enhance involvement during the consultation ${ }^{29,30}$.

Interventions aimed at patients to improve doctor-patient communication are often successful in increasing patient participation, and have been found to lead to a greater sense of control and preference for a more active role in consultations. What forms of intervention are most successful in what contexts is still not known, although intensive face-to-face interventions seem more effective than written interventions ${ }^{31}$. Consultations with increased patient participation, as evidenced by patients asking questions and GPs offering guidance in checking understanding, are often rated as 'good consultations' by GPs. This could increase GPs' perceived effectiveness in changing patient behaviour, which in turn is associated with improved preventive care efforts by patients $^{32,33}$.

\section{Implementation of the guideline and risk tables: findings from our trial}

Contrary to our expectations of the innovative intervention, we found no substantial changes in GPs' performance as regards CVRM. In developing the intervention, we tried to address the most important barriers, and used strategies that had proved to be effective ${ }^{34,35}$. Initially, we looked at the 'intervention mapping' approach as a method to develop the implementation strategies. Intervention mapping is composed of five steps: (1) creating a matrix of proximal programme objectives, (2) selecting theory-based intervention methods and practical strategies, (3) designing and organising a programme, (4) specifying adoption and implementation plans and (5) generating programme evaluation plans ${ }^{36}$. For steps 3 and 4 , we would have had to gather information from each GP on (1) their knowledge about the guideline, the risk table, and risk communication; (2) their attitude towards CVD prevention and guidelines on CVD prevention; (3) their skills in risk communication and presentation; (4) their consultation style; (5) their selfefficacy regarding CVD prevention; (6) their preferred learning style for theory 
and skills, etc. Based on this information, a highly tailored intervention strategy based on GP preferences could then have been built, which could have resulted in more than 40 different programmes. Although we recognise the rationale of this method, it did not seem feasible in our project because of a lack of resources (time, staffing and money). The tailoring aspect in our study was reflected by our investigation into barriers that were perceived as important and modifiable and that could be managed at group level within our range of capabilities.

Lack of knowledge was addressed by a combination of different approaches. The first approach worked at an individual level, featuring a training programme for the cholesterol guideline (PIN-Cholesterol) disseminated via the Dutch College of General Practitioners. Completion of this individual knowledge training programme before the start of the trial was rewarded by accreditation points. During our 4-hour small group training sessions, knowledge was addressed again in interactive small group sessions using real-life vignettes. A counselling expert used role-play to train the GPs in risk communication skills and in presenting a patient with the decision support tool with the instruction to read this at home and return for a second consultation for shared decision making. A video of a simulated consultation was used as an example of how the decision support tool could be used to enhance patient involvement and even to facilitate shared decision-making. This process of shared decision making was guided by the Ottawa Decision Support Framework (ODSF), which facilitates the development of interventions to support health decision making in a context of uncertainty. Compared to usual care or simpler information leaflets, decision support interventions based on the ODSF performed better with patients in terms of greater knowledge, more realistic expectations, lower decisional conflict and greater agreement between values and choices. To achieve all these favourable outcomes, however, much more investment is required than a 4-hour training session. We had clearly been too optimistic, and the implementation of the ODFS came after our intervention and is still hampered by many barriers at various levels ${ }^{37}$.

During the training, the GPs welcomed the decision support tool as something they had lacked so far. Nevertheless, it seems that we may have made life more complicated for the GPs. What we tried to do is introduce two new features at the same time. The first was the application of the high-risk approach by using the risk tables, and the second was the use of a decision support tool that, in our view, demanded a different approach to patient care by spreading it over two consultations instead of one. Apparently, this is quite a complex innovation and our implementation strategy, consisting of a 4-hour training session, may not have been powerful enough to meet this implementation challenge. 
More intensive training of GPs in patient involvement and the use of decision support tools seems advisable but is no guarantee for success ${ }^{12,38-41}$. Since pressure of time is an important barrier to the use of the decision support tools $^{42}$, the use of additional supportive staff, e.g. practice nurses instead of GPs, seems a more promising approach to cardiovascular prevention in primary care ${ }^{43,44}$. On the other hand, it is known that delegating such tasks to practice nurses can also have its drawbacks; for instance, most practices in the USA cannot afford to dedicate staff time to patient counselling or to fund training ${ }^{45}$.

We did not find any effect of the intervention on patients' risk perception, nor did we observe fear being induced. They seemed eager to learn or become involved: more than $80 \%$ of the invited patients returned to discuss their risk. Nevertheless, this did not result in a more realistic risk perception, as has also been found by others ${ }^{46}$. More attention for GPs' risk communication skills could have helped here. GPs have to become familiar with different ways and means of presenting risk. Patients were found to prefer natural frequencies and different ways of framing, including uncertainty and the use of population diagrams are currently not commonly used in daily practice ${ }^{10,12,47}$ where risk is more often presented as a percentage, single-event frequency, relative risk, or narratives, formats that may be misunderstood ${ }^{12,48,49}$.

In our trial we tried to implement the high-risk approach for primary CV prevention. We did not question this approach in itself although it is still questioned and might have attributed to the barriers we encountered. Basing treatment decisions on predetermined levels of risk score maximizes efficient use of limited resources. It implies fairness in ensuring equitable distribution of limited resources. However, the risk based approach as advocated in current guidelines favours the patients at high risk (elderly, smokers); each averted death has the same 'weight'. Contrarily, the health economist approach, adopted by the British National Institute for Health and Clinical Excellence (NICE), maximizes the life-years gained (time-based) which implies inequivalence of death at different ages and as such favours the young, nonsmokers, with a normal bodyweight, and a high SES ${ }^{50}$. This inequity is further enhanced by the risk tables since social deprivation is not included in the risk assessment, and - as it appeared from our study - patients from lower SES did respond less well to the decision aid compared to middle and higher SES. Most risk tables are based on the Framingham risk function which overestimates CVD risk in the high SES group compared to the low SES resulting in relative under use of treatment in the low SES group. Adding social deprivation as a risk factor could restore equity between social groups ${ }^{51-55}$.

Generally spoken, apart from the two different approaches, risk-based or timebased, it is said that new health programs always tend to increase inequity since they will initially reach those who are already better off ${ }^{56}$. However, 
epidemiological data on health indicators for children in the US indicates that the timing factor is essential in the interpretation of the equity impact of new technologies. It seems that after an initial increase of inequity - when the wealthy quickly reach a certain level of improvement -the poor begin to catch up and the inequity gap begins to decrease ${ }^{57}$.

\section{Patients' responsiveness}

All patients read the booklet, their comprehension of the risk factors and risk tables was fair to good, and the majority perceived the information as relevant and reassuring. Those who returned for the second consultation and patients with a medium SES had the best understanding of the booklet. The returnees also felt more reassured. Surprisingly, this positive response of the patients was not reflected in more appropriate risk perception. This could be due to the quality of the booklet. Recently, 12 quality criteria for patient support technologies (decision aids) have been established by the International Patient Decision Aids Standards (IPDAS) Collaboration (www.ipdas.ohri.ca). In our opinion, our booklet satisfied the criteria on information having to be based on up-to-date evidence, as well as those on the systematic development process, including disclosing conflicts of interest, and those on the use of plain language. Our booklet probably met the criteria on providing information about options and presenting probabilities, although the risk figures were only presented in the form of natural frequencies and not visualised in population diagrams. We may not have fully satisfied the criteria on balancing the presentation of options and establishing effectiveness. The decision aid did not clarify and express values. Although guiding or coaching patients in their deliberations was addressed in the 4-hour training session for the GPs, this was not sufficient. Overall, the quality of the first booklet was sufficient, though it needs to be revised using the IPDAS checklist for appraising the quality of decision aids ${ }^{58}$. We recognise that one of the limitations of the decision support tool is its use for patients of lower socioeconomic status and foreign patients, who often live in socially deprived areas and often have a high cardiovascular risk.

The process evaluation of our implementation strategy showed that patients' failure to return was sometimes due to the GPs' failure to instruct them in the proposed way, missing an opportunity for more sustained patient involvement in the discussion and decisions. We are aware, however, that adopting a new approach to improve the quality of care is often hard in daily practice routine, especially in primary care, resulting in underuse of interventions ${ }^{59}$. 


\section{Implementation: lessons from the literature}

The development of effective strategies for the implementation of cardiovascular risk tables in primary prevention has so far been sparsely studied. The most common type of strategy used so far is organisational, involving methods like presenting CVD risk on the front page of patients' files or as a laboratory facility, and pro-active screening by pop-up alerts on the computer screen. Patient-mediated implementation strategies have hardly been studied.

Most of the studies we found do not seem to be theory-driven or problemdriven (i.e. tailored to barriers and facilitators), although studies whose strategy was guided by a systematic survey of barriers and facilitators before the start of implementation often found no effects either ${ }^{60,61}$. There is a need for more indepth qualitative methods, e.g. in-depth interviews or focus groups with health professionals, to increase our understanding of this lack of effect ${ }^{62}$. Ideally, this should be done along the lines of established planning models for implementation processes ${ }^{63,64}$.

Although financial incentives are an effective way of changing professional behaviour, none of the studies we found used a financial incentive for the implementation of risk tables. It might be a powerful strategy, since most professionals might in the near future well be faced with financial incentives that are linked to the quality of care, as is already customary in the UK. Many indicators of the Quality and Outcomes Framework are related to prevention of CVD, and it appears that significant health gains could result from achieving these quality targets ${ }^{65-67}$.

\section{Methodological considerations}

The 15 GPs who took part in our investigation of the barriers to cardiovascular prevention were interviewed at their surgeries. They differed in terms of major personal and practice characteristics. The data saturation indicated that we seemed to have covered all the relevant barriers perceived by GPs when working with the guideline. To test the credibility and trustworthiness of our findings, we presented our barriers in a questionnaire to a representative sample of Dutch GPs $(n=500)$, asking them to rate on a 5-point scale the importance of each barrier to CVD prevention according to the cholesterol guideline and risk table. Unfortunately, our triangulation method failed ${ }^{68,69}$, as the survey arrived in the middle of a conflict between the government and the GPs about wages and working hours. The response, $28 \%$, was too low to allow conclusions about the weight of each barrier to the prevention of CVD.

We investigated both rational aspects (probability perception) and emotional aspects (anxiety) of patients' perceived risk ${ }^{70,71}$. As regards anxiety, we first considered using the Spielberger State-Trait Anxiety Inventory (STAI), an instrument to measure anxiety in adults. The STAI clearly differentiates 
between the temporary condition of 'state anxiety' and the more general and long-term quality of 'trait anxiety', and helps professionals distinguish between a client's feelings of anxiety and depression ${ }^{72,73}$. For our purpose, however, the 40-item STAI was regarded as 'overkill' and as not useful to measure worry, the other concept of interest.

The effectiveness trial reflected real practice conditions. Most of the GPs had a special interest in cardiovascular prevention, which ensured a positive attitude and performance and meeting the minimal organisational conditions. CVD prevention was discussed in $50 \%$ of the first consultations at the GPs' initiative. The same was found for intervention and controls, returnees and nonreturnees, minimising selection bias. Moreover, the intra-class correlation coefficient (ICC) was low: 0.00-0.04.

The GPs only managed to include about half the number of patients we had envisaged, reducing the study's power to detect small but relevant differences ${ }^{74}$. When we started to recruit GPs for our trial, we addressed most of the barriers to and facilitators of research in general practice. Therefore it is difficult to say why the initial response was insufficient. In any case, it forced us to substantially enlarge our recruitment area, which in turn complicated the logistic management of the trial. We would perhaps have been more successful if we had approached regional GP groups or GPs in existing research networks. The reason for the low patient inclusion rate by the GPs could be: (a) the fact that the inclusion and exclusion criteria were simple but apparently hard to implement in daily practice, (b) the fact that GPs had to be constantly aware of the study during consultations, (c) the patients had to be informed about the existence of the study by the GP and not by a mailed letter signed by their GP. The last two of these factors are regarded as especially important barriers to success. Despite our awareness of these problems, Lasagna's law still holds in Dutch primary care research ${ }^{75,76}$.

Since the decision support tool was well accepted by the patients, this study may have underestimated the potential effect of the intervention on the outcome. This could be due to a lack of power or because we failed to measure the right outcome to evaluate the effect of the tool. We considered measuring patients' level of satisfaction with the consultations (i.e., patient enablement) by means of the Patient Enablement Inventory (PEI) ${ }^{77}$, or assessing decisional conflict with the Decisional Conflict Scale (DSC) ${ }^{78}$. Whereas we regarded the scope of the PEI as too narrow for our purpose, that of the DSC seemed better, as it assesses the domains of feeling informed, clarification of values, support, uncertainty and effective decision making. However, the DSC seemed inappropriate for CVD prevention because decisions regarding CVD are made in the course of time and are not always very obvious, in contrast to the treatment of patients with cancer, where patients are ill and a decision about various treatment options has to be made. With hindsight, we probably should 
have used a process measure. A well-known new instrument for measuring the process of patient involvement is OPTION, which is based on scoring audiotaped or videotaped consultations ${ }^{79}$. Another instrument is COMRADE, a patient-based outcome measure including items on satisfaction with the information and on patient enablement, but specifically designed to evaluate the effectiveness of risk communication and treatment decision making in consultations $^{80}$.

\section{Implications for practice}

There is no doubt that primary cardiovascular prevention by reducing risk factors is an effective strategy to reduce mortality from coronary heart disease. Since primary prevention has a fourfold greater impact than secondary prevention, it is definitely worthwhile to try and improve it through further research ${ }^{81}$. Although there may be little doubt that primary prevention ought to be embedded in primary care, one may question whether primary prevention is a doctor's task.

A practice nurse performing consultations in a coaching manner (nurse-led clinics) might be better skilled for this task, so delegating it to a practice nurse who is trained to diagnose and treat persons at high risk according to the CVRM guideline and under the responsibility of a GP could be beneficial to both patients and GPs. In this approach, the role of the GP is that of expert, manager, trainer/coach of the practice nurse and monitoring the quality of the CVD prevention in his or her practice.

Management has to do with organising support for the practice nurse in identifying patients at high risk (case-finding), for example by pop-up alerts in the practice management system or by actively inviting patients for risk assessment ${ }^{82}$. In addition, the practice nurse needs to be supported in recording risk factors, risk assessment and risk calculation. The practice management system will have to be adjusted to facilitate risk factor recording and monitoring the quality of the CVD prevention. Depending on the quality of the CVD prevention at the introduction of nurse-led clinics, various quality indicators could be chosen, e.g. risk factor recording or treatment goals for clinical parameters such as blood pressure, cholesterol, etc., but also the quality of the nurse's health counselling, which could be assessed by observation or feedback on videotaped or audiotaped consultations.

The GP will have to ascertain that the practice nurse has sufficient knowledge and skills to run a CVD prevention clinic. This will nearly always involve additional training of the practice nurse on medical issues in the CRVM guideline and adjustments in individual practices. The practice nurse will need to be skilled not only in the medical aspects, but also in lifestyle counselling, and will have to be equipped with educational materials to support risk 
communication and risk presentation. Motivational Interviewing (MI) seems a promising technique to help patients change to a more favourable lifestyle (e.g. stop smoking, weight reduction, increased physical activities $)^{83}$. Ideally, both the GP and the practice nurse would learn this technique, so that the GP can support the practice nurse in $\mathrm{Ml}$ as well.

However, even when the practice nurse knows all about CVRM and has adopted a patient-centred counselling style to elicit behaviour change, this is not enough. Risk communication and risk presentation are important parts of CVD prevention that need special attention within the consultation. The GP has to train the practice nurse in using different ways of presenting and framing CVD risk, supported by educational materials such as risk tables and population diagrams. The use of a decision aid on CVRM for patients could assist both the practice nurse and the patient as regards risk presentation and communication, and facilitate shared decision making about a preferencebased CVRM plan. Our decision support tool could serve as a prototype, but needs to be revised and updated. An electronic version of the decision aid, presented on the Internet to allow more in-depth information to be presented, could be made more sophisticated by using multimedia techniques.

\section{Implications for research}

In recent years, research on patient involvement has focused on theory and model building, and on clarifying the concept of patient involvement and shared decision-making. Moreover, the effect of this approach has been studied on patient outcomes such as decisional conflict. Since the effects on patients were promising, training programmes for professionals to effectively promote patient involvement have been developed and tested. This has resulted in additional instruments to measure patient involvement and shared decision making at the process level (OPTION). The challenge now seems to be - apart from theory building, developing decision aids, and making decision aids widely available on the Internet - to really make a change in clinical practice. Research should also focus on determinants of change relating to the professionals and organisations involved. We need to find out how to make professionals adopt a more patient-centred approach in their consultation style, in which shared decision making becomes internalised as routine practice. We have to examine the effective determinants of change, as these can be seen as the cornerstones of new strategies to implement patient involvement in practice routine.

As regards cardiovascular risk management, we think that delegating tasks to nurses may be a promising implementation strategy, as discussed above. The suggested strategy for patient involvement in cardiovascular risk management has to be evaluated in a trial assessing its effectiveness and feasibility. The 
question is what cardiovascular risk outcomes can best be used to assess the effectiveness of patient involvement in decision making. The reduction in absolute cardiovascular risk, involving the variables age, sex, blood pressure, serum cholesterol and smoking, is often used but fails to cover the effects of other lifestyles than smoking. In shared decision making and motivational interviewing, the agenda for lifestyle change is set by the patient, so the target for risk reduction is not known beforehand. It could involve eating more fruit and vegetables, using less alcohol or saturated fat or increasing physical exercise. To resolve this problem and to keep patient questionnaires on selfreported lifestyle behaviour within reasonable length, we might need a new kind of sum score or index to measure adherence to decisions on lifestyle improvement.

Another question is how to measure patient involvement in decision making. In addition to measuring patients' adherence to their personal cardiovascular risk management plan $^{84}$, we could monitor the process using questionnaires for professionals or score audiotaped or videotaped consultations. Or we might have to ask patients specific questions on the process of patient involvement and their experiences in this matter.

Further research is also necessary to assess the value of motivational interviewing as a facilitator of shared decision making. In the current IMPALA trial, practice nurses are trained to involve patients in decision making on cardiovascular risk management, by using a risk communication tool and a decision aid for patients to discuss CVD risk and options for risk reduction, and by applying adapted motivational interviewing. We hope to learn more about these questions from the results of this new trial ${ }^{85}$. 


\section{References}

1. De Backer G, Ambrosioni E, Borch Johnsen K, Brotons C, Cifkova R, Dallongeville J, Ebrahim S, Faergeman O, Graham I, Mancia G, Cats VM, Orth Gomer K, Perk J, Pyorala K, Rodicio JL, Sans S, Sansoy V, Sechtem U, Silber S Thomsen T, Wood D. European guidelines on cardiovascular disease and prevention in clinical practice. Atherosclerosis 2003;171:145-55.

2. Jackson R. Updated New Zealand cardiovascular disease risk-benefit prediction guide. BMJ 2000;320:709-10.

3. Anonymous. Joint British recommendations on prevention of coronary heart disease in clinical practice: summary. British Cardiac Society, British Hyperlipidaemia Association, British Hypertension Society, British Diabetic Association. BMJ 2000;320:705-8.

4. Thomas S, van der Weijden T, van Drenth BB, Haverkort AFM, Hooi JD, van der Laan JD. NHG-Standaard Cholesterol (eerste herziening). Huisarts Wet 1999;42:406-17.

5. Burgers JS, Simoons ML, Hoes AW, Stehouwer CD, Stalman WA. Guideline 'Cardiovascular Risk Management'. Ned Tijdschr Geneeskd 2007;151:1068-74.

6. Adriaanse M, Snoek F, Dekker J, Spijkerman A, Nijpels G, van der Ploeg H, Heine R. Perceived risk for type 2 diabetes in participants in a stepwise population-screening programme. Diabet Med 2003;20:210-5.

7. Molewijk A. Individualized evidence-based decision support and the ideal of patient autonomy in actual medical decison making. University of Leiden, 2006.

8. Edwards A, Unigwe S, Elwyn G, Hood K. Effects of communicating individual risks in screening programmes: Cochrane systematic review. BMJ 2003;327:703-9.

9. Paling J. Strategies to help patients understand risks. BMJ 2003;327:745-8.

10. Gigerenzer G, Edwards A. Simple tools for understanding risks: from innumeracy to insight. BMJ 2003;327:741-4.

11. Knapp P, Raynor DK, Berry DC. Comparison of two methods of presenting risk information to patients about the side effects of medicines. Qual Saf Health Care 2004;13:176-80.

12. Hollnagel $\mathrm{H}$. Explaining risk factors to patients during a general practice consultation. Conveying group-based epidemiological knowledge to individual patients. Scand J Prim Health Care 1999;17:3-5.

13. Freeman $A C$, Sweeney K. Why general practitioners do not implement evidence: qualitative study. BMJ 2001;323:1100-2.

14. Hulscher ME, van Drenth BB, Mokkink HG, van der Wouden JC, Grol RP. Barriers to preventive care in general practice: the role of organizational and attitudinal factors. $\mathrm{Br} \mathrm{J}$ Gen Pract 1997;47:711-4.

15. van Drenth BB, Hulscher ME, van der Wouden JC, Mokkink HG, Van Weel C, Grol RP. Relationship between practice organization and cardiovascular risk factor recording in general practice. Br J Gen Pract 1998;48:1054-8.

16. Beaulieu M TY, Jada AR, Xhignesse M. Enhancing prevention in primary care: are interventions targeted towards consumers' and providers' perceived needs? Health Expect 2000;3:253-62.

17. Yarnall $\mathrm{K}$, Pollack KI, Outbid T, Krause KM, Michener JL. Is there enough time for prevention. Am J Public Health 2003;93:635-41.

18. Mazur DJ, Hickam DH. Patients' preferences for risk disclosure and role in decision making for invasive medical procedures. J Gen Intern Med 1997;12:114-7.

19. Bottorff J, Ratner P, Johnson J, Lovato C, SA. J. Communicating cancer risk informating: the challenges of uncertainly. Patient Educ Couns 1998;33:67-81.

20. Howitt $A$, Armstrong $D$. Implementing evidence based medicine in general practice: audit and qualitative study of antithrombotic treatment for arterial fibrillation. BMJ 1999;318:1324-7.

21. Sherman SJ, Cialdini R .B, Schwartzman D. F., Reynolds K, D. Imagining can heighten or lower the perceived likelihood of contracting a disease: the mediating effect of ease of imagery. Pers Soc Psychol Bull 1985;11:118-27. 
22. Tversky A, Kahneman D. Judgment of and by representativeness. In: Kahneman D, Slovic P, Tversky $A$, editors. Judgment under uncertainty: Heuristics and biases. Cambridge MA: Cambridge University Press, 1982:84-101.

23. Lippman Hand A, Fraser FC. Genetic counseling: provision and reception of information. Am J Med Genet 1979;3:113-27.

24. Parsons EA, P. . Lay constructions of genetic risk. Soc Health Illness 1993;15:437-55.

25. Wertz DC, Sorenson JR, Heeren TC. Clients' interpretation of risks provided in genetic counseling. Am J Hum Genet 1986;39:253-64.

26. Weinstein ND. Why it won't happen to me: perceptions of risk factors and susceptibility. Health Psychol 1984;3:431-57.

27. Croyle R, Sun $Y$, Hart M. Processing risk factor information: Defensive biases in healthrelated judgments and memory. In: Petrie KJ WJ, editor. Perceptions of health and illness:current research and applications. Amsterdam: Harvard Academic Publishers, 1997:267-90.

28. Weinstein ND. Unrealistic optimism about susceptibility to health problems: conclusions from a community-wide sample. J Behav Med 1987;10:481-500.

29. Marteau TM, Kinmonth AL. Screening for cardiovascular risk: public health imperative or matter for individual informed choice? BMJ 2002;325:78-80.

30. Paterson JM, Llewellyn Thomas HA, Naylor CD. Using disease risk estimates to guide risk factor interventions: field test of a patient workbook for self-assessing coronary risk. Health Expect 2002;5:3-15.

31. Harrington J, Noble LM, Newman SP. Improving patients' communication with doctors: a systematic review of intervention studies. Patient Educ Couns 2004;52:7-16.

32. Ely JW, Goerdt CJ, Bergus GR, West CP, Dawson JD, Bn D. The effect of physician characteristics on compliance with adult preventive care guidelines. Family Med 1998;34: 34-9.

33. Skolbekken JA. Communicating the risk reduction achieved by cholesterol reducing drugs. BMJ 1998;316:1956-8.

34. Bero LA, Grilli R, Grimshaw JM, Harvey E, Oxman AD, Thomson MA. Closing the gap between research and practice: an overview of systematic reviews of interventions to promote the implementation of research findings. The Cochrane Effective Practice and Organization of Care Review Group. BMJ 1998;317:465-8.

35. van Bokhoven MA, Kok G, van der Weijden $T$. Designing a quality improvement intervention: a systematic approach. Qual Saf Health Care 2003;12:215-20.

36. Bartholomew LK, Parcel GS, Kok G. Intervention mapping: a process for developing theoryand evidence-based health education programs. Health Educ Behav 1998;25:545-63.

37. Legare F, O'Connor AM, Graham ID, Saucier D, Cote L, Blais J, Cauchon M, Pare L. Primary health care professionals' views on barriers and facilitators to the implementation of the Ottawa Decision Support Framework in practice. Patient Educ Couns 2006;63:380-90.

38. Edwards A, Elwyn G, Covey J, Matthews E, Pill R. Presenting risk information--a review of the effects of "framing" and other manipulations on patient outcomes. Health Commun 2001;6:61-82.

39. Elwyn G, Edwards A, Hood K, Robling M, Atwell C, Russell I, Wensing M, Grol R. Achieving involvement: process outcomes from a cluster randomized trial of shared decision making skill development and use of risk communication aids in general practice. Fam Pract 2004;21:337-46.

40. Sepucha KR, Mulley AG. Extending decision support: preparation and implementation. Patient Educ Couns 2003;50:269-71.

41. Lewis DK, Robinson J, Wilkinson E. Factors involved in deciding to start preventive treatment: qualitative study of clinicians' and lay people's attitudes. BMJ 2003;327:841.

42. Edwards A, Barker J, Bloor M, Burnard P, Covey J, Hood K, Matthews E, Pill R, Russell D, Russell I, Stott N, Wilkinson C. A systematic review of risk communication - improving effective clinical practice and research in primary care. London: NHS Executive 1998.

43. Horrocks S, Anderson E, Salisbury C. Systematic review of whether nurse practitioners working in primary care can provide equivalent care to doctors. BMJ 2002;324:819-23. 
44. Steptoe A, Doherty S, Rink E, Kerry S, Kendrick T, Hilton S. Behavioural counselling in general practice for the promotion of healthy behaviour among adults at increased risk of coronary heart disease: randomised trial. BMJ 1999;319:943-7.

45. Woolf SH, Chan EC, Harris R, Sheridan SL, Braddock CH, 3rd, Kaplan RM, Krist A, O'Connor $\mathrm{AM}$, Tunis $\mathrm{S}$. Promoting informed choice: transforming health care to dispense knowledge for decision making. Ann Intern Med 2005;143:293-300.

46. O'Connor AM, Stacey D, Entwistle V, Llewellyn Thomas H, Rovner D, Holmes Rovner M, Tait $\mathrm{V}$, Tetroe J, Fiset V, Barry M, Jones J. Decision aids for people facing health treatment or screening decisions. Cochrane database of systematic reviews Online Update Software ISE: 1469 493X 2003:Cd001431.

47. Timmermans D, Molewijk B, Stiggelbout A, Kievit J. Different formats for communicating surgical risks to patients and the effect on choice of treatment. Patient Educ Couns 2004; 54:255-63.

48. Reventlow S, Hvas AC, Tulinius C. "In really great danger..." The concept of risk in general practice. Scand J Prim Health Care 2001;19:71-5.

49. Van der Weijden T, Timmermans D, Wensing M. Dus alles is goed dokter? Hoe informeer ik mijn patiënten over grote en kleine risico's? Huisarts en Wet 2006;49:550-3.

50. Essink-Bot ML, Kruijshaar ME, Barendregt JJ, Bonneux LG. Evidence-based guidelines, time-based health outcomes, and the Matthew effect. Eur J Public Health 2007;17:314-7.

51. Thomsen RW, Johnsen SP, Olesen AV, Mortensen JT, Boggild H, Olsen J, Sorensen HT. Socioeconomic gradient in use of statins among Danish patients: population-based crosssectional study. Br J Clin Pharmacol 2005;60:534-42.

52. Tunstall-Pedoe $\mathrm{H}$, Woodward $\mathrm{M}$. By neglecting deprivation, cardiovascular risk scoring will exacerbate social gradients in disease. Heart 2006;92:307-10.

53. Woodward $M$, Brindle $P$, Tunstall-Pedoe $H$. Adding social deprivation and family history to cardiovascular risk assessment: the ASSIGN score from the Scottish Heart Health Extended Cohort (SHHEC). Heart 2007;93:172-6.

54. Bonneux L. Cardiovascular risk models. BMJ 2007;335:107-8.

55. Hippisley-Cox J, Coupland C, Vinogradova Y, Robson J, Brindle P. Performance of the QRISK cardiovascular risk prediction algorithm in an independent UK sample of patients from general practice: a validation study. Heart 2008;94:34-9.

56. Hart JT. The inverse care law. Lancet 1971;1:405-12.

57. Victora CG, Vaughan JP, Barros FC, Silva AC, Tomasi E. Explaining trends in inequities: evidence from Brazilian child health studies. Lancet 2000;356:1093-8.

58. Elwyn G, O'Connor A, Stacey D, Volk R, Edwards A, Coulter A, Thomson R, Barratt A, Barry $M$, Bernstein $S$, Butow $P$, Clarke A, Entwistle V, Feldman Stewart D, Holmes Rovner M, Llewellyn Thomas H, Moumjid N, Mulley A, Ruland C, Sepucha K, Sykes A, Whelan T. Developing a quality criteria framework for patient decision aids: online international Delphi consensus process. BMJ 2006;333:417.

59. Meehan TP, Wang Y, Tate JP, Curry M, Elwell A, Petrillo MK, Holmboe ES. Improving the quality of preventive cardiovascular care provided by primary care physicians: insights from a US Quality Improvement Organization. Int J Qual Health Care 2006;18:186-94.

60. Fretheim A, Oxman AD, Havelsrud K, Treweek S, Kristoffersen DT, Bjorndal A. Rational prescribing in primary care (RaPP): a cluster randomized trial of a tailored intervention. PLoS Med 2006;3:e134.

61. van Steenkiste B, van der Weijden T, Stoffers HE, Kester AD, Timmermans DR, Grol R. Improving cardiovascular risk management: a randomized, controlled trial on the effect of a decision support tool for patients and physicians. Eur J Cardiovasc Prev Rehabil 2007;14: 44-50.

62. Fretheim A, Havelsrud K, Oxman AD. Rational Prescribing in Primary care (RaPP): process evaluation of an intervention to improve prescribing of antihypertensive and cholesterollowering drugs. Implement Sci 2006;1:19.

63. Grol R, Grimshaw J. From best evidence to best practice: effective implementation of change in patients' care. Lancet 2003;362:1225-30. 
64. Grol R, Wensing M. What drives change? Barriers to and incentives for achieving evidencebased practice. Med J Aust 2004;180:S57-60.

65. Roland M. Linking physicians' pay to the quality of care--a major experiment in the United kingdom. N Engl J Med 2004;351:1448-54.

66. Sutton M, McLean $\mathrm{G}$. Determinants of primary medical care quality measured under the new UK contract: cross sectional study. BMJ Clinical research ed ISE: 14685833 2006;332: 389-90.

67. McElduff $P$, Lyratzopoulos G, Edwards R, Heller RF, Shekelle P, Roland M. Will changes in primary care improve health outcomes? Modelling the impact of financial incentives introduced to improve quality of care in the UK. Qual Saf Health Care 2004;13:191-7.

68. Kimchi J, Polivka B, Stevenson JS. Triangulation: operational definitions. Nursing Research 1991;40:364-5.

69. Morse JM. Approaches to qualitative-quantitative methodological triangulation. Nursing Research 1991;40:120-3.

70. Loewenstein GF, Weber EU, Hsee CK, Welch N. Risk as feelings. Psychol Bull 2001;127:267-86.

71. Slovic $P$, Finucane ML, Peters E, MacGregor DG. Risk as analysis and risk as feelings: some thoughts about affect, reason, risk, and rationality. Risk Anal 2004;24:311-22.

72. Bieling PJ, Antony MM, Swinson RP. The State-Trait Anxiety Inventory, Trait version: structure and content re-examined. Behav Res Ther 1998;36:777-88.

73. Stanley MA, Beck JG, Zebb BJ. Psychometric properties of four anxiety measures in older adults. Behav Res Ther 1996;34:827-38.

74. Puffer S, Torgerson D, Watson J. Evidence for risk of bias in cluster randomised trials: review of recent trials published in three general medical journals. BMJ 2003;327:785-9.

75. Huibers MJ, Bleijenberg G, Beurskens AJ, Kant IJ, Knottnerus JA, van der Windt DA, Bazelmans E, van Schayck CP. An alternative trial design to overcome validity and recruitment problems in primary care research. Fam Pract 2004;21:213-8.

76. van der Wouden JC, Blankenstein $\mathrm{AH}$, Huibers MJ, van der Windt DA, Stalman WA, Verhagen AP. Survey among 78 studies showed that Lasagna's law holds in Dutch primary care research. J Clin Epidemiol 2007;60:819-24.

77. Howie JG, Heaney DJ, Maxwell M, Walker JJ. A comparison of a Patient Enablement Instrument (PEI) against two established satisfaction scales as an outcome measure of primary care consultations. Fam Pract 1998;15:165-71.

78. O'Connor AM. Validation of a decisional conflict scale. Med Decis Making 1995;15:25-30.

79. Elwyn G, Edwards A, Wensing M, Hood K, Atwell C, Grol R. Shared decision making: developing the OPTION scale for measuring patient involvement. Qual Saf Health Care 2003;12:93-9.

80. Edwards A, Elwyn G, Hood K, Robling M, Atwell C, Holmes-Rovner M, Kinnersley P, Houston $\mathrm{H}$, Russell I. The development of COMRADE--a patient-based outcome measure to evaluate the effectiveness of risk communication and treatment decision making in consultations. Patient Educ Couns 2003;50:311-22.

81. Unal B, Critchley JA, Capewell S. Modelling the decline in coronary heart disease deaths in England and Wales, 1981-2000: comparing contributions from primary prevention and secondary prevention. BMJ 2005;331:614.

82. Sinclair G, Kerr A. The Bold Promise Project: a system change in primary care to support cardiovascular risk screening. N Z Med J 2006;119:U2312.

83. Emmons KM, Rollnick S. Motivational interviewing in health care settings. Opportunities and limitations. Am J Prev Med 2001;20:68-74.

84. Knight KM, McGowan L, Dickens C, Bundy C. A systematic review of motivational interviewing in physical health care settings. Br J Health Psychol 2006;11:319-32.

85. Koelewijn-van Loon MS, van Steenkiste B, Ronda G, Wensing M, Stoffers HE, Elwyn G, Grol $R$, van der Weijden $T$. Improving patient adherence to lifestyle advice (IMPALA): a clusterrandomised controlled trial on the implementation of a nurse-led intervention for cardiovascular risk management in primary care. Protocol. BMC Health Serv Res 2008;8:9. 
Summary 


\section{Summary}

The subject of this thesis is the national guideline on cholesterol of the Dutch College of General Practitioners (DCGP). The guideline was first published in 1991 and was revised in 1999. The revised guideline on cholesterol was the first national guideline that incorporated so-called 'risk tables' for the primary prevention of cardiovascular diseases (CVD). In May 1999, a research project was started to investigate the implementation of this cholesterol guideline, a project which ran until October 2004. The project was supported by grants from the Netherlands Heart Foundation, the Netherlands Organisation for Health Research and Development (ZonMw) and the CZ health insurance company. In chapter 1, cardiovascular prevention in primary care is defined and the research questions underlying this thesis are presented. Chapters 2 and 3 describe qualitative studies on the barriers to effective implementation of the guideline as perceived by GPs and patients. Chapter 4 quantitatively explores patients' CVD risk perception in relation to their actual absolute 10-year risk of cardiovascular diseases. Chapter 5 reports on the effect of the use of a decision support tool for the prevention of CVD on the performance of GPs and certain patient outcomes, evaluated in a cluster-randomised controlled trial in primary care. In chapter 6 , the patient's response to the decision support tool is further explored. Chapter 7 reports on the results of a systematic review of the literature on health professionals' performance with respect to cardiovascular risk tables. Finally, chapter 8 discusses, integrates and interprets the results presented in the various chapters, and offers recommendations for effective implementation of cardiovascular risk tables, as well as for further research.

Chapter 1 discusses recommendations for the primary prevention of cardiovascular diseases embedded in national and international guidelines. The essential component of the current guideline consists of measuring a patient's risk profile and calculating the absolute risk, in percentages, that they will suffer a CVD event within the next 10 years. The risk tables incorporated in the guideline facilitate individualised risk calculation and directly lead to options for risk management. This highly individualised approach is entirely different from the population-based approaches that were used in the past, and seems to be hampered by many barriers. Some of these barriers, which are described in the literature, are discussed here, as are the results of implementation studies that mainly focused on barriers relating to the professionals and organisational structures involved. Special attention is given to patient-related barriers, since demanding patients seem to play a significant role in the overuse of cholesterol-lowering drugs and may make GPs hesitate about negotiating with their patients. The objective of our project was to develop and 
evaluate an implementation strategy for the new, individualised, 'high-risk' approach to primary prevention of CVD, based on risk tables.

Research questions:

1. What are the barriers, from the GPs' and patients' perspectives, that impede effective implementation of the 1999 DCGP guideline on cholesterol and its incorporated risk tables?

2. How often are GPs confronted with mismatches between patients' actual cardiovascular risk and their perceived risk or anxiety, and what factors determine a high perceived risk or anxiety?

3. What is the effect of a decision support system for both physicians and patients, which aims at their common understanding of the risk and the options for risk management, on the physicians' performance in terms of adherence to the key recommendations of the cholesterol guideline and the patients' risk perception and lifestyle?

4. How do patients respond to active decision support?

5. What is known in the literature about effective implementation strategies for cardiovascular risk tables?

Chapter 2 describes the results of a qualitative survey of the barriers that GPs report as hampering their adherence to the cholesterol guideline with its risk tables. A sample of 15 GPs were interviewed in their practice, after two cardiovascular consultations per GP, audiotaped by the GPs themselves, had been analysed. The barriers we identified were related to the risk tables, the GPs or environmental factors. Lack of knowledge and poor communication skills among GPs, along with pressure of work and demanding patients, caused GPs to deviate from the guideline. GPs regarded barriers external to themselves as being the most important ones and having the greatest influence. It was concluded that the use of risk tables, a key element of the high-risk approach in primary prevention, was hampered by many barriers. Merely incorporating risk tables in guidelines is therefore not sufficient to ensure implementation of these guidelines. There seems to be an urgent need for time-efficient implementation strategies dealing particularly with the communication and presentation of cardiovascular risk to patients.

Chapter 3 describes the role of patients in determining the feasibility of using the 1999 cholesterol guideline in general practice. In a qualitative study, 15 GPs audiotaped one or two consultations on cardiovascular prevention in which they attempted to achieve optimal care, according to their own views. These consultations were then used to guide the subsequent semi-structured in-depth interviews with patients at their homes. Twenty-two patients were interviewed, and it was found that their understanding of the prevention of cardiovascular disease was often insufficient. Cardiovascular risk and the risk 
tables were difficult to understand and the perceived risk was often unrealistic and dichotomous, and mainly based on personal experience. Both overestimation and underestimation of the actual risk were observed. There was a demand for more information and for cholesterol testing. It became clear that many barriers at the patient level impede effective prevention of cardiovascular diseases. In particular, the highly individualised high-risk approach needs to be clearly explained to patients. Educational patient materials, intended to support GPs and patients, should take into account patients' ideas, fears and expectations.

Chapter 4 explores the association between patients' risk perception and their actual risk. Misconceptions of risk hamper the implementation of risk management in high-risk patients on the one hand, and reassurance of low-risk patients on the other. We thus needed to know more about the type of patients that GPs encounter in their cardiovascular prevention activities, especially as regards the appropriateness of their risk perceptions. A cross-sectional study in 34 general practices, including 490 patients with whom cardiovascular risk was discussed during routine consultations, either at the initiative of the GP or that of the patient, examined the frequency and determinants of inappropriate risk perception. In $17 \%$ of the consultations, the patients appeared to actually be at high risk. Risk was perceived inappropriately by nearly 4 in 5 high-risk patients (incorrect optimism) and by 1 in 5 low-risk patients (incorrect pessimism). Smoking, hypertension and obesity were determinants of perceiving cardiovascular risk to be high, whereas, surprisingly, diabetic patients did not report any anxiety about their cardiovascular risk. Men were more likely to perceive their cardiovascular risk inappropriately than women. It was concluded that in communicating cardiovascular risk, GPs must be aware that they encounter mostly low-risk patients, and that the perceived risk and worry do not necessarily correspond with the actual risk. Incorrect perceptions of cardiovascular risk among men and patients with diabetes were striking, and need special attention.

Chapter 5 discusses a cluster-randomised trial examining the effect of a new implementation strategy for primary prevention of cardiovascular diseases. The strategy, aimed at both physicians and patients, consisted of three elements: a 4-hour interactive small group training for the GPs on the guideline and risk tables, a decision support tool to be presented to patients, and the instruction to invite patients for a second consultation. The GPs were instructed to stimulate patient involvement in decision making during the second consultation, when cardiovascular risk and options for risk reducing strategies should be discussed. GPs' clinical performance and patients' risk perception and self-reported lifestyles were measured at baseline and after 6 months. 
Thirty-four GPs recorded 490 consultations, 276 in the intervention and 214 in the control group. After 6 months, no significant effect of the intervention on the GPs' performance or the patients' risk perception was found. There was only an effect on one of the self-reported lifestyle aspects, in that men in the intervention group increased their physical activity compared to those in the control group (odds ratio 3.8, 95\% confidence interval 1.7-8.7). We concluded that the 4-hour training failed to guarantee correct application of the decision support tool and as such to improve GPs' performance or correct patients' risk perception. The positive effect on physical activity, however, justifies further research on patient involvement.

Chapter 6 describes the assessment of patients' response to the decision support tool. The decision support tool, a16-page booklet, presented the risk table, explained the patients' absolute cardiovascular risk in accessible language, discussed the options for risk factor management and invited the patients to indicate their preferences on a worksheet, which was supposed to facilitate shared decision making in the second consultation. Patients at high or potentially high cardiovascular risk were invited by their GP to prepare themselves for a second consultation in order to participate in decision making on risk management. A process evaluation of the intervention in primary care was used to examine patients' responsiveness. Seventeen $17 \mathrm{GPs}$ issued 276 decision support tools during the 1st consultation. The patients' mean age was 54 years, $47 \%$ were male and $19 \%$ actually had a high cardiovascular risk. Data on 239 patients, a mixture of returnees and non-returnees for a second consultation, showed that they all had read the booklet, that comprehension was fair to good, that $85 \%$ perceived the information as relevant and that $68 \%$ of the patients felt reassured by the information. It was concluded that although cardiovascular prevention spread over 2 consultations and using a decision support tool for patients is not easy for GPs to use, the findings of good patient responsiveness support the implementation of the decision support tool in primary care.

Chapter 7 describes the results of a systematic review of the literature on professionals' performance regarding cardiovascular risk tables. In order to develop effective implementation strategies for cardiovascular risk tables, it is important to understand the conditions for their use, since they are not widely used in routine practice. An extensive strategy was used to search several electronic literature databases from their inception to February 2007. Studies on physicians or nurses were eligible for inclusion if they reported quantitative empirical data on the effect of professional, financial, organisational or regulatory strategies on the implementation of cardiovascular risk tables. Nine studies, covering 3 types of implementation strategies (or combinations) were 
included in the review. The reported effects were moderate, sometimes conflicting and contradictory. Although no clear relation was observed between a particular type of strategy and the success or failure of the implementation, promising strategies for patient selection and risk assessment seem to include teamwork, nurse led-clinics and integrated IT support. Strategies for the implementation of cardiovascular risk tables need to be embedded in systematic and problem-oriented approaches, as developed in implementation science.

Chapter 8 presents a short overview of the main results of the various studies in this thesis and a general discussion, which successively addresses the barriers to the use of risk tables in daily practice, patients' ideas, fears and expectations, findings from our trial on the implementation of the guideline and risk tables, patient responsiveness, and implementation lessons from the literature. The chapter also discusses some methodological considerations regarding the outcome measures and instruments we chose for our research in primary care and the barriers we encountered, insofar as they have not been addressed in previous chapters.

The results are used to formulate recommendations for revising and updating the decision support tool, as well as recommendations for nurse-led CVD prevention clinics in primary care, to be supervised by GPs in a new role of trainer /coach monitoring the quality of the CVD prevention in the surgery. The chapter ends with some recommendations for future research to establish valid outcomes and instruments for the evaluation of these cardiovascular prevention clinics. 
Samenvatting 


\section{Samenvatting}

Dit proefschrift gaat over de implementatie van de landelijke richtlijn voor diagnostiek en behandeling van een verhoogd cholesterolgehalte van het Nederlands Huisartsen Genootschap, de NHG-Standaard Cholesterol. Deze standaard werd voor het eerst gepubliceerd in 1991 en herzien in 1999. De herziene NHG-Standaard Cholesterol was innovatief door de risicotabel voor de primaire preventie van hart- en vaatziekten. In mei 1999 werd begonnen met een onderzoek naar de implementatie van de herziene NHG-Standaard Cholesterol met de bijbehorende risicotabel. Deze implementatiestudie werd afgerond in oktober 2004 en gesubsidieerd door de Nederlandse organisatie voor gezondheidsonderzoek en zorginnovatie (ZonMw), de Nederlandse Hartstichting en zorgverzekeraar CZ.

In hoofdstuk 1 wordt de primaire preventie van hart- en vaatziekten (HVZ) door de huisarts nader besproken, hetgeen uitmondt in de onderzoeksvragen van dit proefschrift. De hoofdstukken 2 en 3 beschrijven een kwalitatieve inventarisatie van knelpunten en belemmeringen voor effectieve implementatie van de cholesterolstandaard bij huisartsen en patiënten. In hoofdstuk 4 wordt het geschatte risico op HVZ door patiënten in de huisartsenpraktijk gerelateerd aan hun werkelijke risico op HVZ. Hoofdstuk 5 beschrijft de effecten van een training voor huisartsen en een keuzehulp voor de preventie van HVZ voor patiënten door middel van een evaluatie in een gerandomiseerd experiment. In hoofdstuk 6 worden de ervaringen van patiënten met de keuzehulp besproken. Hoofdstuk 7 beschrijft de uitkomst van een systematisch literatuuroverzicht naar implementatie van risicotabellen voor de preventie van HVZ door professionals in de zorg. Tot slot worden in hoofdstuk 8 de gevonden resultaten uit de voorafgaande hoofdstukken nader beschouwd en aanbevelingen gedaan voor de dagelijkse praktijk en voor verder onderzoek.

Hoofdstuk 1 bespreekt de aanbevelingen voor de primaire preventie van HVZ, zoals die zijn vastgelegd in nationale- en internationale richtlijnen. Een voor Nederland nieuw element in de herziene standaard is het gebruik van een risicotabel met het absolute 10-jaars-risico op het krijgen van HVZ. Het gaat niet langer om diagnostiek en behandeling van een individuele risicofactor, maar om de hoogte van het absolute risico om in 10 jaar tijd een HVZ te krijgen, dat wordt berekend aan de hand van het risicoprofiel voor HVZ waarin meerdere belangrijke risicofactoren worden geïntegreerd. De implementatie van deze geïndividualiseerde hoogrisico-benadering met het gebruik van de risicotabellen in de dagelijkse huisartsenpraktijk wordt belemmerd door 
verschillende knelpunten. Reeds bekende knelpunten, met name die van de huisarts en van de organisatie van de zorg, worden besproken, evenals de resultaten van implementatieonderzoek dat zich op deze knelpunten richt. Daarnaast lijkt de patiënt die diagnostiek en behandeling min of meer 'afdwingt' een belangrijk knelpunt. Hierdoor wordt de discussie met de huisarts bemoeilijkt en kan onnodig gebruik van cholesterolverlagende medicijnen ontstaan.

Het doel van dit project was het ontwikkelen en evalueren van een implementatiestrategie voor de nieuwe hoogrisico-benadering in de primaire preventie van HVZ met de daarbij behorende risicotabellen.

\section{Onderzoeksvragen:}

1. Wat zijn de knelpunten vanuit het perspectief van zowel de huisarts als de patiënt, voor de implementatie van de herziene NHG-Standaard Cholesterol met de bijbehorende risicotabellen?

2. Hoe vaak worden huisartsen geconfronteerd met patiënten waarbij de risicoperceptie en ongerustheid afwijken van het werkelijke risico op HVZ en welke factoren bepalen een grote ongerustheid of perceptie dat het risico hoog is?

3. Wat is het effect van beslissingsondersteuning voor patiënten en huisartsen, die tot doel heeft om gezamenlijk begrip van het HVZ risico en behandelmogelijkheden te bereiken, op het opvolgen van de kernaanbevelingen van de cholesterolstandaard door de huisarts en op de risicoperceptie en leefstijl van de patiënt?

4. Hoe reageren patiënten op het gebruik van een keuzehulp voor de preventie van HVZ?

5. Wat is er bekend in literatuur over effectieve implementatiestrategieën voor risicotabellen voor HVZ?

Hoofdstuk 2 beschrijft de resultaten van een kwalitatieve inventarisatie van de knelpunten, die huisartsen in de dagelijkse praktijk ondervonden bij het volgen van de cholesterolstandaard en het gebruik van de risicotabellen. Vijftien huisartsen werden in hun huisartsenpraktijk geïnterviewd aan de hand van de analyse van twee door hen op geluidsband opgenomen consulten over primaire preventie van HVZ. Deze interviews leverden een schat aan knelpunten op voor primaire preventie van HVZ. Deze knelpunten konden worden toegeschreven aan de risicotabellen, de huisartsen zelf of omgevingsfactoren. Gebrek aan kennis over de standaard en aan communicatievaardigheden van de huisarts, samen met een hoge werkdruk en eisende patiënten, maken dat de huisarts afwijkt van de aanbevelingen in de 
cholesterolstandaard. Huisartsen ervaren deze omgevingsfactoren als meest belangrijk en van grote invloed op hun handelen.

Er werd geconcludeerd dat er veel knelpunten zijn voor het gebruik van de risicotabellen, een kernelement van de hoogrisico-benadering in de primaire preventie van HVZ. Het eenvoudigweg opnemen van risicotabellen in de cholesterolstandaard bleek niet te resulteren in daadwerkelijke implementatie van de cholesterolstandaard met het gebruik van de bijbehorende risicotabellen.

Er leek met name een dringende behoefte aan tijdefficiënte implementatiestrategieën voor het presenteren en bespreken van het risico op hart- en vaatziekten met patiënten.

Hoofdstuk 3 beschrijft de rol van de patiënt in het licht van de toepasbaarheid van de in 1999 herziene NHG-Standaard Cholesterol in de huisartsenpraktijk. In een kwalitatief studiedesign werden 22 patiënten thuis geïnterviewd aan de hand van de analyses van een op geluidsband opgenomen consult met hun huisarts. Het betrof steeds een consult waarin de huisartsen, naar eigen zeggen, geprobeerd hadden optimale zorg te verlenen in het kader van de primaire preventie van HVZ volgens de NHG-Standaard Cholesterol.

Analyse van de semi-gestructureerde interviews toonde aan dat de bij de patiënt aanwezige kennis en begrip van HVZ en de preventie ervan meestal onvoldoende was. Het risico op HVZ en de risicotabellen waren lastig te begrijpen, de perceptie van het risico op HVZ was vaak onrealistisch en dichotoom van aard en hoofdzakelijk gebaseerd op persoonlijke ervaringen met HVZ. Zowel over- als onderschatting van het risico op HVZ kon worden aangetoond. Er bestond bij de patiënten grote behoefte aan informatie maar ook aan het bepalen van het cholesterolgehalte in het bloed. Uit de interviews bleek duidelijk dat er op patiëntniveau veel knelpunten zijn die effectieve preventie van HVZ verhinderen. Met name de sterk geïndividualiseerde hoogrisico-benadering vraagt veel uitleg aan patiënten. Voorlichtingsmaterialen, die zowel de huisarts als de patiënten beogen te ondersteunen, dienen met name aandacht te schenken aan de vele misvattingen, ongerustheid en vaak irreële verwachtingen van patiënten.

Hoofdstuk 4 bespreekt het gevonden verband tussen het door de patiënt geschatte risico op HVZ en het werkelijke risico. Misvattingen tussen het geschatte en het werkelijke risico op HVZ staan effectief risicomanagement van patiënten met een hoog risico en het geruststellen van patiënten met een laag risico in de weg. Inzicht in de risicoperceptie van de patiënten, die de 
huisarts op het spreekuur ziet in het kader van de preventie van HVZ, was daarom gewenst. Dit werd onderzocht in een cross-sectioneel onderzoek in 34 huisartsenpraktijken onder 490 patiënten die tijdens een regulier praktijkbezoek met de huisarts hadden gesproken over hun risico op HVZ. Het onderwerp hart- en vaatziekten kon zowel door de huisarts als door de patiënt ter sprake worden gebracht; soms was het de reden van het praktijkbezoek. In 17\% van de consulten bleek dat de patiënt werkelijk een hoog risico op HVZ had. Bijna 4 van de 5 patiënten met een hoog risico hebben geen goed besef van hun risico op HVZ; zij schatten hun risico te laag in (incorrect optimisme). Hetzelfde gold voor 1 op de 5 patiënten met een laag risico; zij schatten hun risico te hoog in (incorrect pessimisme). Roken, hoge bloeddruk en obesitas bleken determinanten van een hoge inschatting van het risico en mensen met diabetes bleken zich, tot onze verrassing, niet ongerust te maken over hun risico op HVZ. Misvattingen tussen het geschatte risico op HVZ en het werkelijke risico kwamen vaker voor bij mannen dan bij vrouwen.

De conclusie was dat huisartsen er zich meer bewust van zouden moeten zijn dat zij, in het kader van primaire preventie van HVZ, meestal te maken hebben met patiënten met een laag risico en dat het geschatte risico en de ongerustheid van de patiënt niet noodzakelijkerwijs overeenkomt met het werkelijke risico. Extra aandacht is nodig voor de opvallende mispercepties van het risico op HVZ bij mannen en patiënten met diabetes.

Hoofdstuk 5 beschrijft de resultaten van een clustergerandomiseerd experiment waarin een nieuwe implementatiestrategie voor de NHG-standaard Cholesterol 1999 werd geëvalueerd. De strategie was zowel op de huisarts als op de patiënt gericht en bestond uit een 4-uur durende interactieve training van de huisartsen waarin als eerste aandacht werd besteed aan het begrijpen van de kernelementen uit de herziene NHG-Standaard Cholesterol en het gebruik van de bijbehorende risicotabellen. Daarna was er aandacht voor het gebruik van een keuzehulp voor patiënten en vervolgens voor het uitnodigen van de patiënt voor een tweede consult voor het bespreken van het risico op HVZ. De huisartsen werd gevraagd om pas in het tweede consult, nadat de patiënt de informatie uit de keuzehulp thuis had gelezen, het risico op HVZ met de patiënt te bespreken en pas dan afspraken te maken over de behandeling van een verhoogd risico. De huisartsen werden geïnstrueerd om de patiënt actief te betrekken bij het bespreken van de verschillende opties voor risicovermindering, het opstellen van een persoonlijk behandelplan en de besluitvorming daarover.

Het klinisch handelen van de huisarts, conform de kernaanbevelingen van de cholesterolstandaard, de risicoperceptie van de patiënt en de zelfgerappor- 
teerde leefstijl werden zowel bij de start van het experiment als na 6 maanden gemeten. Vierendertig huisartsen namen deel aan de studie; zij registreerden 490 consulten, 276 in de interventiegroep en 214 in de controlegroep. Na 6 maanden kon geen significant effect van de implementatiestrategie op het klinisch handelen van de huisarts, noch op de risicoperceptie van de patiënt worden aangetoond. Er was alleen een deeleffect op de leefstijl, namelijk een toename van de lichamelijke activiteit van mannen in de interventiegroep in vergelijking met de mannen in de controlegroep (odds ratio 3,8 - 95\% betrouwbaarheidsinterval 1,7-8,7).

De conclusie was dat de 4-uur durende training van de huisarts onvoldoende was geweest voor de beoogde toepassing van de keuzehulp waardoor geen verbetering in het klinisch handelen van de huisarts of de risicoperceptie mogelijk was. Echter, het positieve effect op de lichamelijke activiteit rechtvaardigt verder onderzoek naar het betrekken van patiënten bij de primaire preventie van HVZ.

Hoofdstuk 6 beschrijft de reactie van de patiënten op het gebruik van de keuzehulp voor de primaire preventie van HVZ. De keuzehulp, een brochure van 16 pagina's, geeft informatie over het absolute 10-jaarsrisico op HVZ, hoe een individu het risico voor zichzelf kan berekenen en de verschillende mogelijkheden voor risicoreductie. De risicotabellen uit de herziene cholesterolstandaard zijn wat betreft lay-out aangepast en vormen een onderdeel van de keuzehulp. Het werkblad nodigt de patiënt uit om zijn of haar persoonlijke wensen voor risicoreductie op te schrijven met als doel betrokkenheid bij de besluitvorming bij het opstellen van een persoonlijk behandelplan in het tweede consult te faciliteren.

Voor het onderzoeken van de reactie van de patiënt op het gebruik van de keuzehulp werd gebruik gemaakt van de gegevens uit de procesevaluatie van onze interventiestudie (hoofdstuk 5). Tijdens het eerste consult kregen 276 patiënten van 17 huisartsen een keuzehulp mee naar huis. De gemiddelde leeftijd van de patiënten was 54 jaar; $47 \%$ was man en $19 \%$ van de patiënten had een hoog risico op HVZ. De gegevens van 239 patiënten, een mix van patiënten die wel of geen tweede consult met de huisarts hadden gehad, lieten zien dat iedereen de brochure had gelezen, dat men de informatie redelijk tot goed had begrepen, dat $85 \%$ de informatie voor zichzelf relevant vond en dat $68 \%$ van de patiënten zich gerustgesteld had gevoeld door de informatie in de keuzehulp. Hoewel het voorgestelde gebruik van de keuzehulp, gespreid over twee consulten met de nadruk op besluitvorming over risicomanagement in het tweede consult, door huisartsen niet eenvoudig in te passen bleek, verdient de 
positieve reactie van de patiënten verder onderzoek naar de implementatie van het gebruik van de keuzehulp in de eerstelijns gezondheidszorg.

Hoofdstuk 7 beschrijft de resultaten van systematisch literatuuronderzoek naar effectieve implementatie van het gebruik van risicotabellen voor de primaire preventie van HVZ door professionals in de gezondheidszorg. Voor het ontwikkelen van een effectieve implementatiestrategie voor de risicotabellen is inzicht in de condities voor gebruik belangrijk, temeer omdat het gebruik nog zeker geen routine is. Een uitgebreide zoekstrategie werd gebruikt voor het doorzoeken van verschillende bekende elektronische literatuurdatabases, vanaf aanvang van de database tot februari 2007. Alleen studies met empirische data over het effect van professionele, financiële, organisatorische of gereglementeerde implementatiestrategieën voor het gebruik van risicotabellen voor preventie van HVZ, door verpleegkundigen of dokters, werden geïncludeerd. Negen studies, die rapporteerden over het effect van 3 verschillende implementatiestrategieën of combinaties daarvan, werden in het literatuuronderzoek opgenomen. De gerapporteerde effecten waren matig en soms conflicterend. Hoewel er geen duidelijke voorkeur werd gevonden voor een bepaalde strategie bleek wel dat teamwork, risicospreekuren door verpleegkundigen en in het huisartsinformatiesysteem geïntegreerde ITondersteuning, veelbelovend lijken voor de selectie van patiënten en het vaststellen van het risicoprofiel. De ontwikkeling van implementatiestrategieën voor risicotabellen vraagt om een systematische probleem-georiënteerde aanpak die is gebaseerd op de inzichten uit implementatieonderzoek.

Hoofdstuk 8 beschrijft de belangrijkste resultaten van de verschillende studies in het proefschrift en bespreekt in een algemene beschouwing de knelpunten voor het gebruik van risicotabellen in de dagelijkse praktijk. Zowel de patiënten met hun ideeën, ongerustheid en verwachtingen ten aanzien van preventie van HVZ als de implementatie van de richtlijn en risicotabellen en het gebruik van een keuzehulp door patiënten komen aan de orde. Tevens worden er adviezen gegeven voor implementatie van risicotabellen aan de hand van bevindingen uit literatuuronderzoek.

Een aantal methodologische overwegingen die een rol hebben gespeeld bij de keuze voor de uitkomstmaten en meetinstrumenten worden nader toegelicht. Daarnaast is er aandacht voor de ervaren knelpunten voor wetenschappelijk onderzoek in de eerstelijnsgezondheidszorg.

Aanbevelingen worden gedaan voor herziening en verbetering van de keuzehulp en voor preventiespreekuren voor HVZ door praktijkverpleeg- 
kundigen onder supervisie van de huisarts in de rol van trainer/coach, voor het bewaken van kwaliteit van zorg in de huisartsenpraktijk.

Het hoofdstuk eindigt met een aantal aanbevelingen voor toekomstig onderzoek naar het vaststellen van valide uitkomstmaten en meetinstrumenten voor de effectiviteit van primaire preventie van HVZ in de huisartsenpraktijk. 
Dankwoord 


\section{Dankwoord}

De afgelopen jaren heb ik veel geleerd over implementatieonderzoek en over mezelf als onderzoeker. Implementeren van veranderingen is niet eenvoudig; kleine details zijn vaak belangrijk en worden soms gemist, zodat het ondanks alle inspanningen en goede bedoelingen toch mis gaat. Zo voelt het ook bij het schrijven van mijn dankwoord. Ik ben me ervan bewust dat mijn promotie het resultaat is van de inzet en hulp van velen, die zich daar al dan niet bewust van zijn en wellicht soms door mij over het hoofd zijn gezien. Een groep die, naarmate je langer over je promotie doet, alleen maar groter wordt.

Waar zal ik mijn dankwoord beginnen want velen ben ik dank verschuldigd. Welke benadering is hiervoor het meest geschikt, "top-down" of " bottom-up " wat in het laatste geval begint bij de schoonmaakster die 's morgensvroeg na veel gerammel de deur open doet, omdat ik niet het juiste pasje heb. Of, als je boven komt bij Ine Siegelaer, de "Moeder Overste" van de vakgroep altijd goed voor een grap of een luisterend oor. Of begin ik op mijn kamer bij mijn kamergenoten en de vaste bezoekers Rogier, Wim, Loes, Sandra, Karin en Sjoerd. Hen wil ik speciaal bedanken voor de zinnige gesprekken maar ook voor de lol en het delen van de dagelijkse beslommeringen. Daarnaast de groep langs de zijlijn van mijn promotie, de collega's op de gang, die in belangrijke mate bijdragen aan het dagelijkse plezier in mijn werk, waarvoor ik hen zeer dankbaar ben.

Met het risico dat ik collega's vergeet wil ik toch enkelen hieronder persoonlijk noemen die direct bij mijn onderzoek betrokken waren.

Ik begin met Trudy van der Weijden. Zonder Trudy geen proefschrift, zo simpel is het. Door jouw inzet en creativiteit is het gelukt om een kortdurend project uit te laten groeien tot een volwaardig promotieonderzoek. Voor ieder hoofdstuk wisselende aanstellingen en subsidiegevers, maar steeds weer slaagde je erin om mij en de studie aan de praat te houden. Ook mijn ambivalenties ten aanzien van mijn toekomst als wetenschappelijk onderzoeker lieten je niet uit het veld slaan. Je toonde veel begrip en herkenning en hebt me geholpen bij het vinden van een andere invulling van mijn werkzaamheden. Daar waar jij aan het begin van je carrière stond, die de afgelopen jaren een indrukwekkende vlucht heeft genomen, stond ik voor mijn gevoel al aan het eind, een heel ander perspectief. Voor dit alles ben ik je erg dankbaar. lk heb er veel van geleerd en het is voor mij nog altijd een plezier om met je samen te werken.

Richard Grol wil ik graag bedanken voor de inbreng van zijn grote kennis en ervaring op het gebied van implementatieonderzoek en kwaliteit van zorg. Ik heb veel respect gekregen voor je vermogen om snel hoofd- en bijzaken te kunnen scheiden en ingewikkelde problemen op heldere wijze terug te brengen 
tot de kern waarbij je ons ook de ruimte gaf om andere wegen te bewandelen. Dat leidde steevast tot een olijk: "Hier snap ik niets van!" of:"Voor wie doen we dit eigenlijk?", wanneer ik na veel studie en analyses een stuk had geproduceerd, wat niet te verkopen was.

Jelle Stoffers wil ik graag bedanken voor zijn adviezen bij de ontwikkeling van de interventie en het kritisch becommentariëren van de artikelen die we samen hebben geschreven. Maar ook heb ik waardering voor je geduld. Voor iemand met zo'n sterke drive als jij moeten mijn aarzeling en terughoudendheid wel eens lastig zijn geweest.

Daniëlle Timmermans wil ik graag bedanken voor haar deskundig inbreng en adviezen als besliskundig psycholoog bij de ontwikkeling van de interventie en bij het zoeken naar een passend theoretisch kader voor de onderbouwing van de resultaten. Ton Drenthen, Nederlands Huisartsen Genootschap, en Ineke van Dis, Nederlandse Hart Stichting, de andere leden van de projectgroep, dank ik voor hun inbreng en prettige samenwerking.

Het Nationaal Instituut voor Gezondheidsbevordering en Ziektepreventie bedank ik voor hun deskundige hulp en advies bij de totstandkoming van onze brochure die wij nu een keuzehulp bij de preventie van hart- en vaatziekten zouden noemen. Marion van Lierop en de Huisartsenpraktijk Sittard Oost dank ik voor hun medewerking aan de demonstratie- video over het gebruik van de keuzehulp in de dagelijkse praktijk. De video was een belangrijk onderdeel van de communicatietraining voor huisartsen die door Wiljo Brenninkmeijer, St Radboud Universiteit Nijmegen, werd verzorgd. Ik wil haar graag bedanken voor de inbreng van haar grote ervaring en de prettige samenwerking.

Mijn dank gaat ook uit naar de leden van de beoordelingscommissie, prof. dr. J.F.M. Metsemakers, prof. dr. A.P.M. Gorgels, prof. dr. J.C.J.M. de Haes, prof. dr. N.K. de Vries en dr. M. Wensing. Ik wil hen bedanken voor de aandacht die zij aan mijn proefschrift hebben geschonken en voor hun bereidheid om het te beoordelen op zijn kwaliteit.

De studie is tot stand gekomen door de grote inzet van huisartsen, praktijkassistenten en patiënten van de praktijken die in mijn onderzoek waren betrokken. Een aantal patiënten werd thuis geïnterviewd, anderen werden telefonisch benaderd voor de beoordeling van onze keuzehulp. Honderden patiënten hebben meerdere malen vaak lange vragenlijsten ingevuld. Huisartsen en hun assistenten zorgden voor de verslaglegging van de consulten daarbij ondersteund door onze praktijkconsulenten die de praktijken regelmatig bezochten om de studie onder de aandacht te houden en de 
praktijken te voorzien van tips en trucs. Langs deze weg wil ik hun hartelijk bedanken voor hun inzet.

Huisartsen

Dhr. A. Bedaux, Eindhoven, Dhr. F. Blessing, Udenhout, Dhr. C. Bouter, Utrecht, Mw. B. Bruls, Hoensbroek, Dhr. P. Buis, Harderwijk, Mw. C. Collette, Utrecht, Dhr. J. Crutzen, Simpelveld, Mw. J. de Bres-de Langen, Oss, Dhr. A. de Jong, Goirle, Dhr. C. de Kock, Deurne, Dhr. S. de Ree, Sittard, Mw. M. Dillen, Utrecht, Dhr. J. Ferrée, Berlicum, Dhr. P. Heuberger, Amersfoort, Mw. C. Hussaarts, Ospel, Dhr. V. Kaiser, Eijgelshoven, Dhr. G.Knops, Valkenburg, Mw. M. Langeberg, Maastricht, Dhr. R. Leclerq, Stein, Dhr. M. Link, Obbicht, Dhr. J. Lombarts, Tilburg, Dhr. A. Massuger, Heel, Dhr. A. Matthee, Roermond, Dhr. J. Palmen, Heerlen, Dhr. R. Ramcharan, Utrecht, Dhr. Y. Rosier, Brakel, Dhr. G. Saes, Horn, Dhr. P. Schepers, Bocholtz, Mw. O. Sikkes-Mekel, Geleen, Dhr. F. Soomers, Kerkrade, Dhr. S. Steenhuisen, Veldhoven, Dhr. G. ten Oever, Roermond, Dhr. P. Top, Zwijndrecht, Dhr. R. Ubachs, Nieuwstadt, Mw. A. van Aarnhem, Nieuwegein, Dhr. P. van Aubel, Heerlen, Dhr. W. van der Kraan, Utrecht, Dhr. R. van der Wel, Hilversum, Mw. M. van Dijck, Wylre, Dhr. H. van Hirtum, Helmond, Mw. T. van Leersum, Muiden, Dhr. C. van Lidth de Jeude, Huizen, Dhr. M. van Nunen, Hoensbroek, Dhr. J. van Proosdij, Stein, Dhr. H. van Rens, Beek, Dhr. P. Voorhoeve, Hoensbroek, Mw. M. Weert, Hoensbroek, Dhr. J. Wesselman van Helmond, Vught, Dhr. N. Wieringa, Nederhorst den Berg, Mw. H. Zwanniken, Hoensbroek.

Praktijkconsulenten

Mw. C Broekman, Huizen, Mw. G. Burgsteden, Amersfoort, Mw. R. Jongejan, Sittard, Mw. H. Koelemei, Amersfoort, Mw. L.Roebroeck- van de Zande, Reuver.

Veel dank ben ik verschuldigd aan Jacqueline Vaes. Zij interviewde de patiënten in de voorstudie en aan Marleen Korver voor het regelen van allerlei praktische zaken rondom de trial en het verzamelen van gegevens voor de procesevaluatie. Ook dank ik Jolanda Coenen, Patrice van Steekelenburg Daniëlle Bischoff Tulleken, die als student geneeskunde in het kader van hun wetenschapsstage een deel van mijn onderzoeksvragen nader uitwerkten.

Berna Schouten bedank ik voor haar inbreng en toegewijde ondersteuning als researchassistente van mijn project. Paula Rinkens wil ik bedanken voor haar vriendschap en toegewijde ondersteuning bij het verwerken en analyseren van de onderzoeksgegevens. Het was plezierig samenwerken ondanks het feit dat ieder effect dat we dachten te zien bij nadere beschouwing steevast verdween. Ik heb veel van je geleerd. Arnold Kester bedank ik graag voor de deskundige hulp en uitleg bij statistische analyses. Je voorkwam op tijd dat onze 'gewogen" Mann-Witney toets het licht zag. 
$\mathrm{Na}$ het analyseren komt het publiceren waarbij ik Jan Klerkx bedank voor de prettige samenwerking en de correctie van mijn 'awkward sentences'. De complimenten die ik kreeg over de kwaliteit van het Engels komen jou toe.

Tiny Wouters wil ik graag bedanken voor al het werk dat ze mij uit handen heeft genomen. Haar deskundigheid en ervaring bij de vormgeving, de vele correcties en de druk van dit proefschrift waren onontbeerlijk.

Karin Vaessen en Paddy Hinssen ben ik veel dank verschuldigd voor het verwerken van de interviews, de secretariële ondersteuning, de zinnige en de onzinnige gesprekken. Karin, jij hebt iets speciaals met computers, Paddy jouw ijver en perfectionisme zijn ongeëvenaard.

Sjoerd en Job, nu midden in de puberteit, (bijna) altijd feest, vooral vet cool en ram relaxed. Ik geniet van jullie en jullie avonturen maar hoop wel dat jullie door het uiterlijk vertoon van de promotie niet op het verkeerde been worden gezet en nu echt gaan geloven dat jullie vader "gangster" is.

Marion, voor jou geldt nu meer dan ooit dat hetgeen je nu meemaakt ons zal helpen om samen de weg te vinden. 

Curriculum vitae 



\section{Curriculum vitae}

Ben van Steenkiste werd op 28 februari 1954 geboren in Vlissingen. Na het afronden van de MULO in 1971 maakte hij na twee jaar opleiding voor Fysiotherapie, in 1973, de overstap naar de opleiding voor verpleegkundige in het toenmalige St. Joanna ziekenhuis in Goes. In 1977 behaalde hij het diploma Verpleegkundige-A waarna hij, na het vervullen van zijn militaire dienstplicht, startte met de opleiding tot psychiatrisch verpleegkundige in het Psychiatrisch ziekenhuis Vrederust in Halsteren. $\mathrm{Na}$ het behalen van het diploma Verpleegkundige-B begon hij in 1981 aan de Intensive Care opleiding. Vanaf 1983 werkte hij als IC-verpleegkundige op de Intensive Care afdeling van de Stichting Oosterschelde Ziekenhuizen in Goes. In 1988 volgde hij de tropenopleiding voor verpleegkundigen bij het KIT in Amsterdam, waarna hij samen met zijn vrouw, Marion van Lierop, naar Zambia vertrok. Daar werkte hij tot 1991 als Clinical Instructor bij de Zambian Enrolled Nurses School in Chitambo en als coördinator van de Chitambo Nutrition Group. Bij terugkeer in Nederland in 1992 begon hij met de opleiding Verplegingswetenschap aan de Universiteit Maastricht. De studie werd afgewisseld met het werken als oproepkracht bij verschillende zorginstellingen in de regio Zuid Limburg en de zorg voor zijn zonen Sjoerd en Job. In 1997 behaalde hij het doctoraal diploma. Vanaf die tijd is hij als onderzoeker verbonden aan diverse projecten van het Centre for Quality of Care Research (WOK). Eerst in Nijmegen bij de St Radboud Universiteit en later bij de Universiteit Maastricht waar hij in 1999 met zijn promotieonderzoek begon. Vanaf 2006 werkt hij tevens als projectmanager van een longitudinaal cohortonderzoek (SMILE) van de School for Public Health and Primary Care (Caphri). 
